$71-4935$

BATHEN, Karl Hans, 1934-

HEAT STORAGE AND ADVECTION IN THE NORTH

PACIFIC OCEAN.

University of Hawaii, Ph.D., 1970

Oceanography

University Microfilms, Inc., Ann Arbor, Michigan 


\title{
HEAT STORAGE AND ADVECTION IN THE \\ NORTH PACIFIC OCEAN
}

\section{A DISSERTATION SUBMITTED TO THE GRADUATE DIVISION OF THE UNIVERSITY OF HAWAII IN PARTIAL FULFILLMENT \\ OF THE REQUIREMENTS FOR THE DEGREE OF}

\section{DOCTOR OF PHILOSOPHY}

IN OCEANOGRAPHY

MAY $\quad 1970$

\section{By}

Karl Hans Bathen

\author{
Dissertation Commitiee: \\ Klaus Wyrtki, Chairman \\ Carl Adams \\ Richard Barkley \\ Brent Gallagher \\ Richard Jones
}




\section{ABSTRACT}

An analysis is made of the processes maintaining the seasonal heat storage in the 0 to 250 meter surface layer of the North Pacific Ocean. Approximately 140,000 bathythermograph observations taken in the Pacific Ocean from $10^{\circ}$ South latitude to $70^{\circ}$ North latitude are used. Mean temperature profiles are computed for each month and are numerically integrated to find the total heat stored in the 0 to 250 meter surface layer. The monthly maps show the heat storage decreases eastward and northward from a maximum in the Western Tropical Pacific to a minimum in the Bering Sea. The seasonal amplitude of the heat storage was found to be greatest around Japan, off the coast of Alaska, and south of the Hawaiian Islands. The seasonal amplitude was also found to exceed the amplitude of the net surface heat exchange over most of the ocean. Using the Laplacian of the heat storage, mixing is found to contribute between $10 \%$ and $38 \%$ to the local monthly change in heat storage where the Kuroshio and Oyashio meet, west of Vancouver Island, and south of the Aleutian Islands. Throughout the remainder of the North Pacific, mixing contributes less than 10\% to the local change in heat storage. Advection, estimated from the local change in heat storage, the 
contribution of mixing and the net surface heat exchange, is found to be of equal or greater importance than the net surface heat exchange in determining the local thermal structure.

An attempt is made to explain quantitatively the seasonal interactions existing between the changes in heat storage, the net surface heat exchange, horizontal mixing, and horizontal advection. A theoretical model of the timedependent changes in heat storage in the 0 to 250 meter layer of the North Pacific is developed for this purpose, using the two-dimensional horizontal heat conservation equation. The equation is numerically solved by providing a horizontal mixing coefficient and developing a stream function to provide the required horizontal velocity field information. The numerical solution is iterated in daily steps through an annual cycle many times, varying the stream function or mixing coefficient each time, until the best agreement is obtained between the computed and the observed annual amplitudes and phases of heat storage. A circulation of 42 million $\mathrm{m}^{3} \mathrm{sec}^{-1}$ in the large subtropical anticyclonic gyre is required along with 32 million $\mathrm{m}^{3} \mathrm{sec}^{-1}$ in an East Pacific gyre. A mixing coefficient linearly increasing from $1 \times 10^{6} \mathrm{~cm}^{2} \mathrm{sec}^{-1}$ at $8^{\circ}$ North latitude to $11 \times 10^{6} \mathrm{~cm}^{2} \mathrm{sec}^{-1}$ at $60^{\circ}$ North latitude was found to be best. The success of the two-dimensional horizontal heat conservation equation in simulating the observed seasonal 
changes in heat storage suggests that heat transfer by vertical advection and vertical mixing probably contribute little to the seasonal changes throughout most of the North Pacific Ocean. Using the final theoretical solution, an attempt is made to explain qualitatively the behavior of heat storage anomalies in the North Pacific Ocean. Hypothetical anomalies, simulating an abnormal net surface heat exchange, are added to the theoretical solution. The seasonal growth, movement, and decay of each anomaly is followed. The effect of increasing or decreasing the circulation is also tested. The results show that the heat storage in the area east of Japan and in the Western Tropical Pacific is primarily affected. 
TABLE OF CONTENTS

Title Page

Abstract . . . . . . . . . . . . . . . . . . iii

Table of Contents . . . . . . . . . . . . . . . vi

List of Figures . . . . . . . . . . . . . . . . ix

I. INTRODUCTION . . . . . . . . . . . . . . . . 1

A. STATEMENT OF THE PROBLEM . . . . . . . . . 1

B. SUMMARY OF PAST PERTINENT WORK . . . . . . 2

C. SPECIFIC GOALS OF THIS WORK . . . . . . . . 7

II. DATA . . . . . . . . . . . . . . . . 17

A. AREA COVERED AND DATA USED . . . . . . . . 17

B. GRID SELECTION . . . . . . . . . . . 17

C. SPATIAI AND TEMPORAL COVERAGE . . . . . . . 19

III. METHODS, RESULTS AND DISCUSSION . . . . . . . . 20

A. DESCRIPTIVE . . . . . . . . . . 20

1. Data Reduction and Interpolation

for Missing Data. . . . . . . . 20

2. Finding the Mixed Layer Depth . . . . 22

3. Heat Storage Computation. . . . . 28

4. Seasonal Heat Storage in the Mixed

Layer, the Thermocline Layer, and

the Total Heat Storage... . . . 30 
a. Heat Storage in the Mixed and Thermocline Layers . . . . . . 30

b. Total Heat stored in the 0 to

250 Meter Layer . . . . . . 36

5. Finding the Change in Total Heat Storage

Due to Adrection . . . . . . . . 42

a. Change in Total Heat Storage with

Respect to Time . . . . . . .

b. Change in Total Heat Storage Due to Mixing . . . . . . . . . . 44

c. Change in Total Heat Storage due to the Net Surface Heat Exchange •

d. Change in Total Heat Storage Due to Advection . . . . . . . . 52

e. Comparing the Local Total Heat Storage to the Net Surface Heat Exchange . . . . . . . .

B. NUMERICAL MODEL . . . . . . . . . . . 73

1. Theory and the Equation Used . . . . 74

2. Given Terms, Computed Terms, and General Solution Steps . . . . . . . . . . 77

3. Iterative Techniques . . . . . . . 81

4. Computation of the Stream Function . . 84

5. Theoretical Solution Convergence and Stability . . . . . . . . . . . . 91 
C. COMPARISON OF THE THEORETICAL AND OBSERVED TOTAL HEAT STORAGE • • . • . • • . . • • . 96

1. Comparison of the Annual Amplitudes . 97

2. Difference Between the Annual Amplitudes 102

3. Comparison of the Annual Phase . . . 104

4. Comparison of the Monthly Results . . 107

D. HEAT STORAGE ANOMALIES • . . . . . . . . 109

1. Magnitude and Location of Hypothetical Anomalies . . . . . . . . . . . 109

2. Behavior of the Hypothetical Anomalies 111

3. Effect of Increasing or Decreasing the Circulation. . . . . . . . . . 117

IV. SUMMARY AND CONCLUSIONS • • • • • • • • • • • • 121

V. APPENDIX • . . . . . . . . • • . . . . . . . 131

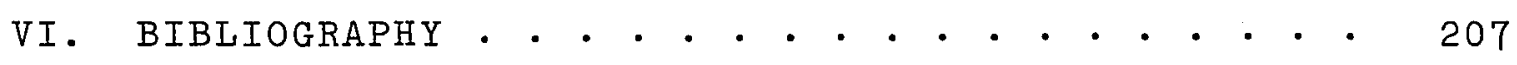




\section{LIST OF FIGURES}

Figure

1

2.

Title

Page

Reference Map . . . . . . . . . . . . 132

Spatial Coverage of the Temperature Data .. 133

Temporal Coverage of the Temperature Data . 134

Mixed Layer Depth for January • • . • . 135

Mixed Layer Depth for February . • . . . 136

Mixed Layer Depth for March . . . . . . 137

Mixed Layer Depth for April . . . . . . 138

Mixed Layer Depth for May . . . . . . . 139

Mixed Layer Depth for June . . . . . . 140

Mixed Layer Depth for July . . . . . . 141

Mixed Layer Depth for August . . . . . 142

Mixed Layer Depth for September . . . . 143

Mixed Layer Depth for October . . . . . 144

Mixed Layer Depth for November . . . . . 145

Mixed Layer Depth for December . . . . . 146

Annual Average Mixed Layer Depth . . . . 147

Annual Amplitude of the Variation in

Mixed Layer Depth • . . . . . . . . 148

Annual Average Heat Stored in the Mixed

Layer . . . . . . . . . . . . . 149

Annual Amplitude of the Variation in Heat

Stored in the Mixed Layer . . . . . . 150 
Annual Average Heat in the Thermocline Layer . . . . . . . . . . . 151

21 Annual Amplitude of the Variation in Heat Stored in the Thermocline Layer . . . . . 152 Seasonal Variation of Total Heat Storage, Heat in the Mixed Layer, Heat in the Thermocline Layer, Mixed Layer Depth, Surface Temperature, and Net Surface Heat Exchange $\cdot$. $\cdot$. $\cdot$. $\cdot$. $\cdot$. $\cdot$.

23 Seasonal Variation of Total Heat Storage, Heat in the Mixed Layer, Heat in the Thermocline Layer, Mixed Layer Depth, Surface Temperature, and Net Surface Heat Exchange • • • • . • . . . . . . 154

24 Total Heat stored in the 0-250 Meter Surface Layer - January • • • • • • • • 155

25 Total Heat Stored in the $0-250$ Meter Surface Layer - February . . . . . . 156

26 Total Heat Stored in the 0-250 Meter Surface Layer - March . . . . . . . . 157

27 Total Heat Stored in the $0-250$ Meter Surface Layer - April . . . . . . . . 158 28 Total Heat Stored in the $0-250$ Meter Surface Layer - May . • . . . . . • • 159 Total Heat Stored in the 0-250 Meter Surface Layer - June . . . . . . . . . 160 
Total Heat Stored in the 0-250 Meter

Surface Layer - July • . . . . . . . . .

31 Total Heat Stored in the 0-250 Meter

Surface Layer - August . . . . . . . 162

32 Total Heat stored in the $0-250$ Meter

Surface Layer - September . . . . . . 163

33 Total Heat Stored in the $0-250$ Meter

Surface Layer - october . . . . . . . 164

34 Total Heat stored in the $0-250$ Meter

Surface Layer - November . . . . . . . 165

35 Total Heat Stored in the 0-250 Meter

Surface Layer - December . . . . . . 166

36 Annual Average Total Heat stored in the

0-250 Meter Surface Layer . . . . . . . 167

37 Annual Amplitude of the Variation in

Total Heat stored in the 0-250 Meter

Surface Layer. . . . . . . . . . . 168

38 Summation by $2^{\circ}$ Strips of Latitude of

the Total Heat Storage, Heat Stored in

the Mixed Layer, and Heat stored in the

Thermocline Layer. . . . . . . . . 169

39 Annual Average Change in Total Heat

Storage (0-250 Meters) due to Horizontal

Mixing . . . . . . . . . . . . . . 170 
40 Annual Average Net Surface Heat

Exchange . . . . . . . . . . . . .

41 Annual Amplitude of the Variation in Net

Surface Heat Exchange . . . . . . . 172

42 Average by $2^{\circ}$ of Latitude of the Net

Surface Heat Exchange. . . . . . . . . 173

43 Annual Average Change in Total Heat

Storage (0-250 Meters) due to Advection . 174

44 Change in Total Heat Storage (0-250 Meters)

due to Horizontal Advection - January . . 175

45 Change in Total Heat Storage (0-250 Meters)

due to Horizontal Advection - February . . 176

46 Change in Total Heat Storage (0-250 Meters)

due to Horizontal Advection - March . . 177

47 Change in Total Heat Storage (0-250 Meters)

due to Horizontal Advection - April . . . 178

48 Change in Total Heat Storage (0-250 Meters)

due to Horizontal Advection - May . . . 179

49 Change in Total Heat Storage (0-250 Meters)

due to Horizontal Advection - June . . . 180

50 Change in Total Heat Storage (0-250 Meters)

due to Horizontal Advection - July . . . . 181

51 Change in Total Heat Storage (0-250 Meters)

due to Horizontal Advection - August . . . 182 
Change in Total Heat Storage (0-250 Meters) due to Horizontal Advection - September . .

Change in Total Heat Storage (0-250 Meters)

due to Horizontal Advection - October . . 184

54 Change in Total Heat Storage (0-250 Meters)

due to Horizontal Advection - November . . 185

55 Change in Total Heat storage (0-250 Meters)

due to Horizontal Advection - December . . 186

56 Change in Total Heat Storage (0-250 Meters)

during March . . . . . . . . . . 187

57 Change in Total Heat Storage (0-250 Meters)

due to Horizontal Mixing - March . . . . 188

58 Net Surface Heat Exchange - March . . . . I89

59 Amplitude Comparison - Total Heat Storage

(0-250 Meters) divided by The Net Surface

Heat Exchange . . . . . . . . . . . 190

60 Phase Comparison - Month of Maximum Total

Heat Storage (0-250 Meters) minus Month of

Maximum Net Surface Heat Exchange . . . . 191

61 Phase Comparison - Month of Minimum Total

Heat Storage $(0-250$ Meters $)$ minus Month of

Minimum Net Surface Heat Exchange . . . . 192

62 Algebraic Summation by $2^{\circ}$ of Latitutude of

the Phase Comparisons of Total Heat Storage

(0-250 Meters) and Net Surface Heat Exchange 
Stream Function used in the Final

Theoretical Solution of the Two Dimensional Heat Conservation Equation . . . . . . 194

64 Theoretical Annual Amplitude of Total Heat Storage (0-250 Meters) - Mixing Coefficient a Linear Function of Latitude . . . . . . .

65 Phase Comparison - Theoretical Month of Maximum Total Heat Storage (0-250 Meters) minus Observed Month of Maximum Total Heat Storage . . . . . . . . . . . . 196

66 Phase Comparison - Theoretical Month of Minimum Total Heat Storage (0-250 Meters) minus Observed Month of Minimum Total Heat Storage . . . . . . . . . . . . . . 197

67 Theoretical Annual Amplitude of Total Heat Storage $(\theta-250$ Meters $)$ - Constant Mixing Coefficient. . . . . . . . . . . 198

68 Theoretical Annual Amplitude of Total Heat Storage (0-250 Meters) - Constant Mixing Coefficient, No North-South Asymmetry, and No East Pacific Gyre . . . . . . . . . 199

69 Difference between the Theoretical and Observed Annual Amplitude of Total Heat Storage $(0-250$ Meters $)$. . . . . . 200 
Seasonal Variation of the Theoretical

Total Heat Storage (0-250 Meters),

Observed Total Heat Storage and the Net

Heating at the Surface . . . . . . . 201

71 Seasonal Variation of the Theoretical

Total Heat Storage (0-250 Meters),

Observed Total Heat storage and the Net

Heating at the Surface . . . . . . . 202

72 Behavior of Hypothetical Heat Storage

Anomalies (Example 1) . . . . . . . . 203

73 Behavior of Hypothetical Heat Storage

Anomalies (Example 2) . . . . . . . 204

74 Effect on the Total Heat Storage

(0-250 Meters) after One Year due to

Increasing the Circulation 10\%

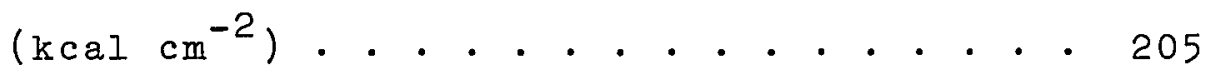

75 Effect on the Total Heat Storage

(0-250 Meters) after One Year due to

Decreasing the Circulation 10\%

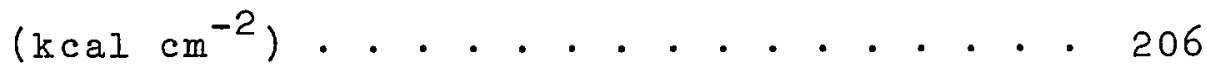




\section{INTRODUCTION}

A. STATEMENT OF THE PROBLEM. Since the turn of the century, meteorologists and oceanographers have sought to understand the energy exchange between the surface of the earth and the atmosphere. A thorough understanding of the ocean's role in seasonally storing and transporting heat to higher latitudes has remained a primary oceanographic goal for some time. Meteorologists made much early progress in understanding the seasonal storage and redistribution of heat in the atmosphere. However, oceanographers could not obtain an early qualitative understanding of the seasonal storage and redistribution of heat in the oceans primarily because of insufficient data. By the mid-1950's, much data had accumulated. Still, little emphasis was placed on using müch of the data to better define the seasonal storage and redistribution of heat in the ocean. This was true primarily because of shortcomings in the form of the data and in the methods that were available for processing large amounts of data. However, recent conversion of the data for modern data processing methods has removed these limitations. Thus, the problem with which this work was principally concerned was to describe quantitatively the seasonal heat storage in the entire 
North Pacific Ocean, and to find and compare the importance of the processes affecting these seasonal changes.

B. SUMMARY OF PAST PERTINENT WORK. The role of the oceans in the heat exchange between the earth and the atmosphere has been under investigation since the early 1900's. Prior to the mid-1950's the data available limited the area that could be considered by each investigator. However, early statistical and empirical studies by Bowen (1926), Gabites (1950), Jung (1955) and others did help increase the general understanding of oceanic heat storage and heat exchange at the surface of the ocean. By the mid-1950's, however, more direct attempts were being made at quantitatively finding, or modeling, the transfer of heat between the ocean and the atmosphere, at estimating the seasonal heat storage in limited areas of the ocean, and at providing early descriptive knowledge of heat anomalies in the ocean. The accumulation of much bathythermograph (BT) data was largely responsible.

Pattullo (1956) provided an estimate of the seasonal heat storage in the oceans. Pattullo studied quantitatively the seasonal variation of heat storage and the related effects of advection at 61 world-wide oceanic locations, with 47 of these located in the North Atlantic. Half of the 61 locations studied were concentrated along coastlines in a $20^{\circ}$ zone extending from $30^{\circ}$ to $50^{\circ}$ North 
latitude. Nonetheless, Pattullo's results emphasized the importance of horizontal seasonal heat transports in middle and high latitudes by showing that seasonal changes in heat storage exceeded the estimate of local heating in these areas by an average of $40 \%$.

An early use of a simplified model to estimate the heat exchange between the atmosphere and the ocean was introduced by Fritz (I958). Using BT and ocean surface temperature data, Fritz computed the seasonal heat budget of the atmosphere by first finding the heat stored and released seasonally by the ocean. He used the results on the atmospheric heat balance by Gabites (1950) as a check on the amount of heat stored in the ocean. Fritz found a net heating in low latitudes and net cooling in high latitudes, with approximately zero heating in middle latitudes. Aside from this conclusion, the use of a simplified model to link surface heat exchange with oceanic heat storage was an important contribution.

Following Fritz's work, Bryan and Schroeder (1960) computed the heat storage and estimated the horizontal heat transport in a small section of the North Atlantic ocean. The data in their section, covering $20^{\circ}$ to $65^{\circ}$ North, were limited, and their results were based upon considerable smoothing of their data with latitude. Like Pattullo, they found a seasonal increase in heat storage near the surface in mid latitudes that was greater than 
the amount of heat exchanged at the surface. However, they also found that the seasonal change in heat stored north of $50^{\circ}$ North latitude was less than the surface heat exchange. Bryan and Schroeder raised the question concerning the importance of seasonal heat storage below 400 meters. They noted that this probably small amount of heat storage is masked by the "thermal noise" resulting from short-period fluctuations in the deep thermal structure. Earlier, Koizumi (1955) had examined temperature data taken to 1500 meters from two weather stations off Japan and foun no seasonal variation below 200 meters. Pattullo (1956) later reexamined Koizumi's data and concluded that 95\% of the seasonal change in heat storage was limited to the 0 to 250 meter layer, with the balance stored probably to 1500 meters depth.

Since 1947, quantitative knowledge of sea-surface temperature variations has been advanced by the contributions of Namias (1959, 1963, 1965), Arthur (1966) and the U. S. Department of the Interior, Fish and Wildlife Service (from 1947 to the present). Namias examined the seasonal interaction between the ocean and the overlying atmosphere in the Eastern North Pacific during 1957 and 1958. He concluded that surface temperature anomalies were primarily related to abnormal wind components. Since 1947, the U. S. Department of the Interior has continued to provide much quantitative information on temperature 
anomalies found on the surface of the North Pacific Ocean. A comprehensive quantitative description of seasonal heat exchange at the surface of the North Pacific Ocean was accomplished by Wyrtki (1966). Using a considerable amount of meteorological and surface water temperature data, and reducing the data to $2^{\circ}$ squares, Wyrtki developed monthly maps of the surface heat exchange for the Pacific from $20^{\circ}$ South to $60^{\circ}$ North latitude. Clark and Willett (1966) also computed the seasonal flux of heat at the surface of the North Pacific Ocean in the area from $15^{\circ}$ to $60^{\circ}$ North latitude. They found that this area of the North Pacific annually loses an average of $7 \times 10^{14}$ cal $\sec ^{-1}$. They also statistically examined surface temperature anomalies occurring in the same area. They found that the surface temperature anomalies were extensive in size, were geographically coherent, and persisted for several months. Through a multilinear correlation analysis, made between the observed seasonal changes in seasurface temperature, the net surface heat exchange, and estimates of the horizontal advection, they estimated that between 12 and 25\% of the seasonal variation of sea-surface temperature is due to the vertical velocity beneath the Ekman layer.

Recently, Wyrtki and Haberland (1968) analyzed the processes maintaining the temperature distribution in the mixed layer of the Pacific Ocean north of $10^{\circ}$ North 
latitude. Considered were the surface temperature and the processes of horizontal and vertical advection and mixing. They computed that a vertical circulation of 8 million $\mathrm{m}^{3} \mathrm{sec}^{-1}$ was necessary to balance an annual excess heat input of $2 \times 10^{14} \mathrm{cal} \mathrm{sec}^{-1}$ received by the Pacific north of $6^{\circ}$ North latitude. They also computed that a horizontal circulation of just 10 million $\mathrm{m}^{3} \mathrm{sec}^{-1}$ was necessary to transport heat from areas of heat gain to areas of heat loss. They concluded that all horizontal heat transports take place in a shallow surface layer, and that horizontal eddy diffusion can contribute to heat transports in areas of strong temperature gradients. Comparing the seasonal variations of surface temperature and heat input, they estimated that a varying mixed layer depth from 30 to 70 meters could store the seasonal heat input, but some phase disagreement exists between the computed and observed mixed layer depths. They concluded that advection is an important contributor to the local thermal structure.

In summary, past investigators agree that the horizontal transport of heat is an important contributor to seasonal changes in the local thermal structure. It is also generally agreed that seasonal changes in heat storage are essentially limited to the upper 200 meters of the ocean. However, disagreement exists in whether the annual amplitude of the total heat storage or of the net surface 
heat exchange is greater at high latitudes. Heat storage anomalies, probably caused by abnormal winds, have been found to be extensive in size and to persist for several months. Except for the work of Pattullo, Fritz, Bryan and Schroeder, and Wyrtki and Haberland, the numerous remaining contributions made since the 1950's were concerned with finding the amount of energy exchanged across the ocean's surface. No one has dealt with the particular problems of finding the monthly change in heat storage in the surface layer covering an entire ocean basin and of determining the qualitative importance of each process affecting the local change in heat storage. Neither has anyone attempted the task of modeling these spatial and temporal changes in heat storage for such a layer in a large ocean basin.

C. SPECIFIC GOALS OF THIS WORK. The basic goal of this work is to develop a quantitative understanding of the seasonal interactions existing between the heat storage, surface heat exchange, and the circulation in the surface layer of the North Pacific Ocean. A surface layer extending from 0 to 250 meters depth will be considered. This layer includes the mixed layer and most of the main thermocline. The heat exchanged at the surface alters the temparature of the mixed layer. The circulation, through advection and mixing, redistributes this heat in both the upper (mixed) and lower (thermocline) portions of the 
surface layer. Seasonal changes in these processes affect both the mixed layer depth and the amount of heat stored in the entire 250 meter surface layer. Short-term changes can result in local heat storage anomalies. This work attempts to describe the seasonal heat storage existing in the North Pacific Ocean, and to explain the quantitative relationships existing between this heat storage, the surface heat exchange, and the circulation. A large part of the BT observations taken in the North Pacific to date (those digitized and on magnetic tape) are used. An attempt is also made to model the spatial and temporal changes in heat storage existing in the surface layer of the North Pacific Ocean.

Three specific objectives were initially established for this work. The objectives and the results expected are as follow:

The First Objective.-To accomplish a detailed and comprehensive examination of the data, and subsequently present a descriptive picture of the mixed layer depth, the heat stored in the mixed and thermocline layers, and the heat stored in the total 250 meter surface layer. With these descriptive results at hand, the following questions could be answered:

1. What is the geographical distribution of the mixed layer depth for each month?

2. What is the annual average and annual amplitude of 
heat stored in the mixed and thermocline layers?

3. What is the geographical distribution of total heat stored in the 250 meter surface layer each month?

4. How does the local annual amplitude of total heat storage compare with the local annual amplitude of the net surface heat exchange?

5. What is the annual phase relationship existing between the local net surface heat exchange and total heat storage?

6. What is the importance geographically of advection and horizontal mixing in redistributing heat in the surface layer?

7. Where is the surface heat exchange, advection or the mixing the predominant factor determining the seasonal change in the local thermal structure?

All of the above descriptive results will provide a basis for understanding how the heat stored in the 250 meter surface layer of the North Pacific Ocean changes seasonally and how these changes relate to horizontal advection and mixing and the net exchange of heat at the surface. The Next Objective. -To attempt to explain quantitatively how the heat exchanged at the surface, the mixing, and the circulation alter the local heat storage. A theoretical model of the time-dependent changes in the total heat storage is developed for this purpose. The model is developed by numerically solving the heat 
conservation equation applied to a 250 meter thick surface layer. Before discussing the last objective of the work it is worthwhile to understand how the heat conservation equation is used in developing the model.

In the data reduction to follow, a horizontal grid will be selected for the North Pacific. This grid, along with the surface and the 250 meter depth, will define grid volumes. The equation for conservation of heat written in the most general integral form for any grid volume is

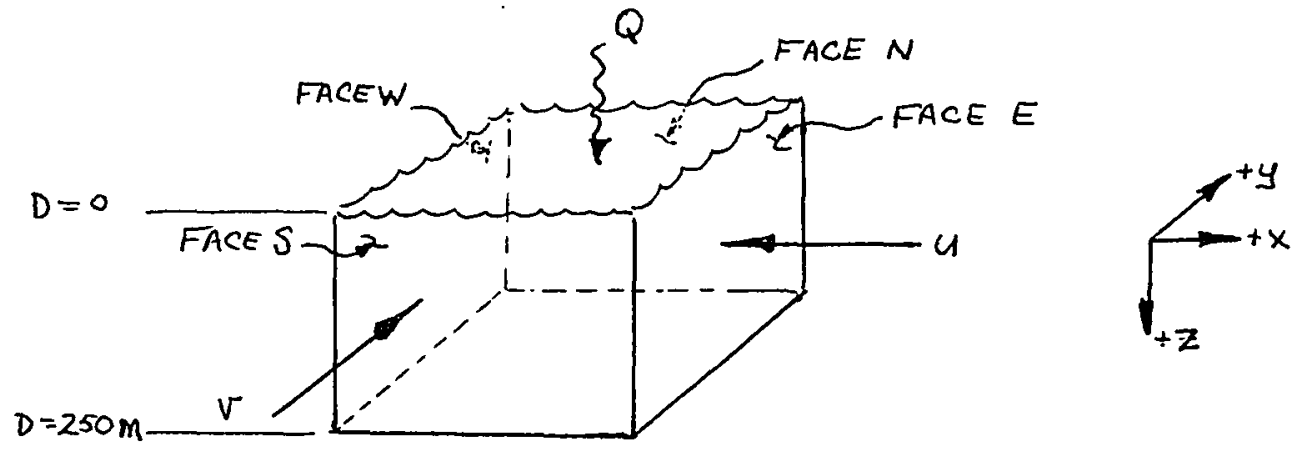

$$
\frac{\partial}{\partial t} \iiint_{\text {VOLUME }} T d z d x d y=\int_{\substack{\text { FACE } \\ \text { FACE }}}^{D}\left(A \frac{\partial T}{\partial x}-T u\right) d y d z+\int_{0}^{D} \int_{y}\left(A \frac{\partial T}{\partial x}-T u\right) d y d z
$$
Face w

$+\int_{0}^{D} \int_{x}\left(A \frac{\partial T}{\partial y}-T v\right) d x d z+\int_{0}^{D} \int_{x}\left(A \frac{\partial T}{\partial y}-T v\right) d x d z$

FACE N

FACE $S$

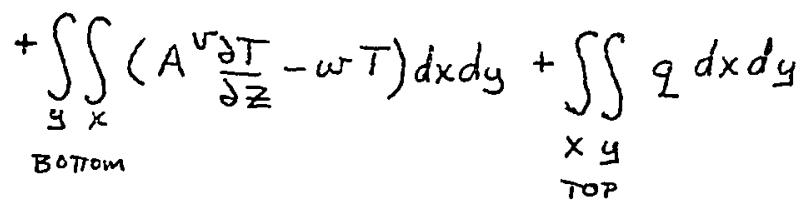


where:

$$
\begin{aligned}
& x, y, z=\text { the three axes: } \quad+x=\text { east } \\
& +y=\text { north } \\
& +z=\text { down }(\mathrm{cm}) \\
& u, v, w=\text { the component of velocity along the } \\
& \text { - } x, y \text { and } z \text { axis, respectively }\left(\mathrm{cm} \mathrm{sec} \mathrm{s}^{-1}\right) \\
& T=\text { temperature }\left({ }^{\circ} \mathrm{C}\right) \\
& \mathcal{L}=Q / \rho C_{p} S ; \quad Q=\text { net surface heat exchange } \\
& \text { ( } \left.\operatorname{cal} \mathrm{cm}^{-2} \mathrm{day}^{-1}\right) \text {, } \\
& \rho=\operatorname{density}\left(\mathrm{gm} \mathrm{cm}^{-3}\right) \text {, } \\
& C_{P}=\text { specific heat at constant } \\
& \text { pressure (cal } \mathrm{gm}^{-1}{ }^{\circ} \mathrm{C}^{-1} \text { ), } \\
& S=\text { seconds } d a y^{-1} \text {. } \\
& A^{r}=\text { vertical eddy diffusion coefficient } \\
& \left(\mathrm{cm}^{2} \mathrm{sec}^{-1}\right) \text {. } \\
& A=\text { horizontal eddy diffusion coefficient } \\
& \left(\mathrm{cm}^{2} \sec ^{-1}\right) \text {. }
\end{aligned}
$$

The integral on the left-hand side of Equation (1)

describes the time change of heat stored in the grid

volume. The first two integrals on the right-hand side

describe the horizontal flow of heat through the two vertical faces in the $x-z$ plane due to horizontal advection and mixing. The thixd and fourth integrals describe the horizontal flow of heat through the two vertical faces in the $y-z^{*}$ plane due to horizontal advection and mixing. The fifth integral describes the vertical flow of heat 
through the bottom of the grid volume due to vertical advection and mixing. The last term on the right-hand side of Equation (1) represents the net exchange of heat integrated over the surface of the grid volume. The second governing equation for each grid volume is the equation of continuity:

$$
\int_{\substack{0 \\ \text { FACEE }}}^{D} \int_{\substack{y \\ \text { FACE } W}}^{D} u d y d z+\int_{\substack{y \\ \text { FACE } N}}^{D} u d y d z+\int_{\substack{x \\ \text { FACE } S}}^{D} v d x d z+\int_{\substack{x \\ \text { FA }}}^{D} v d x d z-\int_{y} \int_{x} w d x d y=0
$$

These two equations govern the change in total heat stored in the 0 to 250 meter surface layer due to the processes of advection and mixing in the presence of heat sources and sinks.

Using Equation (I) to develop a model of the seasonal changes in total heat storage requires knowledge of an initial three-dimensional temperature field, the horizontal (A) and vertical $\left(A^{v}\right)$ eddy diffusion coefficients, and the net surface heat exchange. In addition, each velocity component $u, v$ and $w$ as a function of the dimensions over which each component is integrated must be known. Little is known to date about the three-dimensional velocity field existing seasonally throughout the entire North Pacific Ocean. Therefore, some simplifying assumptions must be introduced to solve Equation (1) for each grid volume. 
The problem can be solved for the entire North Pacific by assuming a balance exists between the vertical advection and mixing. This assumption would simplify Equation (I) to the horizontal processes and the net surface heat exchange. In examining the thermohaline circulation Wyrtki (1961) has shown that for a good first-order approximation the turbulent downward flow of heat and the ascending movements of cooler water can be assumed to balance over large areas of the ocean. In this case the temperature at some depth beneath the main thermocline will be approximately constant in time. As stated earlier, Bryan and Schroeder, Koizumi, and Pattullo agreed that essentially all of the seasonal change in heat storage is Iimited to the upper 200 to 250 meters of the ocean. Later it will be noted that the temperature at the bottom of the 0 to 250 meter surface layer is essentially constant in time over most of the North Pacific Ocean. Therefore, with the above assumption the two terms in the fifth integral on the right-hand side of Equation (I) will balance each other.

Values for the velocity components $u$ and $v$ can then be obtained by assigning a stream function $\phi\left(\mathrm{cm}^{3} \mathrm{sec}^{-1}\right)$ to represent the horizontal velocity field. If the horizontal volume transports $V^{x}$ and $V^{y}$ are defined by:

$$
v^{x}=\int_{0}^{0} u d z
$$




$$
v^{y}=\int_{0}^{D} v d z
$$

then

$$
\begin{aligned}
& \frac{\partial \phi}{\partial y}=V^{x}=\bar{u} D \\
& \frac{\partial \phi}{\partial x}=-V^{y}=-\bar{v} D
\end{aligned}
$$

Therefore, using a stream function $\phi$ gives the mean horizontal velocity components $\bar{u}$ and $\bar{v}$ over the 250 meter

depth D. How well $\bar{u} \frac{\Delta H}{\Delta x}$ and $\bar{v} \frac{\Delta H}{\Delta y}$ approximate

$$
\rho c_{P} \iint_{y} \frac{\partial T}{\partial x} u d z d y \text { and } \rho C_{P} \iint_{x} \frac{\partial T}{\partial y} v d z d x \text { respectively }
$$

will be discussed in Section III.B.I.

All temperature aata in each grid volume is reduced to mean monthly temperature profiles. Each mean temperature profile is assumed to represent the entire grid volume. The total heat storage (H) is found for each grid volume by vertically integrating the temperature profiles (with constant $\rho C_{P}$ ) from the surface to 250 meters depth. Monthly net surface heat exchange data are known for each grid volume. The value given for each month will be. assumed constant over the horizontal surface of each grid volume. This term represents the balance between four components: the surface heat exchange due to incoming radiation and back radiation, the heat of evaporation, and the 
heat transferred by conduction.

Considering the above assumptions Equation (I) can be simplified. Since the turbulent flux of heat downward and the vertical advection of cold water upward are assumed in balance, these terms will not be carried further. Since the total heat storage $H$ is obtained by vertically integrating mean temperature profiles, and since the horizontal velocities are obtained from a given stream function, the dependence of the heat conservation equation on changes in the vertical ( $z$ ) direction can be removed. Therefore, dividing Equation ( 1 ) by the surface area of the volume and going to the limit for an infinitely small surface area, the heat conservation equation can be written in the twodimensional differential form for the total heat storage H:

$$
\frac{\partial H}{\partial t}=A\left[\frac{\partial^{2} H}{\partial x^{2}}+\frac{\partial^{2} H}{\partial y^{2}}\right]-u \frac{\partial H}{\partial x}-v \frac{\partial H}{\partial y}+Q(x, y, t)
$$

The term on the left-hand side of Equation (2) represents the local rate of change of total heat storage. The terms on the right-hand side represent the processes affecting the change in heat storage. The first two represent the rate of change due to horizontal mixing. The third and fourth represent the rate of change due to horizontal advection.

Equation (2) can be used to develop a theoretical model of the seasonal changes in heat stored in the 250 
meter surface layer of the North Pacific Ocean. The information gained from the model will help accomplish the second objective of explaining quantitatively the local seasonal changes in heat storage. This help will be primarily in testing the validity of neglecting the vertical processes and in identifying areas where horizontal advection and mixing are important. The steps in the development of the model will be discussed later.

The Last objective. - To examine and attempt to explain qualitatively the behavior of heat storage anomalies in the North Pacific Ocean. This can be accomplished by using the final theoretical model once it has been developed and once the quantitative interaction between the local heat storage, the circulation, and the heat exchanged at the surface is understood. Hypothetical anomalies, simulating an abnormal net surface heat exchange, can be added to the model at various initial times and locations. The behavior of these anomalies can then be followed through one or more annual cycles. It will also be possible to test the consequences of increasing or decreasing the circulation on the seasonal heat storage. Both of these anomalous situations will be investigated. 
II. DATA

A. AREA COVERED AND DATA USED. Figure 1 shows the geographical limit of the temperature and net surface heat exchange data used. This work was concerned principally with the area of the Pacific ocean north of the Equator. This area includes the cyclonic and anticyclonic circulation systems in the North Pacific, the Equatorial Countercurrent and Undercurrent, and most of the latitudinal zone in which the heat equator seasonally shifts. The National Oceanographic Data Center's collection of 135,383 BT casts were used to obtain values for the monthly heat storage in this area. These data, covering 96 ten-degree Marsden squares in the Pacific north of the Equator, have been recently placed on magnetic tape and are suitable for rapid data-processing. The results of Wyrtki (1966), covering the Pacific Ocean from $20^{\circ}$ South to $60^{\circ}$ North latitude, provided the required net surface heat exchange information along with supplementary surface temperature information. These data, divided into two-degree squares, had also been placed on magnetic tape.

B. GRID SELECTION. A grid covering the North Pacific ocean was selected prior to reducing the data. 
Two criteria were considered in selecting the grid size. First, a small grid size would be advantageous for the numerical solution to be later attempted, but too small a grid size would result in an excessive number of areas having insufficient data coverage. Second, the storage limitation of the computing facility used was also considered because many variables must be stored for each grid area during the numerical solution of the heat conservation equation.

Figure 1 shows a sample of the grid that was selected and used for all subsequent work. The grid lines follow lines of latitude and longitude. Each area defined by the grid is one-fifth of a $10^{\circ}$ Marsden square. At the Equator, the grid dimensions are $1112 \mathrm{~km}$ east-west by $222 \mathrm{~km}$ northsouth. At $60^{\circ}$ North latitude the east-west dimension is reduced to $556 \mathrm{~km}$ east-west. The grid divides the total area in the Pacific, from $10^{\circ}$ South to $70^{\circ}$ North latitude and from $70^{\circ}$ East to $110^{\circ}$ West longitude, into 402 grid rectangles. The rectangles have their long axis lying east-west. Such an orientation favors a north-south resoIution. This is desirable because the primary gradient of temperature in the upper layer of the North Pacific is north-south. More important, the grid chosen results in acceptable temporal data coverage for each of the 402 grid rectangles. 
C. SPATIAL AND TEMPORAL COVERAGE. Figures 2 and 3 show the spatial and temporal coverage of the BT data reduced to the $2^{\circ}$ by $10^{\circ}$ grid rectangles. The largest number of observations (Figure 2) are concentrated at mid latitudes, and at high latitudes around Alaska and the Aleutian Islands. The temporal coverage of these observations in the North Pacific (Figure 3 ) is quite good over the same broad areas. No data was available from the area just east of the Kurile Islands in the Northwestern Pacific. Except for this area, the remainder of the North Pacific has good temporal coverage from the Equator to $45^{\circ}$ North latitude in the Western Pacific and from the Equator to $60^{\circ}$ North latitude in the Eastern Pacific. 
III. METHODS, RESULTS AND DISCUSSION

A. DESCRIPTIVE

1. Data Reduction and Interpolation for

Missing Data. Monthly vertical temperature profiles for each grid rectangle were required for the heat storage computation. They were obtained in the föllowing manner:

All BT data contained in each grid rectangle for each month were averaged. Temperature profiles extending from the surface to 250 meters depth were obtained for most grid rectangles from this computation. Next a GregoryNewton Forward extrapolation (Salvadori and Baron, 1961, p. 77) was used to extend any temperature profile that was short of 250 meters depth. The last ten temperatures in the profile being extended were used to extrapolate (vertically) the missing temperatures in 5 meter intervals down to 250 meters depth. Data missing for any month, in any rectangle, were then interpolated for each 5 meter layer from 0 to 250 meters using the neighboring monthly curves. A Lagrange interpolation (Salvadori and Baron, 1961, p. 88) was used for this interpolation. The purpose of this first interpolation in time was to obtain missing monthly temperature profiles in cases where six or 
more monthly profiles were available in the grid rectangle. At the completion of this first interpolation, monthly temperature profiles extending from 0 to 250 meters were available for most of the 409 grid rectangles.

Next, an interpolation in space was made to determine missing monthly temperature profiles for the few grid rectangles having less than six months of data coverage in the 0 to 250 meter surface layer. Data from the neighboring grid rectangles were used for this second interpolation. The missing monthly temperature profiles were interpolated for each 5 meter layer by again applying a Lagrange interpolation. Either the north-south or eastwest neighboring rectangles were used, depending upon the predominant direction of the current generally found in the area during the month being interpolated. Three references were used to determine the monthly predominant direction of the prevailing current. These references were 1. Hydrographic office Publications 569 and 570, Atlas of Surface Currents Northwest and Northeast Pacific Ocean, 1953 .

2. Provisional CSK Atlas for Summer 1965-March 1967. 3. Oceanic observations of the Pacific, 1955-The NORPAC AtIas.

At the completion of the data reduction, extrapolation, and interpolation, monthly mean temperature profiles were available for each of the 409 grid rectangles being 
considered in the Pacific Ocean. In 341 of the 409 grid rectangles, the mean temperature profiles show that the temperature at 250 meters depth is approximately constant in time and with depth. The remaining 68 grid rectangles are located primarily in the Central and Tropical Western Pacific and southwest of the Hawaiian Islands.

The monthly net surface heat exchange and surface temperature data were obtained already averaged by $2^{\circ}$ squares. These data covered most of the Pacific from the Equator to $60^{\circ}$ North latitude, and from $75^{\circ}$ West to $120^{\circ}$ East longitude (see Figure 1). Monthly net surface heat exchange and surface temperature values were obtained from each $2^{\circ} \times 10^{\circ}$ grid rectangle by averaging the monthly data from the five $2^{\circ}$ squares comprising each grid rectangle. Data were missing from the area just east of the Kurile Islands and the area around New Guinea. Monthly values for the net surface heat exchange were extrapolated (horizontally) for each of the grid rectangles in these areas using the data from the neighboring grid rectangle (Gregory-Newton Forward extrapolation). It was more advantageous to work with approximations of the monthly net surface heat exchange in these areas than to eliminate them entirely from all subsequent work.

2. Finding the Mixed Layer Depth. Prior to finding the heat stored in the mixed and thermocline layers it was necessary to find the mixed layer depth. 
The mixed layer depth was found using the mean monthly vertical temperature profiles previously obtained for each grid rectangle. The mixed layer depth was found from these curves by three methods: a visual inspection and two statistical tests. The purpose in using three methods was to compare the accuracy of each method in determining the mixed layer depth. In adition, comparing the results of each method increased the confidence in the values obtained for the mixed layer depth. In a few cases the mixed layer depth was not visually obvious and the results of the other two methods helped determine the mixed layer depth. The three methods used were:

Method 1: Visually inspecting each curve and determining either the depth at the bottom of the isothermal surface layer, or the depth where the temperature gradient changed from the constant temperature gradient that began at the surface. In most cases, this depth was quite evident. Method 2: Statistically testing the hypothesis that the mean temperature in the mixed layer is equal to the surface temperature. Starting with the first three temperatures (sample size = 3) below to the surface, the probability that the mean of these temperatures deviates significantly from the surface temperature was computed. A student's t-test with a significance level of 5\% (1-tailed test) was used to judge the significance. The test was continued by proceeding down in 5-meter steps and including 
the next temperature in the sample size. The computation was continued until the probability was significant that the mean of temperatures in the sample was deviating significantly from the surface temperature. The depth at which this occurred was taken as the mixed layer depth. The computation was continued one more step to verify that a significant deviation was occurring. Method 3: Testing the rate of change of the temperature with depth. A line was fitted to the first three temperatures closest to the surface (base line) and to the next three temperatures (test line) using the method of least squares in each case. The slopes of the test line and the base line were then compared. If the absolute difference was less than 0.02 the computation was continued, proceeding down in 5 meter steps and recomputing the test line slope. The temperature that was passed was included in the computation of a new base line slope. The test was continued until the absolute difference between the slope of the test and base line was greater than 0.02 . When this point was reached the depth of the middle temperature in the test line was taken as the mixed layer depth. The test was continued one more step to verify that the absolute difference in slope between the test and base Iine was continuing to increase.

In the cases where a temperature profile included an isothermal mixed layer, the three methods gave mixed layer 
depths within \pm 5 meters. When the temperature in the mixed layer decreased at a constant rate from the surface to the bottom of the mixed layer, the mixed layer depth obtained by the first and third methods agreed well, but the mixed layer depth obtained from the second method occasionally varied more than \pm 5 meters from the average of the other two tests. Dropping the significance level to $1 \%$ in the second method made the test less sensitive, and the value obtained for the mixed layer depth agreed within \pm 10 meters of the other two methods. In general, however, the results of the three methods agreed within \pm 5 meters. When they did, an average was taken of the three for the mixed layer depth. In questionable cases, the results of the visual inspection were accepted over the other two tests.

Figures 4 through 15 show monthly maps of the mixed layer depth. Figures 16 and 17 show respectively the annual average and amplitude of the mixed layer depth. The monthly maps of the mixed layer depth show that throughout middle and high latitudes the shallow surface layer in the North Pacific responds strongly to summer heating. From the months of December to April, the mixed layer depth is generally greater than 100 meters north of $30^{\circ}$ latitude. In May, a very shallow mixed layer, less than 40 meters deep, begins developing in a narrow zone at about $20^{\circ}$ to $30^{\circ}$ latitude in the western and Central North 
Pacific. In June this shallow mixed layer expands across the entire North Pacific at approximately $25^{\circ}$ North latitude. The shallow summer mixed layer, however, has not yet developed in the Bering sea and in the area south of the Aleutian Islands. In sharp contrast to June, the shallow warm layer in July extends over the entire Pacific north of approximately $20^{\circ}$ latitude. This shallow layer remains until october, whereupon it begins deepening in Bristol Bay, north of the Alaskan Peninsula. In November, the mixed layer depth becomes greater than 80 meters throughout the Pacific north of approximately $45^{\circ}$ latitude. In low latitudes in the Western Pacific the influence of summer heating is not as pronounced as in midale and high latitudes. A slight shoaling of the mixed layer does occur from August to November between $25^{\circ}$ and $10^{\circ}$ North latitude. A shallow summer mixed layer is not evident between the Equator and $10^{\circ}$ North latitude.

Figure 16 shows a map of the annual average mixed layer depth. In the North Pacific it ranges from 15 meters off the Coast of Panama to 122 meters in the Bering Sea. The annual average mixed layer depth is approximately 65 meters across the Central Pacific from $20^{\circ}$ North latitude in the west to $40^{\circ}$ North latitude in the east. The average mixed layer depth increasesnorthward to 122 meters in the Bering sea and increases southward to greater than 100 meters south and east of the Hawaiian 
Islands and east of Guam Island. Averaging the values for all grid rectangles in the North Pacific gives an overall geographic mean of 75 meters. The annual average mixed layer depth varies little from this overall mean of 75 meters throughout most of the Western and Central Pacific. The information contained in Figure 16 was very useful for the subsequent work. Information helpful in initially selecting the locations of major gyre centers was obtained from the annual average map. This information was required for the development of the stream function used in the theoretical model. The map shows the locations where seasonally consistent maxima and minima mixed layer depth are found.

Figure 17 shows a map of the annual amplitude of the variation in mixed layer depth. The greatest seasonal changes from the annual mean mixed layer depth are found in the areas northwest of Vancouver Island ( +94 meters) and in the Bering sea ( +93 meters). The annual amplitude generally decreases toward the Equator. In the Eastern Tropical Pacific, north of the Galapagos Islands, the smallest annual change in mixed layer depth ( \pm 5 meters) is found. In the Western Tropical Pacific the seasonal variation in the mixed layer depth varies between \pm 9 meters to \pm 30 meters. In the Eastern Tropical Pacific the mixed layer depth is shallower and varies annually between \pm 5 meters to \pm 27 meters. The seasonal change in the mixed 
layer depth increases in the mid latitudes. Here the mixed layer depth is seasonally varying between +40 meters and \pm 70 meters. The greatest seasonal change is found in high latitudes, where the mixed depth varies between 12 and 201 meters $( \pm 94$ meters). The amplitude contours shown in Figure 17 are strongly oriented east-west throughout most of the North Pacific. The annual amplitude at each latitude is quite similar across the entire North Pacific, particularly in middle and low latitudes. This suggests that the mixed layer depth is probably responding primarily to the annual wave of insulation.

3. Heat Storage Computation. The next descriptive task was to find the heat stored in the 0 to 250 meter surface layer of the North Pacific Ocean. The heat sotred in the mixed layer, thermocline layer (250 meters minus the mixed layer depth), and the total heat storage were found. In the subsequent work only the total heat storage was used. The reasons will be discussed later. The heat storage was found by vertically integrating each monthly mean temperature profile. Simpson's onethird rule (Salvadori and Baron, 1961, p. 90) was used for the integration in 10 meter intervals from 0 to 250 meters depth. The expression used to give the resulting heat storage $(H)$ was 


$$
H=\rho C_{p} \int_{0}^{250 m} T d z
$$

where

$$
\begin{aligned}
\rho= & \text { density }\left(\mathrm{gm} \mathrm{cm}^{-3}\right) \\
C_{p}= & \text { specific heat at constant pressure } \\
& \left(\text { cal } \mathrm{gm}^{-1} \mathrm{o}^{-1}\right) \\
T= & \text { temperature in } 5 \text { meter intervals from the } \\
& \text { surface to } 250 \mathrm{~m} .
\end{aligned}
$$

The term $\rho C_{P}$ was considered constant at 0.977 cal $\mathrm{cm}^{-3} \mathrm{deg}^{-1}$. The density $(\rho)$ in the North Pacific varies from 1.018 to $1.032 \mathrm{gms} \mathrm{cm}^{-3}$ ( $\left.+0.70 \%\right)$ while the specific heat $\left(C_{p}\right.$ ) varies from 0.945 to $0.961 \mathrm{cal} \mathrm{cm}^{-1} \mathrm{deg}^{-1}$ $( \pm 0.84 \%)\left(\right.$ Cox and Smith, 1959). Therefore, $\rho C_{P}$ varies a maximum of $\pm 1.5 \%$ from a mean of $0.977 \mathrm{cal} \mathrm{gm}^{-1} \mathrm{deg}^{-1}$. This variation was considered negligible to simplify the computations.

The vertical integration from the surface to the mixed layer depth gave the monthly heat storage in the mixed layer. The integration from the surface to 250 meters gave the monthly total heat storage. The monthly heat storage in the thermocline layer was obtained by subtracting. All of the results were plotted in monthly maps. It must be emphasized that no spatial or temporal smoothing was applied to any of the resulting heat storage fields. 
4. Seasonal Heat Storage in the Mixed Layer, the Thermocline Layer, and the Total Heat Storage. Before discussing the total heat stored in the 250 meter surface layer, it is worthwhile to examine the results for the mixed and thermocline layers. Though these results were not directly used for the subsequent modeling work, some information useful for all subsequent work was obtained from them. Comparing how much heat is stored annualy in the mixed and thermocline layers, and how the heat storage in each layer varies seasonally gives some insight into the importance of horizontal advection of heat in each layer.

a. Heat storage in the mixed and thermocline layers. - Figures 18 and 19 show respectively the annual average and seasonal amplitude of the heat stored in the mixed layer. Figures 20 and 21 show the equivalent maps for the thermocline layer. Comparing the annual average maps for the mixed and thermocline layers shows the geographic distribution of heat stored in the two layers is similar in some respects. In both layers the greatest amount of heat is stored at low latitudes in the Western and Central Pacific. During the year the location of the maximum heat stored in the mixed layer is found either north of the Philippine Islands, between Guam and Wake Islands, west of Hawaii, or west of the Line Islands. This maximum ranges from 
$351 \mathrm{kcal} \mathrm{cm}^{-2}$ in September to $447 \mathrm{kcal} \mathrm{cm}^{-2}$ in January. In the thermocline layer, the location of the maximum heat storage is found either north or west of New Guinea, just north of the Philippine Islands or south of Guam IsIand. This maximum ranges from $403 \mathrm{kcal} \mathrm{cm}^{-2}$ in March to $564 \mathrm{kcal}$ $\mathrm{cm}^{-2}$ in May. A second basic similarity between the two layers is that the amount of heat stored in each layer decreases eastward and northward in both layers. The least amount of heat is stored at high latitudes, particularly in the Bering Sea. The minimum heat stored in either the mixed or the thermocline layer is found here, and ranges from Il $\mathrm{kcal} \mathrm{cm}^{-2}$ in March to $5 \mathrm{kcal} \mathrm{cm}^{-2}$ in April. A third similarity between the mixed and thermocline layers is that the contours of heat storage are oriented east-west in mid and high latitudes in both layers. However, in low latitudes, particularly in the Eastern Pacific, the orientation of portions of the heat storage contours in both layers is more north-south.

The amount of heat stored seasonally in the mixed and thermocline layers differs in some respects. On the average, the thermocline layer stores approximately $60 \%$ of the total heat contained in the 250 meter surface layer. A second difference between the heat storage fields of the two layers is the latitude where the maximum north-south heat storage gradients occur. In the mixed layer, this maximum gradient crosses the Pacific at approximately $20^{\circ}$ 
North latitude. In the thermocline layer this maximum gradient occurs closer to $40^{\circ}$ North latitude. The transfer of heat to higher latitudes by any north-south transport is a result of how these gradients in the heat storage fields correspond with the pattern of circulation in each layer. Since the North Pacific subtropical anticyclonic gyre is bounded between approximately $12^{\circ}$ and $40^{\circ}$ North latitude, the transfer of heat to higher latitudes in this gyre must be principally accomplished in the mixed layer.

Another clear difference between the heat storage fields of the mixed and thermocline layers is the heat storage gradients found in the Central and Eastern Equatorial Pacific. A strong annual mean north-south gradient of heat storage is very apparent in the mixed layer in this area (Figure 18) but not in the thermocline layer. This gradient is probably caused by the Equatorial Countercurrent. Knauss (1961) indicates that the Equatorial Countercurrent exists throughout the year, but is particularly strong during the Northern Hemisphere summer. During the months of May and June this north-south gradient begins to appear. During the months of July to January a strong north-south gradient remains well defined at approximately $7^{\circ}$ North latitude, just to the west and east of the Line Islands south of Hawaii. During February and March the strong north-south gradient in this area becomes less defined, and by April is rather poorly defined. The time 
of strong north-south heat storage gradients lags the time when the eastward transport in the Equatorial Countercurrent is greatest by approximately three months. As would be expected, no similar heat storage gradients caused by the Equatorial Countercurrent are apparent in the heat storage field of the thermocline layer (Figure 20). These results indicate that both mixing and northsouth transports in the mixed layer can be important contributors to the seasonal change in local heat storage in the Equatorial region. This is particularly true in the latitudinal zone containing the Equatorial Countercurrent ( $6^{\circ}$ to $10^{\circ}$ North latitude).

Any effect the Equatorial Undercurrent may have on the heat storage distribution in the thermocline layer is not apparent in Figure 18. The heat storage gradients in the path of the Equatorial Undercurrent are weak throughout the year all the way across the Pacific. Little heat must be transferred to the east by this transport. However, the influence of vertical motion in the mixed layer, associated with both the Equatorial Undercurrent and the Equatorial Countercurrent, is probably important (Montgomery, 1962). Cold vertical advection would affect both the mixed layer depth and the local heat storage. It was noted in the discussion of the mixed layer depth that vertical movements are probably responsible for the strong north-south gradient of mixed layer depth in the Central and Eastern 
Equatorial Pacific. Later we will find that vertical circulation may also be responsible for the high annual amplitude of total heat storage observed in the same areas. Figure 19 shows that the seasonal variation of heat stored in the mixed layer is greatest between $30^{\circ}$ and $40^{\circ}$ North latitude. In low and high latitudes the seasonal variation of heat stored in the mixed layer is generally less. In low latitudes the seasonal change in the mixed layer depth (Figure 17) and surface temperature is small. Therefore, the annual change in heat storage in the mixed layer is small. In high latitudes the seasonal change in mixed layer depth and the surface temperature is substantial, but since the heat stored in high latitudes is low, the seasonal variation is also low. In mid latitudes the annual change in the mixed layer depth and the surface temperature is moderate, but the amount of heat storage is greater in mid latitudes than in high latitudes. Therefore, the seasonal difference between the maxima and minima is greater.

Figures 19 and 21 show that the annual amplitude of heat stored in the mixed and thermocline layers is quite similar. This is because the seasonal change in the mixed layer depth is the cont:olling factor governing the allocation of heat between the mixed and thermocline layers. Figures 22 and 23 clearly show this fact. The figures show curves of the seasonal variation of the surface 
temperature, net surface heat exchange, mixed layer depth, heat stored in the mixed and thermocline layers, and total heat storage at eight locations selected from throughout the North Pacific (see Figure 1). At all eight locations the apparent annual change in heat stored in the mixed and thermocline layers is much greater than the annual change in total heat storage. Comparing the curves in each diagram of Figures 22 and 23 for the seasonal change in heat stored in the mixed layer with seasonal changes in the mixed layer depth clearly shows that the apparent change in heat storage is principally due to changes in the mixed layer depth. The phase of heat stored in the mixed and thermocline layers is also opposite for the same reason. This raises the question: How do the mixed and thermocline layers respond to an increase (or decrease) in the net surface heat exchange? A number of responses are possible. If the mixed layer depth remained unchanged, an increase in the net surface heat exchange could result in an increase of heat stored in the mixed layer, a transfer of heat to the thermocline layer, or an increase in the horizontal transfer of heat by advection and mixing. However, the mixed layer depth may also undergo a change. Thus the specific local response to an increase (or decrease) in the net surface heat exchange could be quite complex. It is difficult to say with certainty what combinations of the above responses are acting each month at 
each location throughout the North Pacific. This is chiefly because the vertical exchange processes seasonally existing between the mixed and thermocline layers are dependent on many factors. In modeling the seasonal changes of heat storage in the North Pacific Ocean it is best to consider the entire 250 meter layer rather than divide the 250 meters into the mixed and thermocline layer and attempt to model the layer simultaneously. Modeling the entire 250 meter surface layer eliminates the necessity of knowing the amount of heat transferred vertically between the mixed and thermocline layers.

b. Total heat stored in the 0 to 250 meter layer. -The results of vertically integrating each monthly temperature profile over 250 meters gave the total heat storage. Monthly maps of the total heat stored in the 0 to 250 meter layer, and maps of the annual average and the annual amplitude are shown respectively in Figures 24 through 37 . These results were used for all subsequent work.

Figures 24 through 35 show that the greatest amount of heat stored in the 0 to 250 meter surface layer of the North Pacific Ocean is in the Western Tropical Pacific. The monthly heat storage remains uniformly high in this area throughout the year. The maximum amount of heat stored each month in the North Pacific is consistently found around Guam Island. This maximum value varies little 
and is annually found between 601 and $620 \mathrm{kcal} \mathrm{cm}^{-2}$. Another maximum in total heat storage is found around New Guinea during January to June between 607 and $628 \mathrm{kcal}$ $\mathrm{cm}^{-2}$. The total heat storage decreases eastward and northward across the Pacific from the Western Tropical Pacific. Like the mixed and thermocline layers, the heat storage contours show a strong east-west orientation in mid latitudes. The minimum total heat storage is found in the Bering Sea. This minimum varies annually from 20 to 57 $\mathrm{kcal} \mathrm{cm}^{-2}$.

The heat storage gradients in the 0 to 250 meter surface layer, along with the horizontal velocity field in the layer, determine the areas where the advective transfer of heat is important. Strong north-south gradients of total heat storage exist in the Eastern Equatorial Pacific. They are probably the result of the Equatorial circulation. During September to March these north-south gradients are well developed. From April to May the gradients are not obvious, but by June to August they are again forming at $7^{\circ}$ North latitude around the Iine Islands. The second area in the Pacific where a strong north-south gradient of total heat storage occurs is at $35^{\circ}$ to $49^{\circ}$ North latitude, to the east and west of Japan. Note that this is identical to the gradient found in the thermocline layer. The north-south gradients previously found in the mixed layer at $20^{\circ}$ North latitude to not appear in the total heat storage maps. 
The influence of advection in the Central Pacific, due to the North Equatorial Current and the California Current, should be noted. The effect of the California Current is evident throughout the year in the southward deflection of the heat storage contours off the coasts of California and Baja California. Similarly, the effect of the westward transport of water south and southwest of Hawai due to the North Equatorial Current is quite evident in the monthly maps of total heat storage. Note the rather constant monthly penetration westward of the 500 $\mathrm{kcal} \mathrm{cm}^{-2}$ contour at approximately $10^{\circ}$ North latitude. This emphasizes the fact that the monthly total heat storage field in the Eastern Tropical Pacific is quite stable. In contrast, the eastward penetration of the $500 \mathrm{kcal} \mathrm{cm}^{-2}$ contour at $20^{\circ}$ North latitude changes position annually from the east to the west of Hawail.

Figures 24 through 35 show that independent areas exist in the monthly heat storage fields where the local total heat storage is slightly higher or lower than the surrounding field. Some of these local deviations develop, move and dissipate during the year. As an example, note the heat storage deviation found just southwest of the southern tip of Baja California. The months of August to December clearly show the appearance, growth and dissipation of this local variation in heat storage. Other such local variations in heat storage appear in the Kuroshio 
east of Japan (December to April), and in the Equatorial Countercurrent (May, July, August, November). Two more permanent local maxima or minima of heat storage are also evident in Figures 24 to 35 . The first, a maximum surrounding Guam Island, remains approximately the same size throughout the year. The second, the large minimum southeast of Hawai, changes size and location during the year. The annual average total heat storage map (Figure 24) clearly shows these local maxima and minima. The information concerning the location and size of local variations in heat storage was useful in helping to establish the best locations and size for hypothetical heat storage anomalies later tested with the numerical solution.

One of the most important and useful maps obtained from the monthly total heat storage results is the map of the annual amplitude of total heat storage (Figure 37). In addition to showing the locations of areas having a large annual change in total heat storage, Figure 37 provided one criterion for judging the success of the theoretical model. This map of the observed annual amplitude was compared with a similar map of the theoretical annual amplitude. Work on the theoretical solution was continued until the best possible agreement was obtained between the observed annual amplitude and the theoretical annual amplitude.

Figure 37 shows the locations of four areas in the North Pacific where the annual amplitude of total heat 
storage is greater than $50 \mathrm{kcal} \mathrm{cm}^{-2}$. The largest area extends from Korea into the Kuroshio east of Japan. Here

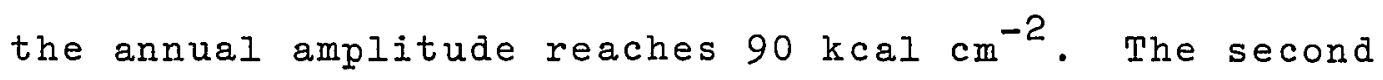
area is in the Gulf of Alaska close to the coast of Alaska where the annual amplitude is as high as $58 \mathrm{kcal} \mathrm{cm}^{-2}$. The third area lies in the Central and East Central Pacific at approximately $32^{\circ}$ North latitude. Two small locations where the annual amplitude is as high as $72 \mathrm{kcal} \mathrm{cm}^{-2}$ are found at this latitude. Last, two large areas of high annual amplitude in total heat storage are found south of Hawai .

Figure 38 shows the results of an east-west summation by $2^{\circ}$ strips of latitude of the total heat storage for the months of March, June, September and December. Included in the figure are curves for the annul mean heat storage in the mixed and thermocline layers as a function of latitude.

Figure 38 shows that the total heat storage decreases with increasing latitude. At the Equator the annual change in total heat storage is on the average $3 \%$ of the total heat stored, and at $60^{\circ}$ North latitude the annual change increases to $45 \%$ of the total heat stored. Integrating the annual average total heat storage over the area between the Equator and $60^{\circ}$ North latitude (an area of approximately $82.2 \times 10^{16} \mathrm{~cm}^{2}$ ) gives a total of $3.6 \times 10^{23} \mathrm{cal}$. The average annual change is approximately $12 \%$, or $4.3 \times 10^{22}$ 
cal.

The influence of the Equatorial circulation on the heat storage between $4^{\circ}$ and $12^{\circ}$ North latitude is apparent in the curves for the total heat storage and the annual average heat stored in the mixed layer in Figure 38 . Note that the latitudinal summation of heat stored in the mixed layer continually decreases with increasing latitude from approximately $9 \times 10^{21}$ cal at the Equator to $1 \times 10^{21}$ cal at $60^{\circ}$ North latitude. The rate of decrease is essentially constant at $1.3 \times 10^{20}$ cal per degree of latitude. In contrast, the curve for the summation of heat stored in the thermocline layer shows an almost constant amount of $11^{6} \times 10^{21} \mathrm{cal} / 2^{\circ}$ of latitude of heat stored in the thermocline layer from the Equator to $25^{\circ}$ North latitude.

Farther north the amount of heat stored in the thermocline layer decreases rapidly with increasing latitude. This implies that on the average, most of the transfer of heat to higher Iatitudes from the Equator to $25^{\circ}$ North latitude takes place in the mixed layer. North of $25^{\circ}$ North latitude the average gradient of heat storage with increasing latitude in the thermocline layer is greater than in the mixed layer. But the transport northward in the thermocline is probably less. Therefore, on the average, heat is probably transferred northward at a similar rate in each layer. 


\section{Finding the Change in Total Heat Storage due to Advection. All the terms in}

Equation (2) except the net surface heat exchange $Q$ can be obtained using the known monthly values of total heat storage, if the horizontal velocity and the mixing coefficients are specified. However, if the monthly change of total heat storage iwth respect to time, the monthly change of heat storage due to mixing, and the monthly net surface heat exchange are known, a simple addition of these terms in Equation (2) will give the change of heat storage due to horizontal advection. These results allow a comparison to be made of the importance of each process affecting the local monthly change in total heat storage.

The monthly contribution of horizontal mixing, advection, and the net surface heat exchange to the change in total heat stored in each grid rectangle were computed. A description of the method used to compute each term of Equation (2) follows, along with a brief discussion of each result.

The primary purpose of this step was to obtain monthly maps of the contribution to the local change in total heat storage due to advection. It was hoped that such maps would show the geographic distribution of advection for each month in the North Pacific ocean. Similar results have not been presented to the present date, and these results will add insight into the seasonal importance of 
advection. Monthly maps for the contribution to the local change in total heat storage due to advection are therefore presented and are discussed in detail. A map of the results for each term of Equation (2) is also presented, compared, and discussed using March as an example month.

a. Change in total heat storage with respect to time. The change in total heat storage with respect to time in each grid rectangle was obtained using the following expression (January example):

$$
\left[\frac{\partial H}{\partial t}\right]_{\text {JAN }}=\frac{H_{F E B}-H_{D E C}}{2 D_{\text {JAN }}} C_{A L C M^{-2} D A Y}{ }^{-1}
$$

where:

$$
\begin{aligned}
& H=\text { the total heat storage in each grid rectangle. } \\
& D=\text { the number of days in the month. }
\end{aligned}
$$

The rate of change of total heat storage each month varies with location in the North Pacific. In general, the rate of change decreases with latitude. Six areas exist where the daily change in total heat storage is

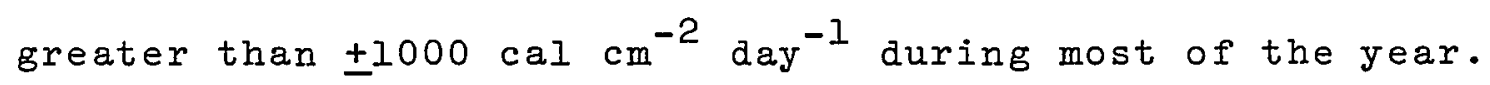
In these areas the daily change in total heat storage ranges annually from \pm 1002 to $\pm 2628 \mathrm{cal}^{\mathrm{cm}^{-2}} \mathrm{day}^{-1}$. The areas are just north of Taiwan, southeast and east of Japan, around the Aleutian Islands, in the Gulf of Alaska close to the coastline, south of the Hawaiian Islands, and off the coast of Central America. Only in the areas east 
and southeast of Japan, and south of the Hawailan IsIands does the local daily change in total heat storage remain consistently high throughout the year. In the large area extending from the Western Tropical Pacific, northeast across the Central Pacific, and up to the center of the Gulf of Alaska, the daily change in total heat storage ranges between $\pm 500 \mathrm{cal} \mathrm{cm}^{-2} \mathrm{day}^{-1}$. Scattered through this large area diagonally crosing the Pacific are numerous small randomly-located areas where the daily change in total heat storage may be as high as $\pm 1200 \mathrm{cal} \mathrm{cm}^{-2} \mathrm{day}^{-1}$ for a single month. The only area in the North Pacific where the daily change remains consistently low, between $\pm 300 \mathrm{cal} \mathrm{cm}^{-2} \mathrm{day}^{-1}$, is in the Bering sea.

b. Change in total heat storage due to mixing.-Horizontal mixing coefficients were selected and the Laplacian of the total heat storage was found for each grid rectangle. The contribution to the monthly change in total heat storage due to mixing was then computed using the following equation:

$$
M I X I N G=A\left[\frac{\partial^{2} H}{\partial x^{2}}+\frac{\partial^{2} H}{\partial y^{2}}\right] S \quad C A L C M^{-2} D A Y^{-1}
$$

where:

$$
\begin{aligned}
H= & \text { the total heat storage in the } 0 \text { to } 250 \text { meter } \\
& \text { Iayer (cal } \left.\mathrm{cm}^{-2}\right) \\
A= & \text { the mixing coefficient }\left(\mathrm{cm}^{2} \mathrm{sec}^{-1}\right)
\end{aligned}
$$




$$
S=\sec \mathrm{day}^{-1}
$$

The computation for the Laplacian in those grid rectangles crossed by a land boundary were corrected for the boundary (Salvadori and Baron, 1961, p. 231). The correction involved assigning a value for $H$ on the boundary (taken as the same $H$ as in the grid rectangle in question) and computing the Laplacian using the corrected distance, $X$ or $Y$, from the center of the grid rectangle to the boundary. This method of correction is discussed in detail in Section III.B.3.

Initially, a constant mixing coefficient of $5 \times 10^{6}$ $\mathrm{cm}^{2} \mathrm{sec}^{-1}$ was used for the entire North Pacific. If a constant mixing coefficient of $1.3 \times 10^{5} \mathrm{~cm}^{2} \mathrm{sec}^{-1}$ were used, the mixing contribution to the local change in total heat storage becomes essentially negligible (less than $1 \%$ ) throughout the North Pacific. Using a mixing coefficient of $1.1 \times 10^{9} \mathrm{~cm}^{2} \mathrm{sec}^{-1}$ and finding the contribution due to advection using Equation (2) gives negligible advection throughout the North Pacific. An initial value for the mixing coefficient of $5 \times 10^{6} \mathrm{~cm}^{2} \mathrm{sec}^{-1}$ was selected between these limits. This value allowed mixing to be an important contribution only in areas of the Pacific that are adjacent to strong horizontal gradients of total heat storage. However, in the subsequent development of the theoretical model, different mixing coefficients for different areas of the Pacific were found to considerably 
improve the monthly agreement between the results of the theoretical model and the observations. Many combinations of mixing coefficients varying between $1 \times 10^{5} \mathrm{~cm}^{2} \mathrm{sec}^{-1}$ and $1 \times 10^{7} \mathrm{~cm}^{2} \mathrm{sec}^{-1}$ were tried during the theoretical modeling. The best agreement between the theoretical model and observations was obtained using a mixing coefficient that increased linearly from $1 \times 10^{6} \mathrm{~cm}^{2} \mathrm{sec}^{-1}$ at $8^{\circ}$ North latitude to $11 \times 10^{6} \mathrm{~cm}^{2} \mathrm{sec}^{-1}$ at $70^{\circ}$ North latitude. The mixing coefficient has the following approximate values in each of the following areas:

1. Kamchatka and Alaskan cyclonic gyres (north of $45^{\circ}$ North latitude) $-A=6 \times 10^{6}$ to $11 \times 10^{6} \mathrm{~cm}^{2} \mathrm{sec}^{-1}$.

2. Kuroshio and Oyashio area $\left(30^{\circ}\right.$ to $45^{\circ}$ North latitude) $-A=4 \times 10^{6}$ to $6 \times 10^{6} \mathrm{~cm}^{2} \mathrm{sec}^{-1}$.

3. Central Pacific anticyclonic gyre (between $30^{\circ}$ and $10^{\circ}$ North latitude) and the South Pacific anticyclonic gyre (south of $6^{\circ}$ North latitude)- $A=1 \times 10^{6}$ to $4 \times 10^{6} \mathrm{~cm}^{2} \mathrm{sec}^{-1}$.

4. Equatorial Countercurrent (between $10^{\circ}$ and $6^{\circ}$ North latitude) $-A=1 \times 10^{6} \mathrm{~cm}^{2} \mathrm{sec}^{-1}$.

It is not unreasonable to expect a mixing coefficient to be greater at higher latitudes than at low latitudes. Numerous estimates of mixing coefficients have been made. These estimates for the mixing coefficient of a property vary from $1 \times 10^{4} \mathrm{~cm}^{2} \mathrm{sec}^{-1}$ to $4 \times 10^{8} \mathrm{~cm}^{2} \mathrm{sec}^{-1}$. Comparing, for example, the result of Montgomery (1939) for the 
Atlantic Equatorial Countercurrent with the results of Neumann (1940) for the surface layer of the Northwestern Atlantic ocean shows the mixing coefficients to be ten times greater for the North Atlantic. An estimate for the California Current, by Sverdrup and Fleming (1941), was $2 \times 10^{6} \mathrm{~cm}^{2} \mathrm{sec}^{-1}$.

It was necessary to specify a mixing coefficient prior to computing the mixing terms with Equation (5) and solving for the monthly contribution due to advection with Equation (2). The linearly varying mixing coefficient selected during the development of the theoretical model was used for this computation. This mixing coefficient was dependent to some extent upon the stream function used in the model since both the mixing coefficient and the stream function were varied until the best agreement between the model and the observations was obtained. However, using the same mixing coefficient from the theoretical model to compute the monthly contribution due to advection with Equation (2) does not give exactly the same contribution due to advection as does the theoretical model. Using the final stream function and the monthly total heat storage predicted by the theoretical model (and the same mixing coefficient) will give only the monthly horizontal advection. As stated earlier, vertical advection and mixing are assumed to be in balance; however, any imbalance will be included in the results from Equation (2) 
for the monthly contribution due to advection since the observed monthly heat storage fields are used in the computation. Moreover, the results from Equation (2) for the monthly advection do not give any information about the monthly velocity field that is responsible for this advection.

The mean daily change in total heat storage for each month due to mixing was computed using the linearly increasing mixing coefficient. Figure 39 shows a map of the annual mean change in total heat storage due to mixing. The figure shows that the area in the North Pacific extending from Japan eastward to the Central Pacific is an area where mixing is of primary importance. Mixing here con-

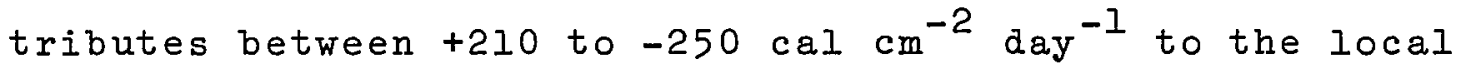
change in total heat storage. The location of the greatest contribution due to mixing varies little from a position 2000 to $3000 \mathrm{~km}$ east of Japan at $39^{\circ}$ North latitude (source) and $41^{\circ}$ North latitude (sink). Mixing is of primary importance in this area where the Kuroshio and Oyashio currents meet.

Two other areas where the contribution to the time change in total heat storage due to mixing is of some importance should be mentioned. The first area extends from Vancouver Island westward approximately 500 to $1000 \mathrm{~km}$ into the Gulf of Alaska. The seasonal contribution in this area is greatest (between +110 to $-100 \mathrm{cal} \mathrm{cm}^{2} \mathrm{day}^{-1}$ ) 
during December to May. The second area of importance is south of Kiska Island in the western end of the Aleutian Islands. Here mixing contributes between +70 to -140 cal $\mathrm{cm}^{-2} \mathrm{day}^{-1}$ to the local change in total heat storage. Scattered throughout the Bering Sea, in the California Current, and in the Equatorial Countercurrent are small

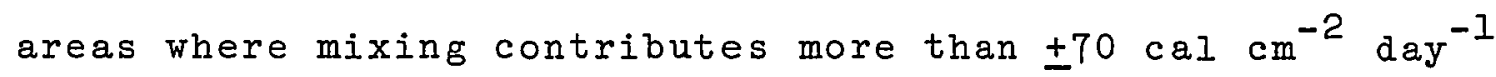
to the daily change in total heat storage for just one or two months. These small transient contributions range from tll0 to $-70 \mathrm{cal} \mathrm{cm}^{-2} \mathrm{day}^{-1}$. In general, mixing in the remaining area of the North Pacific contributes less than $\pm 50 \mathrm{cal} \mathrm{cm}^{-2} \mathrm{day}^{-1}$ to the monthly change in total heat storage.

Comparing the contribution to the local change in total heat storage due to mixing with the monthly change in total heat storage in the Kuroshio-0yashio areas shows that mixing accounts for 6 to $21 \%$ of the total change during each month. Similarly, in the areas off Vancouver Island and south of Kiska Island in the Aleutians, mixing contributes between 15 to $38 \%$ to the monthly change in total heat storage. In the remainder of the North Pacific mixing contributes less than 10\% of the daily change in total heat storage.

c. Change in total heat storage due to the net surface heat exchange. - Figures 40 and 41 show, respectively, maps of the annual average 
net surface heat exchange and the annual amplitude of the net surface heat exchange. They were obtained using the data of Wyrtki (1966). The annual average map (Figure 40) clearly shows a large area of heat loss surrounding Japan and continuing east into the extension of the Kuroshio. The net surface heat exchange in this area ranges from $+296 \mathrm{cal} \mathrm{cm}^{-2} \mathrm{day}^{-1}$ in July to $-946 \mathrm{cal} \mathrm{cm}^{-2} \mathrm{day}^{-1}$ in January. The heat transfer processes in this area around Japan and eastward to approximately $180^{\circ}$ longitude make this area fundamentally important to the heat exchange in the North Pacific. Figure 41 shows that the annual amplitude of the variation in net surface heat exchange in the area around and east of Japan is quite large. Evaporation is the most significant contributor to the large amount of heat exchanged at the surface in this area during the year (Wyrtki, 1966). The rate of evaporation is high in this area because of the winds and large difference between the vapor pressure of the water and the air. Later we will see that advection is responsible for bringing warm water into the area from the Western Tropical Pacific.

The annual average map of the net surface heat exchange (Figure 40) shows that, aside from the area around Japan, heat is also lost from the area off the coast of Alaska and east of the Hawaiian Islands. Heat transfer due to horizontal mixing is not of major importance in these areas, therefore advection must be. Heat 
is gained annually at the surface over the majority of the remaining area in the North Pacific. The largest gains are in the Western Tropical Pacific, the Eastern Tropical Pacific, and on the Equator. In these areas the net surf-

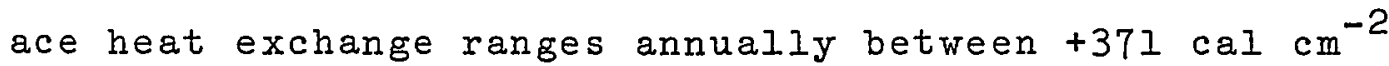
$\mathrm{day}^{-1}$ and $-262 \mathrm{cal} \mathrm{cm}^{-2} \mathrm{day}^{-1}$. The areas around Guam

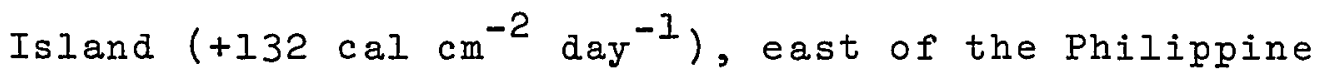
Islands $\left(+171\right.$ cal $\left.\mathrm{cm}^{-2} \mathrm{day}^{-1}\right)$, along the Equator east of the Iine Islands ( $\left.+205 \mathrm{cal} \mathrm{cm}^{-2} \mathrm{day}^{-1}\right)$, and off the coasts

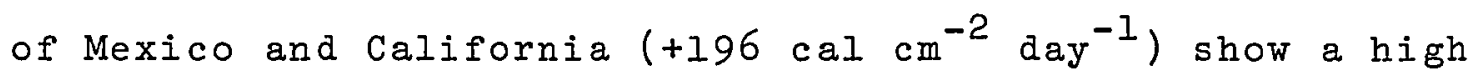
annual net gain of heat at the surface. Earlier we noted that the monthly change in total heat storage in this area was consistently high throughout the year. Most of the Central and Eastern Equatorial Pacific and the area along the coasts of Central America, Mexico and California annually gains heat at the surface, therefore heat must be transferred annually from this southeastern corner to the northwestern corner of the North Pacific. Integrating the annual average net surface heat exchange over the Pacific from the Equator to $60^{\circ}$ North latitude shows this area annually receives a surplus of $2.9 \times 10^{14} \mathrm{cal} \mathrm{sec}^{-1}$. This annual surplus is probably compensated by the ascending of cold water and by an outflow of warm surface water in the Western Equatorial Pacific (Wyrtki, 1965b).

Figure 42 shows the results of an east-west summation of the monthly and annual average net surface heat exchange 
by $2^{\circ}$ of latitude. It is obvious from the annual average curve in this figure, and from the previous discussion, that the ocean annually gains heat at the surface south of $32^{\circ}$ North latitude, and loses heat between $32^{\circ}$ and $43^{\circ}$ North latitude. This requires a considerable transfer of heat annually from low to high latitudes. As shown earlier, mixing accomplishes just a small portion of the local heat transfer; that is, approximately 6 to $38 \%$ of the daily changes in total heat storage. Therefore, the transfer of heat to higher latitudes by advection must be a major contributor to the local seasonal change in total heat storage.

d. Change in total heat storage due to advection. - Using the computed change in total heat storage in each grid rectangle for each month, the estimated contribution due to mixing, and the net surface heat exchange, Equation (2) was solved for the contribution due to advection using the following equation: $\begin{array}{rlcc}H_{\text {change }} & =H_{\text {local }}-Q_{\text {surface }}-H_{\text {change }} \text { cal } \mathrm{cm}^{-2} \mathrm{day}^{-1} \\ \text { due to } & \text { change } & \text { heat } & \text { due to } \\ \text { advec- } & \text { in } & \text { exchange } & \text { mixing } \\ \text { tion } & \begin{array}{l}\text { total } \\ \text { heat } \\ \text { storage }\end{array} & \end{array}$

No information is required about the local velocity field for this algebraic solution. The resulting change due to advection is actually a summation of the horizontal and vertical advection and vertical mixing. But, as discussed 
earlier, it has been assumed that the vertical advection and vertical mixing balance. On this basis, the advection computed here represents the horizontal advection. Figure 43 shows the annual average of this advective heat transport. The results for each month are shown in Figures 44 through 55. Positive values mean heat is being added to the area during the month, and negative values mean heat is being lost due to advection.

The annual average change in heat storage due to advection (Figure 43) should be closely compared to the annual average net surface heat exchange (Figure 40). It has been previously shown that mixing is important throughout the year primarily in the area east of Japan. Mixing was noted to be important for a few months of the year west of Vancouver Island and around the Aleutian Islands. Elsewhere in the North Pacific, mixing contributes a rather small portion to the local changes in total heat storage. The local change in total heat storage is the result of the amount of heat contributed due to mixing, advection, and net surface heat exchange. However, the net change in total heat storage is zero over the annual cycle. Therefore, in areas where the contribution due to mixing is slight, the advection and net surface heat exchange must be approximately equal over the annual cycle. Conversely, in areas where mixing is important, Figures 43 and 40 should differ if the mixing coefficients are 
reasonably correct. This is exactly the case. The two figures agree (with the obvious sign change) quite closely throughout most of the Pacific. The primary differences Iie in the Kuroshio, Alaskan and Bering Sea areas. The solution of Equation (6) was completed using a mixing coefficient linearly increasing at the rate of $1.6 \times 10^{5}$ $\mathrm{cm}^{2} \mathrm{sec}^{-1} / 0$ latitude from $1 \times 10^{6} \mathrm{~cm}^{2} \mathrm{sec}^{-1}$ at $8^{\circ}$ North latitude.

At first glance the monthly maps appear complex. This is because the total heat storage data were not smoothed either spatially or temporally. The irregular shape of the contours is primarily due to the results of the computation for the monthly local change in total heat storage. However, a careful review of Figures 44 through 55 shows that some simple patterns and consistencies do exist throughout the year. Note the following points:

1. The heat storage contours for all months generally favor an east-west orientation, particularly in the Central Pacific. This corresponds with the strong zonal flow in the Central Pacific. The contours divide the North Pacific into latitudinal zones where heat is being gained or lost due to advection. In some months, as January and June, these zones extend east-west across the Pacific. In other months, as March and October, the east-west zones may be broken into a number of smaller areas. 
2. Within each large zone, small local maxima or minima

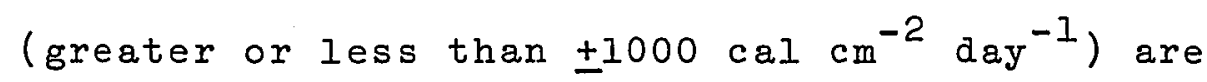
generally found. The locations of these small areas of high advective gain or loss remain reasonably fixed throughout the year. These local maxima or minima are generally found just north of Taiwan (maxima), east of Japan in the Kuroshio (maxima), in the Gulf of Alaska close to the coastline (maxima), around the Hawaiian Islands (minima), on the Equator in the area from the Gilbert Islands to the Galapagos Islands (minima), and just east of the Philippine Islands (minima). These areas of high heat gain or loss result from a strong transport crossing a strong local heat storage gradient. The heat storage gradients are maintained by the flux of heat at the surface (see Figure 40). Note that each area given above, except the one around the Hawaiian Islands, is located where strong transports are known to exist.

3. The advection maps show that some areas undergo a simple seasonal change in advection. For example, the Western Pacific from Taiwan to Japan gains a considerable amount of heat (more than $500 \mathrm{cal} \mathrm{cm}^{-2} \mathrm{day}^{-1}$ ) from warm advection during February to August and loses heat from September to January (Iess than -300 cal $\mathrm{cm}^{-2} \mathrm{day}^{-1}$ ). Thus this area accumulates heat during the spring and summer and releases the heat in 
the fall. Another example is in the Gulf of Alaska, close to the coastline. Heat is gained here from warm advection during February to June, and October to November, and is lost during the remaining months.

4. The Western Tropical Pacific alternately gains and loses heat throughout the year. In general, more heat is lost than gained during the year from this portion of the North Pacific. During September, for example, the entire Western Tropical Pacific is losing heat due to advection. Figure 43 shows that the area east of the Philippine Islands loses the most heat annually (-139 cal $\mathrm{cm}^{-2} \mathrm{day}^{-1}$ ) in the Western Tropical Pacific. The Eastern Tropical Pacific also alternately gains and loses heat during the year due to advection. The months of January to April show the greatest heat gain from advection. During February the advective heat gain reaches a maximum of $+727 \mathrm{cal} \mathrm{cm}^{-2} \mathrm{day}^{-1}$. Figure 43 shows that the area between the Hawaiian Islands and Mexico gains heat annually $\left(61 \mathrm{cal} \mathrm{cm}^{-2}\right.$ day $^{-1}$ ) but the area off the coast of Central America

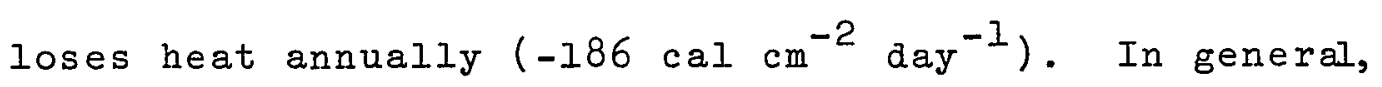
heat is lost from advection over most of the Tropical Pacific and is gained east and northeast of Japan up to the Bering Sea.

5. Upwelling causes an apparent loss of heat from an area. Tully (1964) has noted that upwelling occurs 
in the Gulf of Alaska during the summer. Thus the large loss of heat from the Gulf of Alaska during

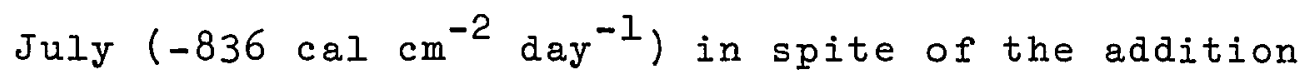
of heat at the surface is probably the result of upwelling. The upwelling area off the coast of California is losing the greatest amount of heat ( -531 cal $\mathrm{cm}^{-2} \mathrm{day}^{-1}$ ) during March, a known month of intense upwelling (Sverdrup and Fleming, 1941). Only during July and December does the California area gain heat due to warm advection. The upwelling area on the Equator shows an apparent advective loss of heat occurring from July to November. The greatest advective heat loss of $-818 \mathrm{cal} \mathrm{cm}^{-2} \mathrm{day}^{-1}$ occurs in November. A large heat loss also occurs in October

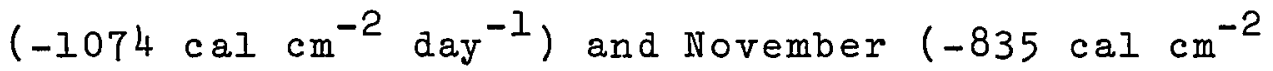
day ${ }^{-1}$ ) at $9^{\circ}$ North latitude just off the coast of Central America. Vertical circulation may be contributing to the heat loss in this area during these winter months (Wyrtki, 1964). Later, at the completion of the theoretical model, we will find that discrepancies will exist between the heat storage predicted by theory and the observed heat storage in each of the above locations. This will be primarily due to neglecting upwelling in these areas.

6. An area having a high net gain of heat at the surface during any one month may or may not have a 
simultaneous maximum loss of heat due to advection. Consider, for example, how the several local advective maxima found around the Hawaiian Islands correspond seasonally with the net surface heat excharge in the same areas. During the months of May to september, the area just southwest of the Hawaiian Islands is gaining heat at the surface. During these same months the area is losing heat due to cold advection from the northeast, but the overall result is that the local change in total heat storage is increasing slightly. Therefore, during these months just a portion of the heat gained at the surface is removed from the area. The balance left in the area is responsible for a net increase in the local heat storage. In contrast to this area southwest of Hawai, consider the area of high advective heat gain found just northwest of the Hawaian Islands during August and September. The area is also gaining heat at the surface during these months. The result is a substantial increase in the local heat storage from August to september. Thus the local advection is not always in phase with the net surface heat exchange. The result is areas that will accumulate heat seasonally and release heat in subsequent months. In the discussion of heat storage anomalies examples of this will be given and discussed. The point here is that 
the theoretical modeling of the advective transport of heat will be modeling primarily the general transport of heat from low to high latitudes. Successfully modeling the small areas of local phase agreement in addition is impossible unless the stream function is time-dependent and includes much local detail. As previously stated, we limited this work to the 0 to 250 meter layer and to a two-dimensional problem. Therefore, some local discrepancies between the observations and theoretical results are to be expected.

In summation, the areas where heat is gained or lost due to advection vary in the Pacific during the year. Areas may accumulate heat for a number of months (as north of Taiwan) and release this heat in subsequent months. Horizontal advection can be in or out of phase with the local net surface heat exchange. If in phase, the local heat storage is amplified (as northeast of the Hawaiian Islands during the late summer). If out of phase, the annual amplitude of the local heat storage is decreased (as west of Vancouver Island). In general, however, the heat removed from low latitudes is transported primarily to the Northwestern Pacific. The largest advective heat losses occur over large areas off the coast of Central America and in the Western Tropical Pacific. In contrast, the areas of the greatest advective heat gain are east of 
Japan, in the Bering Sea, in the Gulf of Alaska, and east of Hawaii. Following is a list of nine locations selected from throughout the North Pacific Ocean (see Figure I). The annual average contributions of the surface heat exchange, mixing, and advection at each location are given. The list shows the importance of each process at each location.

\begin{tabular}{|c|c|c|c|c|}
\hline Location & Key & $\begin{array}{l}\text { Surface } \\
\text { Heat } \\
\text { Exchange }\end{array}$ & Mixing & Advection \\
\hline $\begin{array}{c}\text { Eastern Tropical } \\
\text { Pacific }\end{array}$ & $10-1$ & +138 & -8 & -130 \\
\hline $\begin{array}{c}\text { Central Equatorial } \\
\text { Pacific }\end{array}$ & $16-5$ & +189 & +6 & -195 \\
\hline $\begin{array}{c}\text { Western Tropical } \\
\text { Pacific }\end{array}$ & $60-2$ & +82 & +1 & -83 \\
\hline Hawaiian Islands & $88-4$ & +28 & -7 & -21 \\
\hline California Coast & $121-3$ & +137 & +2 & -139 \\
\hline Central Pacific & $127-5$ & +49 & +11 & -60 \\
\hline North Kuroshio & $129-1$ & -212 & -145 & +357 \\
\hline South Kuroshio & $130-5$ & -56 & +4 & +52 \\
\hline Gulf of Alaska & $196-3$ & +19 & -32 & +13 \\
\hline
\end{tabular}

Examples of how surface heating, advection and mixing establish the local change in total heat storage can be seen by reviewing the results for March. March was selected because the net surface heat exchange and the mixing in March are quite similar to annual averages (see 
Figures 40 and 39 respectively). The change in total heat storage for March, and the contribution to this change due to the net surface heat exchange, and horizontal mixing advection are shown in Figures $56,57,58$, and 46 respectively.

Figure 46 shows the areas gaining or losing heat in the North Pacific during March. An area extending across the Pacific from the south of Japan almost to Central America is gaining heat during March from warm advection. This same area is also gaining heat at the surface (Figure 58). As a result, the total heat stored in this subtropical belt is increasing during March (Figure 56). Similarly, the total heat storage is increasing north of the Hawaian Islands and north of New Guinea during March. Over the remaining area in the North Pacific, particularly at high latitudes, the total heat storage is decreasing. During the previous month the entire area north of $20^{\circ}$ North latitude was losing heat from the surface. In the next month almost all of the North Pacific will be gaining heat at the surface north of $15^{\circ}$ latitude. This rapid change during the three-month period is reflected in the advection plots for February, March and April (Figures 45, 46, and 47). During this period warm advection to high latitudes is decreasing.

Figure 58 shows that, during March, up to 419 cal $\mathrm{cm}^{-2} \mathrm{day}^{-1}$ are being lost from the surface in the Kuroshio 
from south of Japan to approximately $5000 \mathrm{~km}$ east of Japan. To partially compensate for this loss, warm advection (Figure 46) is adding heat to the area south and southwest of Japan. This warm advection from the Western Tropical Pacific provides a considerable amount of heat (up to $1538 \mathrm{cal} \mathrm{cm}^{-2} \mathrm{day}^{-1}$ ) to the area southwest of Japan. The result is that the total heat storage in the area between Taiwan and Japan and south of Japan is increasing (see Figure 56) despite a net loss of heat from the surface. However, the combined loss of heat from the area northeast of Japan due to mixing and the surface heat exchange results in a decrease in total heat storage northeast of Japan during March.

Advection in March is important in the Central and Eastern Equatorial Pacific. During March, the entire Central and Eastern Equatorial Pacific, from Panama to Central America to the Gilbert Islands is gaining up to $356 \mathrm{cal} \mathrm{cm}^{-2} \mathrm{day}^{-1}$ at the surface (see Figure 58). The change in total heat storage due to mixing in this area is slight during March. It varies from +28 to $-41 \mathrm{cal} \mathrm{cm}^{-2}$ $\mathrm{day}^{-1}$. Except for the area just west of Central America, most of the Equatorial Pacific is losing heat in March (Figure 56). Figure 46 shows that during March a large amount of heat is being removed from the Equatorial Pacific by advection. Large advective heat losses are found at $5^{\circ}$ North latitude east and west of the Iine 
Islands. Earlier we noted that the Equatorial Countercurrent is weakest during the summer. Therefore, warm advection from the western Tropical Pacific is probably slight during March. The advective heat loss is probably due to cold water arriving from the Eastern South Pacific. The effect of vertical circulation in March can be seen by looking at upwelling areas. March is a month of intense upwelling off the coast of California (sverdrup and Fleming, 1941). In March, this area is gaining over $100 \mathrm{cal} \mathrm{cm}^{-2} \mathrm{day}^{-1}$ at the surface (Figure 58). Yet the area shows a loss in total heat storage in March (approximately $400 \mathrm{cal} \mathrm{cm}^{-2} \mathrm{day}^{-1}$ ). Thus cold advection, a large part of which is probably upwelling, is removing up to 531 cal $\mathrm{cm}^{-2} \mathrm{day}^{-1}$ from the area. In the Gulf of Alaska, the reverse is true. Upwelling occurs generally in July and August (Tully, 1964; Smith, 1968). In March the area is losing heat at the surface, yet the total heat storage off the Coast of Alaska is increasing. Figure 46 shows that

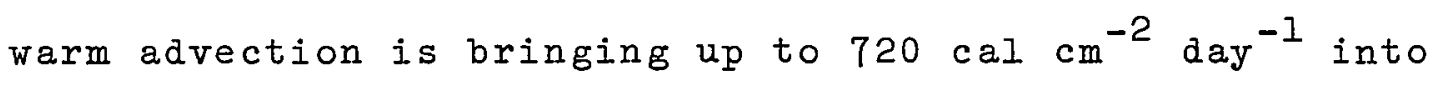
the area. In both of these cases advection is out of phase with the local net surface heat exchange and tends to retard the local change in total heat storage during the month.

e. Comparing the local total heat storage to the net surface heat exchange. -The geographic importance of advection and mixing combined can 
be found by comparing the annual amplitude of the total heat storage with the annual amplitude of the net surface heat exchange. This can be shown in a simplified manner: If the total heat storage $(H)$, the advection and mixing combined (A) and the net surface heat exchange $(Q)$ are represented by the simple sinusoids:

$$
\begin{aligned}
& H=\bar{H}+H_{0} \cos (\omega t) \\
& A=A_{0} \sin (\omega t+\theta) \\
& Q=Q_{0} \cos (\omega t+\phi)
\end{aligned}
$$

where:

$$
\begin{aligned}
\bar{H} & =\text { the annual average total heat storage } \\
H_{0}, A_{0}, Q_{0} & =\text { the annual amplitude of each term } \\
t & =\text { time (days) } \\
\omega & =\text { frequency }\left(\frac{2 \pi}{365} \text { radians day }{ }^{-1}\right) \\
\Theta, \phi & =\text { phase }
\end{aligned}
$$

Then Equation (2) can be written as:

$$
H^{\prime}=\omega H_{0} \sin (\omega t)=A_{0} \sin (\omega t+\theta)-Q_{0} \cos (\omega t+\phi)
$$

The ratio of the annual amplitude of the change in total heat storage divided by the annual amplitude of the net surface heat exchange is $\omega H_{0} / Q_{0}$. If $A_{0}$ and $Q_{0}$ were equal to $I$ and the advection and mixing (A) were $\pi / 2$ out of phase with the net surface heat exchange $(Q)$, then the change in total heat storage ( $\omega H_{0}$ ) would be zero. 


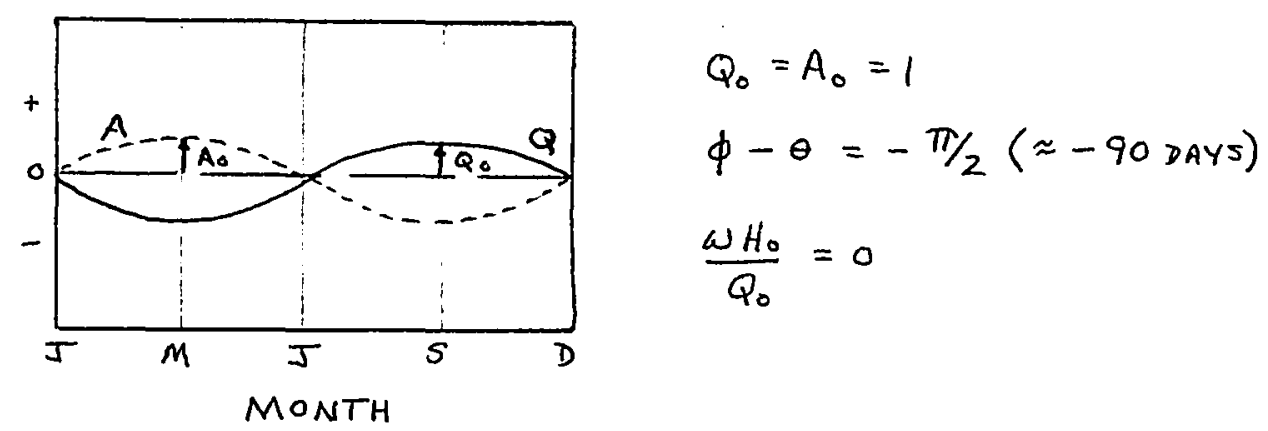

If the advection and mixing were in phase with the net surface heat exchange, then $\omega H_{0}=2$ :

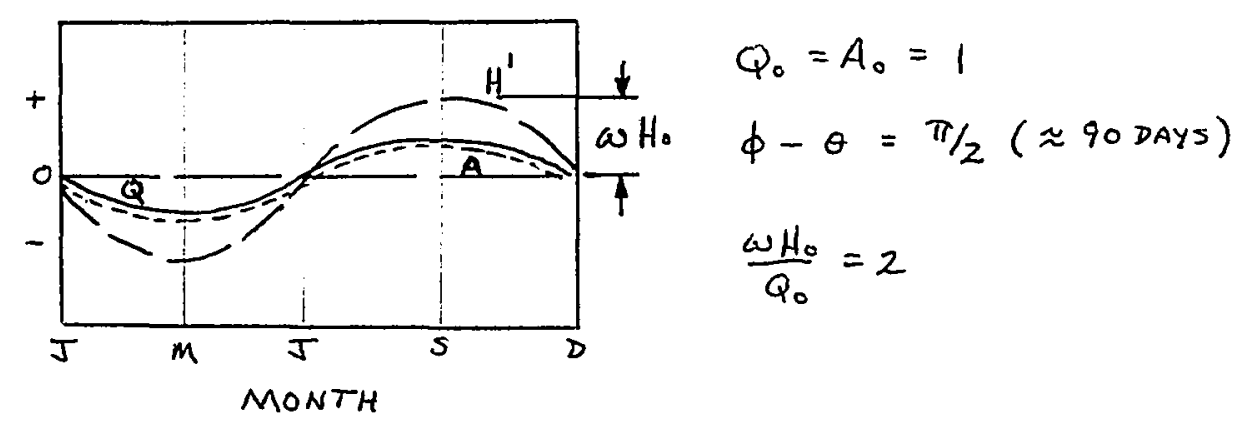

In the case that $|\phi-\theta|=\pi / 4$ then $\omega H_{0}=1$

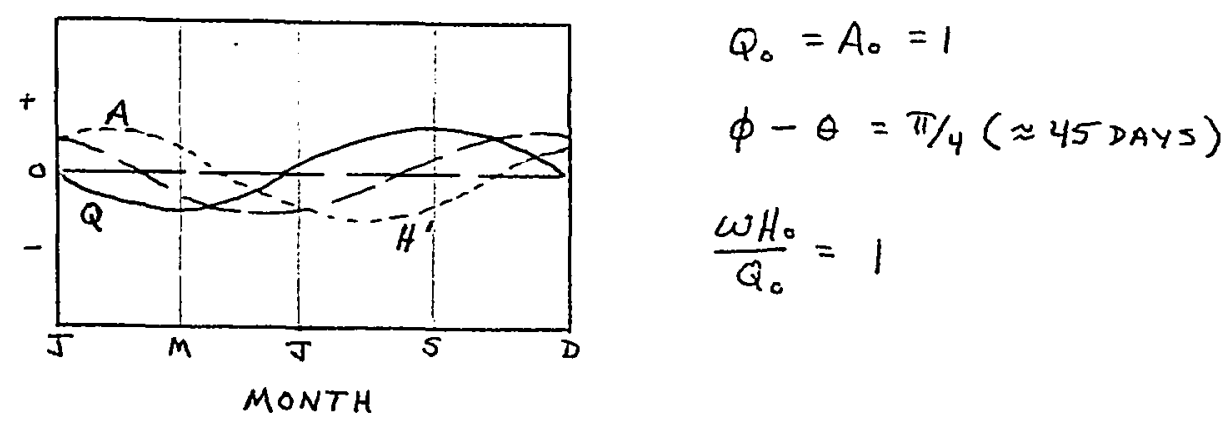

Therefore, the ratio $\omega H_{0} / Q_{0}$ can vary from $0 \leq \frac{\omega H_{0}}{Q_{0}} \leq\left(1+\frac{A_{0}}{Q_{0}}\right)$. In the cases where the ratio is less than or equal to 1 , the advection and mixing combined leads the net surface heat exchange by 135 to 225 days. In all other cases $\omega H_{0} / Q_{0}$ will be greater than 1 . Figure 59 shows a map of 
the result of dividing the amplitude of total heat storage ( $\omega H_{0}$ ) by the amplitude of the net surface heat exchange $\left(Q_{0}\right)$ for each grid rectangle. (If the ratio at one location is twice that at another, this does not imply that the advection and mixing at the second location is twice that at the first, because of the influence of the phase difference.)

Figure 59 clearly shows that advection and mixing are important throughout the Pacific. In only five areas is the amplitude of the net surface heat exchange greater than the amplitude of the total heat storage. These areas are around Guam Island, in the Gulf of Alaska, approximately $1100 \mathrm{~km}$ west of the Oregon Goast, southwest of Vancouver Island, and southeast of Kamchatka. Advection and mixing account for as much as one-third of the annual amplitude of the total heat storage. For example, the annual amplitude of the net surface heat exchange $\left(Q_{0} / \omega\right)$ in the area around Guam Island is $48.2 \mathrm{kcal} \mathrm{cm}^{-2}$, but the annual amplitude of the total heat storage in the same area is only $34.4 \mathrm{kcal} \mathrm{cm}^{-2}$. Therefore, advection and mixing must remove on the average approximately $13.8 \mathrm{kcal}^{\mathrm{cm}^{-2}}$ from the area during the year.

In an area just east of Japan and one area approximately $2500 \mathrm{~km}$ east of Japan, the amplitude of the total heat storage closely equals the amplitude of the net surface heat excrange. In the simplified examples given 
earlier we noted that $\omega H_{0} / Q_{0}$ can be equal to $I$ even when combined advection and mixing (A) have an annual amplitude equal to the annual amplitude of the net surface heat exchange $(Q)$. We also noted earlier that the net surface heat exchange was high east of Japan due to evaporation. Horizontal advection is partially responsible for this high evaporative heat loss because warm advection into this area maintains a difference between the temperature of the water and temperature of the air. Throughout the remainder of the North Pacific the annual amplitude of the total heat storage is greater than the net surface heat exchange. Figure 59 shows that advection and mixing account for more than half of the local change in heat storage. Advection and mixing are particularly important south of the Aleutian Islands, off the Coast of Alaska, and in the large portion of the Pacific between the Equator and $30^{\circ}$ North latitude. In the area south of the Hawaiian Islands, for example, the net surface heat exchange is only one-fifth of the annual change in total heat storage.

Averaging the amplitude ratio in Figure 59 for all grid rectangles in the North Pacific gives a mean ratio of 2.2. Evaluating the results for the 25 locations in the North Pacific used by Pattullo (1956) gives a comparable value of 2.0. On the average the seasonal changes in the thermal structure of the North Pacific are an equal result of combined mixing and advection and the local net surface 
heat exchange. Advection and mixing are important throughout the North Pacific, but particularly in the Tropical Pacific south of $30^{\circ}$ latitude, and in the North Pacific south of the Aleutian Islands.

The influence of advection and mixing in annualy redistributing heat in the North Pacific can also be seen by comparing the phase of the net surface heat exchange and the total heat storage. This phase is determined by how the amplitude and phase of advection and mixing combined and the net surface heat exchange compare. If, for example, all of the net surface heat exchange was stored locally, that is, advection and mixing were negligible, then the months of maximum and minimum net surface heat exchange would correspond with the months of maximum and minimum change in total heat storage $\left(H^{\prime}\right)$. Referring to the sketch below, the annual wave of net surface heat exchange $(Q)$ would therefore precede the annual wave of total heat storage $(H)$ by one-quarter of the annual cycle, or three months.

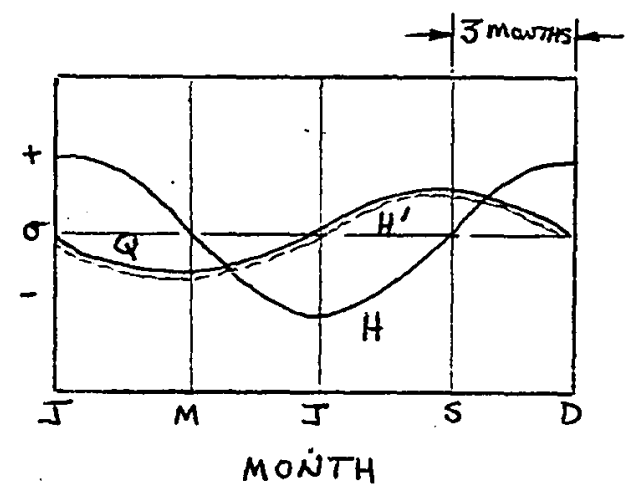

If on the annual average, advection and mixing are not negligible, then the phase of the local heat storage will 
lag the surface heat exchange by greater or less than three months. The amount the phase comparison differs from +3 months depends on both the amplitude and phase relationship between the surface heat exchange ( $Q$ ) and advection and mixing combined (A). If, for example, the amplitudes were equal and $A$ leads $Q$ by 3 months, then the total heat storage (H) will lag the net surface heat exchange by $11 / 2$ months.

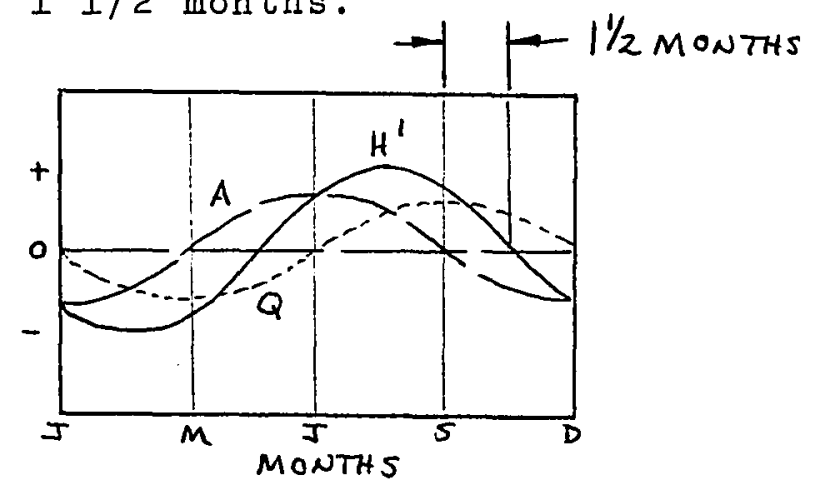

If the amplitude of the advection and mixing combined ( $\left.A_{0}\right)$ was equal to $1 / 2 Q_{0}$ then the total heat storage lags the net surface heat exchange by 2 months. If $A_{0}=2 Q_{0}$ the lag becomes 1 month.

Figures 60 and 61 respectively show the results of subtracting the month of maximum and minimum net surface heat exchange from the comparable month of maximum and minimum total heat storage. A phase lag of the total heat storage is shown as positive.

The annual wave of total heat storage does generally lag the net surface heat exchange throughout most of the Pacific. This lag varies geographically from one to three months for the maxima, and from one to five months for the 
minima. The areas where the phase lag is greatest are found off Japan (maxima and minima), in the Gulf of Alaska (minima), and in the Bering Sea (minima). Where the phase comparison is +3 months indicates that advection and the net surface heat exchange are in phase.

In a few areas of the North Pacific the phase of the local heat storage leads the net surface heat exchange. This can be caused by warm advection into the area before the net surface heat exchange becomes positive. These areas are the Bering Sea (maximum), the Okhotsk sea (minimum), the central portion of the Gulf of Alaska (maximum), and two small areas north of the Hawaiian Islands (maximum and minimum). The phase lead of the maxima in the Tropical Pacific is confined to a narrow zone crossing the Pacific at about $10^{\circ}$ North latitude. This zone widens eastward and splits into two larger branches, one east of Hawaii, and the other just north of the Equator. In contrast, the comparison of the minima (Figure 6I) shows the phase of the total heat storage leads the net surface heat exchange over most of the Pacific south of $15^{\circ}$ North latitude. The local annual amplitude of advection and mixing combined must be greater than the annual amplitude of the net surface heat exchange and the advection and mixing must lead the surface heat exchange by three to six months for the total heat storage to lead the net surface heat exchange. However, some of the phase leads in low latitudes may be due to the 
difficulty of selecting the annual maxima and minima from the data. The annual amplitude of the net surface heat exchange in the Equatorial Pacific is very small. In addition, the two maxima and minima that occur there annualy can be very close to, or in fact equal in size. The phase lead found in parts of the Equatorial Pacific may be partially due to the difficulty of selecting the annual maxima and minima.

In general, both the amplitude and phase comparisons (Figures 59, 60, and 61) clearly indicate that the surface heat exchange alone is not sufficient to establish the local thermal structure. Advection and mixing are important contributors to local changes in the annual thermal structure.

Figure 62 shows the result of algebraically summing and averaging the results of the above phase comparison east-west across the Pacific in $2^{\circ}$ steps of latitude. These results give a clear picture of the latitudinal influence of advection and mixing in altering the annual phase relationships between the local heat storage and the local surface heat exchange. The data fluctuate somewhat with latitude. However, it is obvious that the phase lag of the total heat storage relative to the net surface heat exchange generally increases from the Equator to $30^{\circ}$ latitude. This phase lag increases from approximately +1 month (maxima) and $+1 / 2$ month (minima) at the Equator to 
approximately $+21 / 2$ months at $30^{\circ}$ North latitude. North of $30^{\circ}$, to approximately $42^{\circ}$ latitude, the phase lag begins decreasing slightly ( $1 / 2$ month) for both the maxima and minima. Farther north, the phase lag of the maxima decreases while the phase lag of the minima increases to $+31 / 2$ months.

Following is alist of the average ratio of the amplitude of total heat storage divided by the amplitude of the net surface heat exchange $\left(\omega H_{0} / Q_{0}\right)$ and the average phase (total heat storage minus net surface heat exchange) for six $10^{\circ}$ latitudinal zones:

Latitude $\quad \frac{\left.\text { Amplitude Ratio ( } \omega H_{0} / Q_{0}\right)}{\text { (Months) }}$

$\begin{array}{lll}1^{\circ}-9^{\circ} & 2.8 & 1 / 2 \\ 11^{\circ}-19^{\circ} & 2.4 & 11 / 4 \\ 21^{\circ}-29^{\circ} & 2.0 & 21 / 4 \\ 31^{\circ}-39^{\circ} & 1.8 & 2 \\ 41^{\circ}-49^{\circ} & 1.8 & 13 / 4 \\ 51^{\circ}-59^{\circ} & 2.0 & 11 / 2\end{array}$

A simple analysis, approximating the net surface heat exchange $(Q)$, the local change in total heat storage $\left(H^{\prime}\right)$ and the advection and mixing combined (A) by simple sinusoids as before, gives the following values for the amplitude ratio of combined advection and mixing divided by the net surface heat exchange and the phase comparison between $A$ and $Q$ : 


$\begin{array}{ccc}\text { Latitude } & \text { Amplitude Ratio }\left(A_{0} / Q_{0}\right) & \frac{\text { Phase Comparison }}{(Q-A \text { Months })} \\ 1^{\circ}-9^{\circ} & 2.5 & 3 \\ 11^{\circ}-19^{\circ} & 1.7 & 21 / 2 \\ 21^{\circ}-29^{\circ} & 1.1 & 3 / 4 \\ 31^{\circ}-39^{\circ} & 1.2 & 11 / 2 \\ 41^{\circ}-49^{\circ} & 1.4 & 21 / 4 \\ 51^{\circ}-59^{\circ} & 0.7 & 2\end{array}$

Therefore, on the average, combined advection and mixing lead the net surface heat exchange throughout the North Pacific. The overall mean amplitude ratio of advection divided by the net surface heat exchange $\left(A_{0} / Q_{0}\right)$ is 1.4 and phase comparison is 2 months.

B. NUMERICAL MODEL. As stated earlier, the second objective of this work was to model the seasonal changes of total heat storage in the 250 meter surface layer of the North Pacific Ocean. The purpose of developing a model is to attempt to learn quantitatively more about the processes of mixing and advection. The following discussion gives the steps that were used in the model development, and the resulting solution. First, the equation that is used is given and justified. Next, the input data and the terms found in solving the equation are discussed. Included in this discussion is a list of the general steps used to solve the equation numerically and the criteria used to judge the success of the solution. Next, the details 
concerning how the equation was solved numerically are given and discussed. This discussion includes comments on the stability and convergence of the numerical solution. Last, the results of the solution are given, followed by discussion of how the total heat storage predicted by the numerical solution agrees with the observed total heat storage, discussion of the resulting stream function, and comments on the discrepancy between the theoretical results and the observations.

1. Theory and the Equation Used. The model of the seasonal changes in total heat storage in the 250 meter surface layer was obtained using the two-dimensional heat conservation equation:

$$
\frac{\partial H}{\partial t}=A\left[\frac{\partial^{2} H}{\partial x^{2}}+\frac{\partial^{2} H}{\partial y^{2}}\right]-u \frac{\partial H}{\partial x}-r \frac{\partial H}{\partial y}+Q \quad C A L C m^{-2} D A Y^{-1}
$$

Earlier the assumption was made, and justified, that the turbulent downward flow of heat and the ascending movements of cooler water are in approximate balance and can therefore be neglected as a first-order approximation. Simplifying the equation to two dimensions allows a stream function to be used to define a horizontal velocity field. This horizontal velocity field must be known in order to compute the contribution to the change in total heat storage due to horizontal advection.

The grid previously defined (see Figure 1), along with the surface and the 250 meter depth, divided the 250 
meter layer into 402 volumes. Equation (2) was applied to each of these volumes. The equation expresses an equality between the change in heat storage in a given volume with respect to time, and the sum of contributions to the change in heat storage due to mixing, advection, and the net surface heat exchange. Since the vertical processes at the bottom face of the volume are assumed to balance, the change in heat $H$ in each volume is a result of the processes acting at each of the five remaining faces:

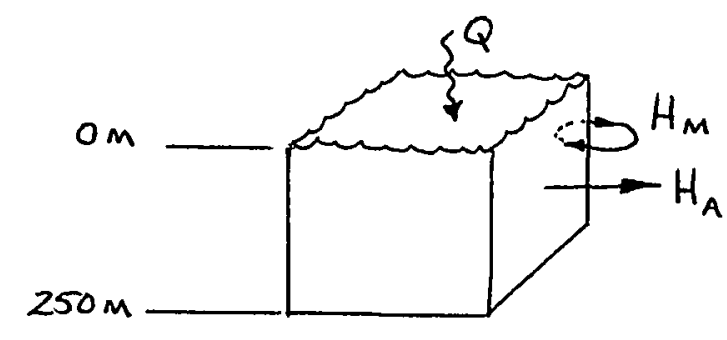

where:

$$
\begin{aligned}
& Q=\text { net surface heat exchange } \\
& H_{M}=\text { mixing (at the jur vertica faces). } \\
& H_{A}=\text { adve - on (at the four vertical faces). }
\end{aligned}
$$

The processes must be integrated over each appropriate face of each volume being considered. In this case, the differential form of the heat conservation equation can be used. As noted earlier, all temperature observations in each grid volume were averaged by month, and the monthly total heat storage values for each volume were computed using these averaged curves. This is equivalent to assigning uniform thermal properties throughout each grid volume, 
and therefore, the differential form of the two-

dimensional heat conservation can be applied directly to each grid volume. As stated earlier, the horizontal velocity components $U$ and $V$ in the advection terms of Equation (2) will be obtained using a stream function. The components, therefore, will represent mean velocities $(\bar{u}$ and $\bar{v})$ over the 250 meter depth. The consequences of using mean velocities and heat storage values, integrated over the 250 meters, was checked by comparing the following expressions:

$$
\begin{array}{lll}
\bar{u} \frac{\Delta H}{\Delta x} \text { AND } & \frac{\rho C_{p}}{Y D} \iint_{y} \frac{\partial T}{\partial x} u d z d y & T=T_{(z)} \\
\bar{v} \frac{\Delta H}{\Delta y} \text { AND } \frac{\rho C_{p}}{x D} \iint_{x} \frac{\partial T}{\partial y} v d z d x & u=U(z, y)
\end{array}
$$

where:

$$
\begin{aligned}
\Delta H= & \text { the difference in total heat storage between } \\
& \text { two neighboring volumes. } \\
\Delta x, \Delta y= & \text { grid spacing between two neighboring volumes. } \\
\rho C_{p}= & \text { the density }(p) \text { times the specific heat }\left(C_{p}\right) . \\
y D= & \text { the area of the face of the grid volume in the } \\
& y-z \text { plane. } \\
X D= & \text { the area of the face of the grid volume in the } \\
& x-z \text { plane. } \\
T= & \text { the difference in }{ }^{\circ} \mathrm{C} \text { between two neighboring } \\
& \text { grid volumes in } 5 \text { meter intervals from the } \\
& \text { surface to } 250 \text { meters. }
\end{aligned}
$$


The comparison was made for a few locations in the North Pacific Ocean where vertical velocity profile data were available. The data of LaFond (1968) (Kuroshio), Reed and Laird (1966) (off California), and Knauss (1966) (Equator) were used. The results showed that the advective contribution calculated with each expression at these locations agreed within $\pm 12 \%$. However, agreement may be poor at locations on the Equator because no attempt will be made to model the Equatorial Undercurrent.

2. Given Terms, Computed Terms, and General Solution steps. A successful numerical model of the seasonal changes in total heat storage in the 0 to 250 meter layer must have an annual cycle; that is, it must return at the completion of 365 daily iteration steps as closely as possible to the initial conditions given at the start of the year. In addition, the annual amplitude and phase of the computed total heat storage for each grid volume must agree reasonably well with the observed amplitude and phase if the model is to be considered successful. Numerically solving Equation (2) for each grid volume, each day, requires knowledge of the total heat storage field (H) from the previous day, the net surface heat exchange $(Q)$, the mixing coefficient $(A)$, and the horizontal velocity field $(u$ and $v$ ). With these objectives in mind, Equasion (2) was applied to each grid volume in the following general manner: 
Step 1: The solution of Equation (2) requires the initial conditions to be specified. The initial conditions were specified by providing an initial heat storage field (H) for the first day of the annual cycle. The observed total heat storage field for January was used for this initial data.

Step 2: Monthly values for the net surface heat exchange $(Q)$ were provided from the given data. Step 3: The equation was iterated through 365 (daily) steps by solving for the daily change in total heat storage in each grid volume. It is also necessary to specify boundary condition for the solution of Equation (2). This condition defines uniquely the solution within the region considered. The boundary condition was that the derivative of the total heat storage $(H)$ normal to the boundary be equal to zero. This condition will be discussed in detail later in this section.

Equation (2) shows that a summation of the five terms on the right-hand side gives the daily change in total heat storage. The horizontal gradients of total heat storage ( ) used in the mixing and advection terms were found using the total heat storage field once corrected for the previous day's change. The numerical technique used to calculate the first and second-order derivatives will be discussed later. The horizontal velocity field $(U$ and $v)$ was found by numerically differentiating a 
given stream function. This stream function, which was considered constant during the year, will also be discussed later. An initial value for the mixing coefficient (A) was available following a review of the descriptive results as was discussed earlier. Therefore, all information required to compute the daily change in total heat storage was provided. The mixing coefficient and the horizontal velocity field were given, the net surface heat exchange was given data, and the heat storage field was provided from the previous day. The daily change in total heat storage was computed and then used to modify the existing heat storage field for each grid volume. The computation was started on January 15th using the initial heat storage field. At the first of each month new values for the net surface heat exchange were introduced for the duration of the next month. The computations were repeated 365 times and the final total heat storage field was compared to the initial total heat storage field. Step 4: The results of the numerical solution were checked against the observed monthly heat storage maps during the iteration through the annual cycle, and against the observed annual amplitude and phase of total heat storage at the completion of the annual cycle. The monthly comparisons provided checks on the progress of the solution during the annual cycle. The comparisons between the theoretical and observed annual amplitude and phase of 
total heat storage were used as the primary criteria for judging the success of the theoretical solution.

The comparisons between the theoretical solution and the observations were made in the following manner. The ratio of theoretical annual amplitude divided by the observed annual amplitude was found for each grid rectangle, and a mean of these ratios was computed. The mode of the ratios was then found by dividing the ratio values into classes of 0.1 steps from 0.1 (or less) to 2.0 (or greater). These results were then plotted and the mode was found for each major gyre defined by the stream function. Similarly, the distribution, mode, and mean were found for the results of the phase comparison using classes of \pm 1 month steps. Changes in the distribution, mean, and mode of both the amplitude ratio and phase comparison were used to judge the success of the numerical solution. If the comparison between the heat storage predicted by theory and that given by the observations did not agree reasonably well, the given stream function or mixing coefficient was changed and the 365 iteration steps were repeated beginning atain at Step 1 above. The manner in which the mixing coefficient or stream function was changed will be discussed later.

The entire computation was repeated many times until the best possible agreement was obtained between the heat storage predicted by theory and that given by the 
observations. By finding the best stream function and mixing coefficient the purpose of the model development was essentially accomplished. This mixing coefficient was then used in the algebraic solution of Equation (2) for the monthly contributions to the change in total heat storage due to mixing and advection. These results have been described earlier.

3. Iterative Techniques. The first and secondorder derivatives in Equation (2) were computed numerically using the information from the total heat storage fields $(H)$. As stated earlier, the total heat storage field was recomputed in daily steps beginning with an initial field provided for the l5th of January.

The first-order derivatives in the advection terms $u \frac{\partial H}{\partial x}$ and $v \frac{\partial H}{\partial y}$ were computed using either forward or backward difference operators (Salvadori and Baron, 1961, p. 70 and 0.75$)$. The choice of operator was dependent upon the direction of the velocity component present at each of the four vertical faces of each grid volume. This can be shown as follows:

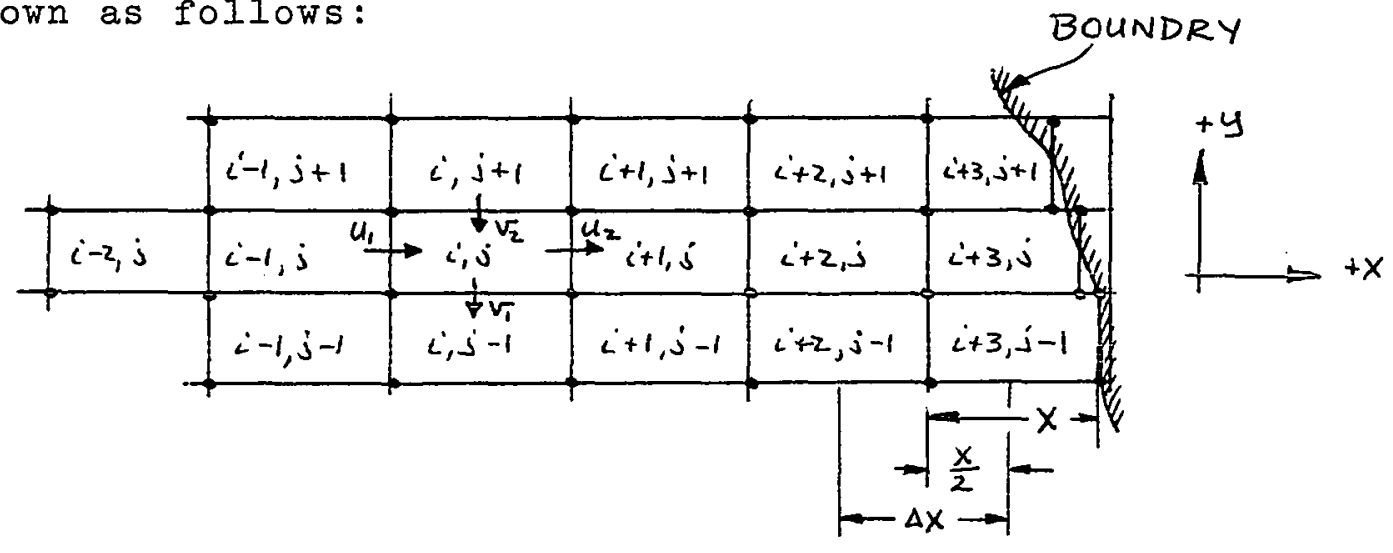


Referring to the above sketch, velocity component $U_{1}$ brings water from the grid volume $i-1, j$ into the volume $i j$. In this case a backward difference operator was used since the water entering volume $i, j$ originates in volume $i-1, j$. Velocity component $V_{2}$ adds water from the grid volume $i j j+1$ to the volume $i, j$. In this case a forward difference operator was used since the water entering volume $i j$ originated in volume $i, j+1$. The sign convention chosell was positive proceeding from volume $i, j$ to $i+1, j+1$. Using the applicable forward or backward operator conserved the proper sign of the advection terms for Equation (2) when taking the product of the horizontal velocity and the respective gradient.

The computation for the first-order derivative was corrected for the land boundary where applicable. The east-west dimension of a grid rectangle that contained a land boundary was taken from the grid line to the nearest $1^{\circ}$ of longitude that intersected the midpoint of the boundary. Referring to the above sketch, an example is shown where the distance labeled " $x$ " is the corrected eastwest dimension of the grid volume $i+3, j-1$. This corrected dimension $X$ was used to find " $\Delta x$ " shown in the sketch, and $\Delta x$ in turn was used to compute the first-order derivative from grid $i+3 j-1$ to grid $i+3, j-1$.

The second-order derivatives were taken using a central difference Laplacian operator (Salvadori and 
Baron, 1961, p. 193). Since a rectangular grid with a length to width ratio of 5 to 1 at the Equator was used (the ratio decreases with increasing latitude to 2.5 to 1 at $60^{\circ}$ North latitude) a compensation factor must be included in the Laplacian operator. Thus the Laplacian operator in finite difference form becomes: Laplacian $=\frac{H_{i+1, j, k}-2 H_{i, j, k}+H_{i-1, j, k}}{D_{1}^{2}}+\frac{H_{i, j+1, k}-2 H_{i, j, k}+H_{i, j-1, k}}{D_{2}^{2}}$ where:
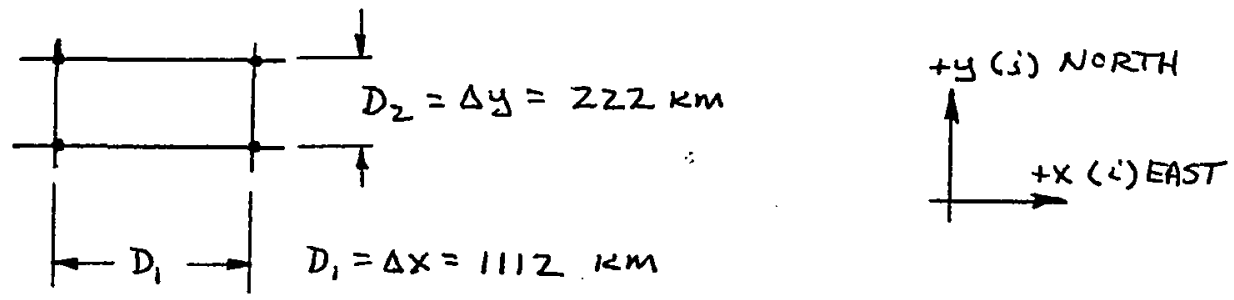

but since $D_{1}=5 D_{2} \cos \theta(\theta=$ latitude $)$ then:

Laplacian $=\frac{H_{i+1, j, k}-2 H_{i, j, k}+H_{i-1, i, k}+25 \cos ^{2} \theta\left[H_{i, j+1, k}-2 H_{i, j, k}+H_{i, j-1, k}\right]}{25 D_{2}^{2} \cos ^{2} \theta}$

The computation for the Laplacian in those grid rectangles containing a land boundary were corrected for the changed dimension of the grid (Salvadori and Baron, 196I, p. 231). The correction involves assigning a value for $H$ on the boundary and correcting the distance from the center of the grid volume to the boundary. These corrections enter the computation for the Laplacian as coefficients of each $H$ term in the numerator. The value 
selected for $H$ on the boundary was taken as the same $H$ existing in the grid volume that the boundary crossed. Referring to the sketch in the preceding discussion for the first-order derivatives, the boundary was approximated by the nearest $1^{\circ}$ line of longitude. The value for $H$ in the center of the grid volume $i+3, j-1$ (center is at $\frac{x}{2}$ ) was also assigned to the $1^{\circ}$ line approximating the boundary on the east side of grid volume $i+3, j-1$. Thus the derivative of $H$ normal to the boundary is equal to zero. This is the boundary condition required for solving Equation (2). The data for the net surface heat exchange $\left(Q_{i, j, k}\right)$ was given as monthly values for each grid volume. These monthly values were considered as representing an average of the daily net surface heat exchange in each grid volume. Therefore, the single value of $Q_{i, s, k}$ for each month was used for all the days in the month during the iteration process.

4. Computation of the Stream Function. Computing the advection terms in Equation (2) requires knowledge of the horizontal velocity components ( $u$ and $v$ ). Since the problem was simplified to two dimensions, stream functions were used to represent the horizontal field.

The stream functions used in this work were analytically developed. The development was started by numerically representing the land boundaries of the North Pacific Ocean. The width of the Pacific was approximated for each 
$2^{\circ}$ latitudinal strip comprising the area from $10^{\circ}$ South to $60^{\circ}$ North latitude. Each $2^{\circ}$ latitudinal strip was then divided into $1^{\circ}$ longitudinal strips. The land boundaries on the east and west end of each $2^{\circ}$ latitudinal strip were taken as the nearest $1^{\circ}$ line of longitude intercepting the land boundary. Therefore, each $2^{\circ}$ latitudinal strip crossing the Pacific was composed of a number of $2^{\circ}$ (latitude) $x I^{\circ}$ (Iongitude) rectangles.

In the development of an analytical expression for the stream function a number of criteria were considered. First, the stream function must be zero on the north-south and east-west boundaries. Second, the stream function must be a continuous function between the boundaries. Third, there must be a maximum at some position within the boundaries. Fourth, the location of this maximum must be easily relocated in any direction within the boundaries; that is, the stream function can have north-south or eastwest asymmetry. Fifth, the same expression can be used for all areas of the Pacific. Sixth, the expression can be applied to any boundary shape. A stream function ( $\phi$ ) was developed that fulfills all of the above criteria. The general form of this function used to model each gyre in the North Pacific was 


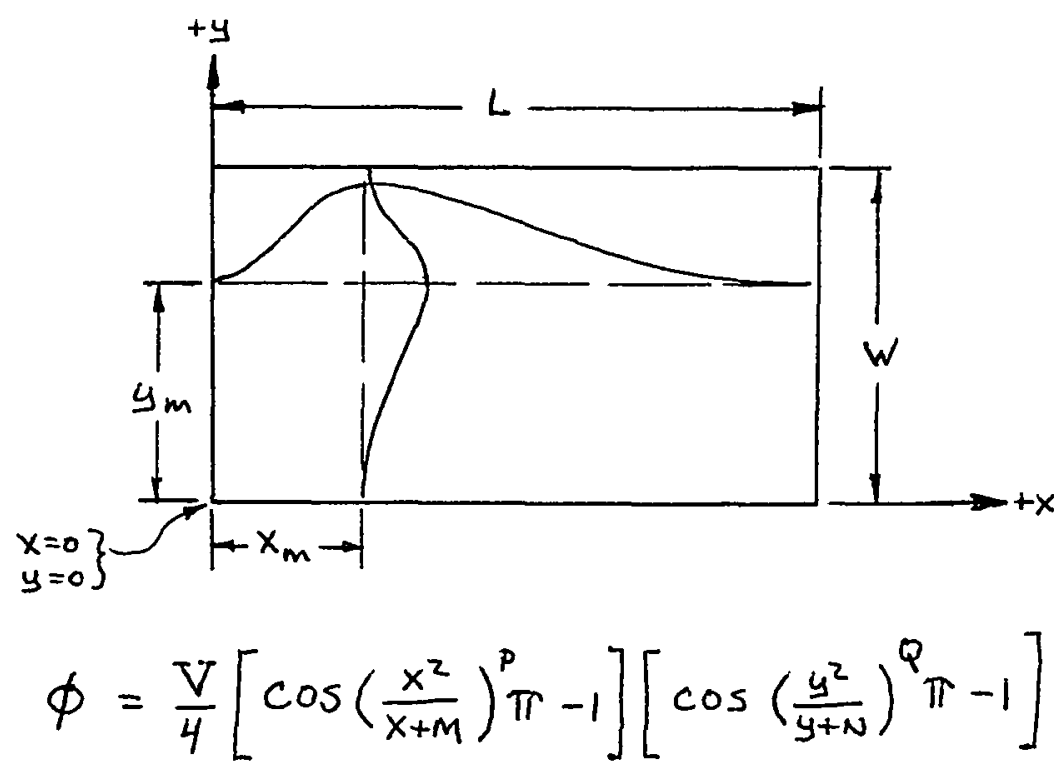

where:

$$
\begin{aligned}
V= & \text { maximum transport in the gyre. This maximum } \\
& \text { is located at position } x=x_{M}, y=y_{M} \\
x= & \text { dimensionless number representing the distance } \\
& \text { from the western land boundary. It is the } \\
& \text { number of degrees of longitude measured from } \\
& \text { the western boundary in each } 2^{\circ} \text { latitudinal } \\
& \text { strip. } \\
y= & \text { dimensionless number representing the distance } \\
& \text { from the southern latitudinal limit of the } \\
& \text { gyre. It is the number of degrees of latitude } \\
& \text { in } 2^{\circ} \text { steps from the southern boundary. } \\
M= & \text { dimensionless constant establishing the amount } \\
& \text { of east-west asymmetry in the gyre ( } M=x_{M}^{2}-x_{m} \text { ). } \\
N= & \text { dimensionless constant establishing the amount } \\
& \text { of north-south asymmetry in the gyre }
\end{aligned}
$$




$$
\begin{aligned}
& \left(N=y_{M}^{2}-y_{M}\right) . \\
P= & \frac{\log (2)}{\log \left(\frac{L^{2}}{L+M}\right)} \\
L= & \text { dimensionless east-west Iength of the Pacific. } \\
& \text { It is the total number of degrees of longitude } \\
& \text { in each } 2^{\circ} \text { latitudinal strip. } \\
Q= & \frac{\log (2)}{\log \left(\frac{W^{2}}{W+N}\right)} \\
W= & \text { dimensionless north-south width of the gyre. } \\
& \text { It is the total number. of } 2^{\circ} \text { steps of latitude } \\
& \text { in each } 10^{\circ} \text { strip of longitude. }
\end{aligned}
$$

The components $(u$ and $v$ ) of the horizontal velocity

field required for the advection terms $u \frac{\partial H}{\partial x}$ and $v \frac{\partial H}{\partial y}$ in Equation (2) were obtained by numerically differentiating the stream function. The equations used were

$$
\begin{aligned}
& u=\frac{1}{2.5 \times 10^{4}} \frac{\partial \phi}{\partial y} \quad \text { cmsec }^{-1} \\
& v=-\frac{1}{2.5 \times 10^{4}} \frac{\partial \phi}{\partial x} \quad \text { cmsec }^{-1}
\end{aligned}
$$

The stream function $\phi$ was computed for each intersection of the $2^{\circ} \times 10^{\circ}$ grid lines. The computation assigns zero to all the remaining points of intersection on the boundary. Five major gyres were included in the initial stream function, simulating each of the major 
current systems in the Pacific Ocean north of $10^{\circ}$ South latitude. These are the North Pacific cyclonic gyre, North Pacific Anticyclonic gyre, Equatorial Countercurrent (2 gyres), and the South Pacific Anticyclonic gyre. Between these major gyres, each in a latitudinal zone of the North Pacific, the sign of the stream function changes. Therefore, the stream function is also zero on the latitudinal boundaries between the gyres. In each latitudinal zone of the Pacific, containing one of the major gyres Iisted above, smaller gyres of varying size were added as required. These small gyres were added by using the same general expression [Equation (7)] as used for the major gyres. In each case the variables $L, W, P$ and $Q$ at each intersection of the grid lines were used to compute the value of the stream function at that point. The constant $V$ was selected for the desired strength of each gyre and the constants $M$ and $N$ were selected to place each gyre center at the desired location. In this manner a stream function was developed for each latitudinal zone of the North Pacific Ocean.

The final stream function used in the model was obtained after much experimentation. The complete analytical expression used for the stream function in each latitudinal zone contained constants which established the latitudinal limits of the zone (W), the number of gyres in the zone, the north-south $(N)$ and east-west $(M)$ 
location of each gyre center in the zone, and the individual gyre strengths $(V)$. These constants allowed a wide range of stream functions to be easily developed or changed for each computation. Each test involved time stepping the numerical solution through an annual cycle, and judging the effect the changes in the stream function had in improving the solution. As mentioned earlier, the annual amplitude and phase comparisons were used as the primary criteria for judging the effect of the changes. The final stream function used in the model was found in the following manner: First, the descriptive results were reviewed and initial values were selected for the latitudinal limits and for the approximate location of the centers of the major gyres existing in the North, Central and Equatorial North Pacific. These values were based upon the location of total heat storage gradients and the configuration of the average mixed layer depth in the North Pacific. For example, the strong north-south gradient (Figure 36 ) off Japan at $35^{\circ}$ to $38^{\circ}$ North latitude indicates the Kuroshio and Oyashio currents meet in this area. Second, the strength of each gyre was estimated and an initial stream function was analytically developed. This stream function was then tested, along with a constant mixing coefficient (A) of $5 \times 10^{6} \mathrm{~cm}^{2} \mathrm{sec}^{-1}$. Next the stream function constants were varied individually to determine the effect of each in improving the 
solution. Much experimentation eventually showed the number of gyres required in each latitudinal zone and the strength of each gyre. During this process it was found that the solution was more sensitive to the relocation of gyres or increasing the gyre strengths than to changes in the mixing coefficient. Once the optimum stream function was obtained, subsequent changes in the mixing coefficient showed that a different coefficient for each latitudinal zone continued to slightly improve the solution. Experimentation was continued by further adjustment of the mixing coefficient. The eventual use of a mixing coefficient that increased linearly with increasing latitude, and some further adjustment of the stream function, lead to the best agreement obtainable between the theoretically predicted and the observed heat storage fields.

Figure 63 shows the final stream function. The location of each gyre center is shown in the figure. The maximum gyre strengths and the latitudinal limits of each

gyre are

1. North Pacific Cyclonic gyres $\left(40^{\circ}\right.$ to $60^{\circ}$ North latitude)

west gyre $-16 \times 10^{6} \mathrm{~m}^{3} \mathrm{sec}^{-1}$

east gyre $-13 \times 10^{6} \mathrm{~m}^{3} \mathrm{sec}^{-1}$

2. North Pacific Subtropical Anticyclonic gyres $\left(12^{\circ}\right.$ to $40^{\circ}$ North latitude)

west gyre $-42 \times 10^{6} \mathrm{~m}^{3} \mathrm{sec}^{-1}$ 
east gyre $-12 \times 10^{6} \mathrm{~m}^{3} \mathrm{sec}^{-1}$ (plus $20 \times 10^{6} \mathrm{~m}^{3} \mathrm{sec}$ from the west gyre)

3. Equatorial Cyclonic gyres ( $8^{\circ}$ to $12^{\circ}$ North latitude) west gyre $-12 \times 10^{6} \mathrm{~m}^{3} \mathrm{sec}^{-1}$ east gyre $-13 \times 10^{6} \mathrm{~m}^{3} \mathrm{sec}^{-1}$

4. Equatorial Anticyclonic gyre ( $4^{\circ}$ to $8^{\circ}$ North latitude) $-15 \times 10^{6} \mathrm{~m}^{3} \mathrm{sec}^{-1}$

5. South Pacific Subtropical Anticyclonic gyre (4० North to $30^{\circ}$ South latitude) $-40 \times 10^{6} \mathrm{~m}^{3} \mathrm{sec}^{-1}$

These results and the stream function will be discussed further in subsequent sections.

5. Theoretical Solution Convergence and Stability. Two primary requirements for the numerical solution of Equation (2) are that the numerical solution must be convergent to the exact solution of Equation (2) and that the numerical solution must remain stable. The conditions under which the numerical solution does converge and remain stable can be calculated. These conditions place limits on the size of the grid, mixing coefficient and time step that can be used in numerically solving Equation (2).

Equation (2) has an exact solution $H_{x, y, t}$ that is continuous over all values of $x, y$, and $t$. However, the finite difference form of Equation (2)

$$
h_{(x=i \Delta x, y=j \Delta y, t=k \Delta t)}=h i, j, k
$$


has a solution only at finite positions in the grid. If $h_{i, j, k}$ is an exact finite difference solution (that is, contains no round-off errors), then the numerical solution $h i, j, k$ converges to the exact solution $H_{x, y, t}$ as $\Delta x, \Delta y$ and $\Delta t$ go to zero. The actual finite difference solution $h^{*} i, j, k$, however, includes round-off error. The error in the finite difference solution must not increase with increasing time for the solution to converge. The solution must also be checked for stability. If the actual finite difference solution $h^{*} i, j, k$ goes to the exact finite difference solution $h_{i, j, k}$ when a disturbance is added to the actual solution, then the numerical solution is stable. The values of $\Delta x, \Delta y$ and $\Delta t$ must be functionally related for this stability. Thus, the limiting conditions of convergence can be derived and the conditions of stability of the numerical solution can be calculated.

The recurrence equation is used to derive the limiting conditions for convergence. The convergence of the numerical solution is governed by the error in the numerical solution. This error must decrease with time; that is, the error terms must be bounded (finite). Deriving the error terms begins with the finite difference recurrence equation. The recurrence equation inciuding the first and second-order terms for the rectangular grid used is 


$$
h_{i, j, k+1}^{*}=a h_{i, j, k}^{*}+b h_{i+1, j, k}^{*}+b h_{i-1, j, k}^{*}+c h_{i, j+1, k}^{*}+c h_{i, j-1, k}^{*}
$$

where:

$$
\begin{aligned}
& a=\left[1-\frac{52}{25} \frac{A K}{D_{2}^{2}}\right] \\
& b=\frac{A K}{25 D_{2}^{2}} \\
& c=\frac{A K}{D_{2}^{2}}
\end{aligned}
$$

Each term of the recurrence equation can be expanded in a Taylor's series and the recurrence equation rewritten to include the error terms. The equation can then be simplified by solving for the error. The result shows the error (E) is proportional to the second and fourth-order terms in the Taylor's expansion (the subscripts denote differentiation):

$$
\begin{aligned}
& E \propto \frac{\Delta t^{2}}{2} H_{t t} \\
& E \propto-A \frac{\Delta t \Delta x^{2}}{12} H_{x x x x}-A \frac{\Delta t \Delta y^{2}}{12} H_{y y y y} \\
& E \propto-u \frac{\Delta t \Delta x}{2} H_{x x}-v \frac{\Delta t \Delta y}{2} H_{y y}
\end{aligned}
$$

where:

$$
\begin{aligned}
\Delta t & =\text { time step } \\
\Delta x & =D_{1} \text { (east-west grid size) } \\
\Delta y & =D_{2} \text { (north-south grid size) } \\
u, v & =\text { horizontal velocity components. }
\end{aligned}
$$

The error must be bounded (finite) and must decrease as $\Delta x, \Delta y$ and $\Delta t$ go to zero. The second and fourth-order 
94

derivatives in Equation (lIb) and (IIC) are finite over the domain considered (the North Pacific Ocean). These derivatives of the heat storage $(H)$, obviously go to zero as $\Delta x$ and $\Delta y$ go to zero. The second order derivative in Equation (Ila) is periodic and it is therefore bounded. The error, therefore, goes to zero as $\Delta t$ goes to zero. Thus the actual finite difference solution $h^{*} i, s, k$ will converge to the exact solution $h_{i, j, k}$

Calculating the limiting conditions for stability of the numerical solution also involves using the recurrence Equation (10). The stability is tested by introducing a disturbance into the solution. If the disturbance decreases with time, the numerical solution is stable. Testing the stability in the usual manner, let the disturbance introdiced be of the form:

$$
h_{i, j, k}^{*}=e^{L(\alpha i+\beta j)+\gamma k}
$$

where $i, j, k$ are as before, $\alpha, \beta$ and $\gamma$ are constants, and $L=\sqrt{-1}$. Substituting this disturbance into the recurrence Equation (10) (letting $[E]=e^{L(\alpha i+\beta j)+\gamma k}$ ) gives:

$$
[E] e^{\gamma}=a[E]+b[E] e^{L \alpha}+b[E] e^{-L \alpha}+c[E] e^{L \beta}+c[E] e^{-L \beta}
$$

Simplifying Equation (12) gives:

$$
e^{\gamma}=a+b\left[e^{L \alpha}+e^{-L \alpha}\right]+c\left[e^{L \beta}+e^{-L \beta}\right]
$$


The sum of the coefficients $a, b$ and $c$ on the right hand side must be equal to or less than 1 for stability (the error must decrease with time). Using the identities:

$$
\begin{aligned}
& \frac{1}{2}\left[e^{L \alpha}+e^{-L \alpha}\right]=\cosh (L \alpha) \\
& \frac{1}{2}\left[e^{L \beta}+e^{-L \beta}\right]=\cosh (L \beta)
\end{aligned}
$$

and

$$
\begin{aligned}
& \cosh (L \alpha)=\cos \alpha \\
& \cosh (L \beta)=\cos \beta
\end{aligned}
$$

and letting $e^{\gamma}=\lambda$, and requiring that $|\lambda| \leq 1$, Equation (13) simplifies to:

$$
1 \geq|a+2 b \cos \alpha+2 c \cos \beta|
$$

Resubstituting values for $a, b$ and $c$ into Equation (14), letting $\tau=\frac{A K}{25 D_{2}^{2}}$ gives:

$$
1 \geq|1-52 \tau+2 \tau \cos \alpha+50 \tau \cos \beta|
$$

The terms $\cos \alpha$ and $\cos \beta$ can have any value from tl to -1 . If they are 0 then Equation (15) is true for any value of $\tau$ ( $\tau$ is always positive). The limiting case is when $\cos \alpha$ and $\cos \beta$ are -1 . In this case:

$$
1 \geq|1-104 \tau|
$$

or

$$
\frac{2}{104} \geq \tau=\frac{A K}{25 D_{2}^{2}}
$$

Equation (16) gives the limiting condition for stability. Substituting in values to test the stability, using the most critical case when $A=11 \times 10^{6} \mathrm{~cm}^{2} \mathrm{sec}^{-1}$ (maximum 
value used), $K=8.46 \times 10^{4} \mathrm{sec}$, and $D_{2}=2.22 \times 10^{7} \mathrm{~cm}$ gives :

$$
\frac{1}{52} \geq \frac{\left(11 \times 10^{6} \mathrm{~cm}^{2} \sec ^{-1}\right)\left(8.46 \times 10^{4} \mathrm{seC}\right)}{25\left(2.22 \times 10^{7} \mathrm{~cm}\right)^{2}}
$$

or

$$
\frac{1}{52} \geqslant \frac{1}{1.32 \times 10^{4}}
$$

The results show the solution remains stable with the added disturbance. The results also show that a larger time step or mixing coefficient could have been used and the solution would still be stable. However, the mixing coefficient that was best was not known prior to finishing the model. Since the mixing coefficients tried were up to $1.1 \times 10^{9} \mathrm{~cm}^{2} \mathrm{sec}^{-1}$ it was necessary to time step in daily steps to insure stability. In addition, a portion of the round-off error in the numerical computation is proportional to $(\Delta t)^{2}$ Equation (Ila). Therefore, daily time steps were used to insure stability.

C. COMPARISON OF THE THEORETICAL AND OBSERVED TOTAL HEAT STORAGE. Figure 64 shows the theoretical annual amplitude of the total heat storage computed using Equation (2). The figure should be compared to Figure 37 , the observed annual amplitude of total heat storage. Figures 65 and 66 respectively show the results of comparing the phase of the annual maxima and minima of the theoretical and observed total heat storage. 
1. Comparison of the Annual Amplitudes.

Comparing Figures 64 and 37 shows that the theoretical annual amplitude of total heat storage agrees quite well with the observed annual amplitude. Most areas in the North Pacific having a high observed annual amplitude

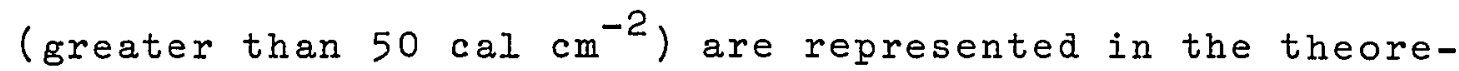
tical solution. However, the size or location of the comparative areas in the theoretical results is not exactly the same in every case. For example, the area of high annual amplitude found southwest of the Hawaiian Islands appears in the theoretical solution slightly north of the location of the similar area in the observations. This was primarily due to limiting the stream function to a straight latitudinal boundary at $12^{\circ}$ North latitude. Moving this boundary South $2^{\circ}$ did increase the agreement in the area south of Hawaii, but then the agreement in the Equatorial zone was poor. In general, however, the twodimensional heat conservation equation, given the appropriate stream function and mixing coefficient, models the observed annual amplitude of total heat storage in the North Pacific quite well.

Earlier, in the descriptive results, we noted that advection is approximateiy equal in importance to the net surface heat exchange in affecting changes in the local thermal structure. Following are a few examples of how changes in the stream function affected the theoretical 
results for the total heat storage.

1. Placing the center of the cyclonic gyre located south of Kamchatka $500 \mathrm{~km}$ further northeast slightly increases the agreement between the theoretical and observational amplitude of total heat storage in the Bering sea, but then the theoretical annual amplitude becomes much too small south of Kamchatka. A third cyclonic gyre located in this latitudinal zone was tried. Its center was placed at various locations in the Bering Sea. But the result was that the annual amplitude around the Aleutians remained too high, even for a weak Bering Sea gyre of just $2 \times 10^{6} \mathrm{~m}^{3} \mathrm{sec}^{-1}$.

2. Moving the center of the cyclonic gyre located south of Alaska $220 \mathrm{~km}$ faxther south increases the theoretical-observational agreement in the area south of the Alaskan Peninsula and south of the Aleutian Islands. But the resultant annual amplitude of total heat storage close to the Alaskan Coast is then too low. Increasing the gyre strength, while retaining its present location, helps the agreement south of the Alaskan Peninsula, but the resulting annual amplitude off Vancouver Island and off the Alaskan Coastline is then too great.

3. The boundary between the western cyclonic gyre in the North Pacific and the western anticyclonic gyre in the Central Pacific is $40^{\circ}$ North latitude. The 
annual amplitude of total heat storage is high in the Kuroshio-Oyashio area at $40^{\circ}$ North latitude. Moving the boundary as little as $2^{\circ}$ north or south of $40^{\circ}$ latitude quickly decreases the amplitude agreement in this area. Strong north-south gradients of total heat storage are found in this area. North of the $40^{\circ}$ latitudinal boundary, the stream function has a southward (Oyashio) velocity component, while south of the boundary it has a northward (Kuroshio) velocity component. The quick decrease in agreement obtained when moving the $40^{\circ}$ boundary is due to changes in the location of the current boundary. 4. An anticyclonic gyre in the East Pacific (southeast of the Hawaiian Islands) is required primarily to help the theoretical-observational agreement in the areas of high annual amplitude of total heat storage located north and south of Hawail (see Figure 37). If this gyre is moved approximately $3000 \mathrm{~km}$ farther west, the theoretical annual amplitude of total heat storage south of Hawai remains high. However, the theoretical annual amplitude north of Hawai is then too low and the theoretical annual amplitude just east of the Philippines is much too high.

5. The small cyclonic and anticyclonic gyres shown in Figure 63 from $4^{\circ}$ North to $12^{\circ}$ North model the Equatorial Countercurrent (centered at $8^{\circ}$ North 
latitude). Movement of the two gyres that are centered south of the Hawaiian Islands, either to the east or west, decreases the theoretical annual amplitude of total heat storage around the Iine Islands. If the gyre centers are moved to a position just northwest of the Galapagos Islands the agreement is again good in the area around the Line IsIands, but then the theoretical annual amplitude of total heat storage in a large area north of the Galapagos Islands is much too high.

Figure 67 shows the result of repeating the numerical solution using a constant mixing coefficient of $5 \times 10^{6}$ $\mathrm{cm}^{2} \mathrm{sec}^{-1}$ in place of a mixing coefficient that is a function of latitude. The most obvious changes are in low and high latitudes. The two areas of high seasonal amplitude of total heat storage that are observed south of the Hawaiian Islands are diminished considerably. Mixing is greater in this area with the higher mixing coefficient and this tends to diminish the local maxima of total heat storage. The area of high annual amplitude off the coast of Alaska also changes. The area is expanded and a second small area of high annual amplitude appears around the Aleutian Islands. At high latitudes mixing is less than before. The result is that mixing does not diminish the local maxima. Decreasing the volume transport in the Alaskan and Kamchatka gyres does decrease the annual 
amplitude of the total heat storage in these areas, but then the phase agreement between the theoretical results and the observations becomes poor.

The numerical solution was repeated again, using a constant mixing coefficient of $5 \times 10^{6} \mathrm{~cm}^{2} \mathrm{sec}^{-1}$, removing the East Pacific Anticyclonic gyre, and removing all northsouth asymmetry from the remaining gyres in the stream function. Figure 68 shows the resulting theoretical annual amplitude of total heat storage. It should be compared to Figure 67 and to Figure 64. Figure 68 shows that without the anticyclonic gyre southeast of the Hawaiian Islands the theoretical amplitude is much too low in this area. The increased mixing coefficient in the Tropical and Equatorial Pacific, combined with a decrease in circulation, result in a general decrease in the annual amplitude of the total heat stored in low latitudes. The most noticeable change in the agreement between the theoretical and observed total heat storage, obtained when using a constant mixing coefficient and removing all northsouth asymmetry, is in middle and high latitudes. In middle latitudes the theoretical annual amplitude decreases over much of Central Pacific. Increasing the strength of the large North Pacific Anticyclonic gyre enough to increase the theoretical-observational agreement over most of the Central Pacific results in the growth of the area of high annual amplitude around Japan to twice its observed size. 
In the north, the lack of north-south asymmetry in the Alaska-Kamchatka area results in the appearance of three areas of high annual amplitude of total heat storage that are not observed. All of the above results demonstrate that the East Pacific Anticyclonic gyre, the northsouth asymmetry in each gyre, and a mixing coefficient that varies with latitude are necessary to obtain the optimum numerical solution.

\section{Difference Between the Annual Amplitudes.}

The observed annual amplitude of total heat storage was subtracted from the theoretical annual amplitude to show the discrepancy between the annual amplitudes. The result, presented in Figure 69, shows that the theoretical and observational results agree well over the majority of the North Pacific. The areas with an annual amplitude greater

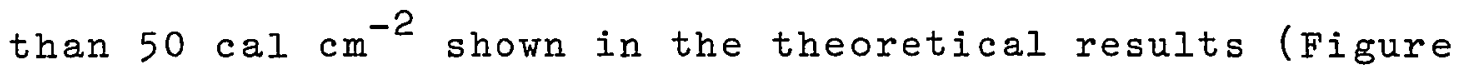
64), do not always correspond exactly with the similar area of high annual amplitude shown in the observations (Figure 37). As a result, the difference between the two can be high where the two areas do not exactly coincide. Examples of this are shown in Figure 69 in the areas located southeast of the Hawaiian Islands (+ $\left.12 \mathrm{kcal} \mathrm{cm}^{-2}\right)$, southwest of the Hawaiian Islands $\left(-18 \mathrm{kcal} \mathrm{cm}^{-2}\right.$ and

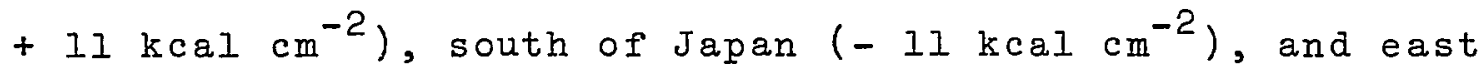
of. Japan ( $-13 \mathrm{kcal} \mathrm{cm}^{-2}$ and $+11 \mathrm{kcal} \mathrm{cm}^{-2}$ ). Along the western edge of the Pacific a discrepancy 
between the theoretical and observed annual amplitude of

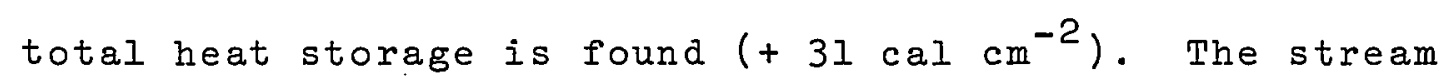
function developed for the numerical solution does not include the area east of Korea in the Japan Sea, and north of the Philippine Islands in the South China Sea. Part of the discrepancy in the Western Pacific is due to omitting horizontal advection in these areas. In addition, vertical temperature gradients are still quite apparent at 250 meters in the Western Pacific from $10^{\circ}$ to $35^{\circ}$ North latitude. Therefore, heat is also probably mixing and advecting downward past the 250 meter depth. Since the theoretical solution does not consider this vertical loss of heat, the theoretical amplitude is expected to be greater than the observed amplitude in the Western Pacific.

In upwelling areas the theoretical annual amplitude of total heat storage can be less than or greater than the observed amplitude. If the upwelling of cold water coincides with a time when the surface heat exchange is positive the observed annual amplitude is decreased. If it coincides with a time when heat is being lost from the surface, the observed annual amplitude can be increased. Figure 69 shows that the computed amplitude is greater than the observed amplitude in the Gulf of Alaska, off the Coast of California, in the Eastern Tropical Pacific, and on the Equator, west of the Galapagos Islands. In each 
of these known upwelling areas the upwelling should occur during months when the net surface heat exchange is positive according to the statement above. The largest discrepancy in an upwelling area $\left(+22 \mathrm{kcal} \mathrm{cm}^{-2}\right)$ is off the California coast where March to June are months of strong upwelling (Smith, 1968). These months coincide with a time when the surface is gaining heat. Figure 23, upper left, shows the effect upwelling probably has on the total heat storage from March to June off the Coast of California. The mixed layer depth is increasing from March to April despite a warming of the surface water, and the total heat storage remains lowest during March and April. In a similar manner, the discrepancies shown in Figure 69 in the Gulf of Alaska, off Central America, and on the Equator west of the Galapagos Islands are probably due primarily to the loss of heat due to upwelling. The negative discrepancy on the Equator south of the Hawaiian Islands may also be associated with a loss of heat due to upwelling. Upwelling here in the fall and winter (Knauss, 1960, 1961, 1962) coincides with a period of low net surface heat exchange. In this case, upwelling would tend to amplify the seasonal decline in total heat storage and the observed annual amplitude of total heat storage would be expected to be greater than the theoretical amplitude.

$$
\text { 3. Comparison of the Annual Phase - Figures } 65
$$
and 66 respectively show the results of comparing the 
month of maximum and minimum theoretical and observed total heat storage. The phase agreement is generally good north of $25^{\circ}$ North latitude. At just a few locations scattered throughout this large area the phase comparisons show some disagreement. This phase and annual amplitude disagreement may be attributed in part to inadequate observations. Recall that the temporal coverage of the data in the area northeast of Japan is weak (see Figure 3). In adition, the monthly net surface heat exchange values for this area were interpolated using the data from the closest area to the east. Apparently the seasonal change in total heat storage in the area northeast of Japan is not similar to the area used for interpolation farther east. The other locations of phase disagreement, northwest of Hawail and off the California Coast, have excellent spatial and temporal coverage of data. Here, the phase and amplitude disagreement between theory and observations is probably the result of excluding vertical advection and mixing from the theoretical solution. For example, upwelling off the California Coast during the spring removes heat from this area. But the rate of net surface heating in this area is a maximum during the spring. The result is that the observed amplitude of the total heat storage. is less than the theoretical amplitude because the increase in total heat storage during the spring is delayed. This delay also leads to a phase disagreement. Aside from 
these few locations, the phase agreement for the majority of the Pacific North of $25^{\circ}$ latitude is quite good.

The phase comparisons between the observed and theoretical total heat storage in the Tropical Pacific (south of $25^{\circ}$ North latitude) show large areas where the phases disagree by more than \pm 2 months. This is the result of a number of factors. First, in low latitudes the seasonal change in total heat storage is not great, and the particular months of maxima and minima are less pronounced. Second, close to the Equator the change in total heat storage proceeds through two cycles annually. Frequently two equivalent maxima or minima exist. Therefore, some difficulty is encountered in comparing the observed irregularly-varying monthly values of total heat storage to the comparable smoothly-changing theoretical values of total heat storage. Third, recall also that the spatial coverage of observations is weak in the Western Tropical Pacific (see Figure 2). Some of the phase disagreement may be attributable to data taken that may not best represent the mean annual cycle at each location. Fourth, vertical advection may add to the phase disagreement, particularly in upwelling areas on the Equator and in the Eastern Tropical Pacific. Fifth, the stream function used was independent of time. The circulation in the Equatorial Pacific, however, is not constant (Sverdrup, Johnson and Fleming, 1946, pp. 709-712; Tsuchiya, 1961). Earlier, in 
reviewing the monthly maps of total heat storage we noted that seasonal changes in the Equatorial Countercurrent are probably responsible for the noticeable annual change in total heat stored just north of the Equator. In summation, some phase disagreement would be expected in the Tropical Pacific due to the above factors.

\section{Comparison of the Monthly Results. Eight} locations were selected from throughout the North Pacific and the results plotted to show the seasonal comparison between the observed and theoretical total heat storage at each location. The results, presented in Figures 70 and 71 include plots of the observed total heat storage, theoretical total heat storage, and the net heat exchanged at the surface each month (kcal $\left.\mathrm{cm}^{-2}\right)$. The locations chosen are shown in Figure 1. They were chosen from areas having different annual cycles of surface heat exchange and local heat storage.

Figures 70 and 71 show that the monthly total heat storage computed with the numerical solution of Equation (2) can agree well with the observed total heat storage. In the preceding discussion of the phase comparison, the point was made that the month to month behavior of the unsmoothed observations was occasionally irregular compared to the well behaved theoretical results. An example is shown in the results for the Kuroshio area, Figure 7l, lower left. Most of the slight month to month variations are probably 
the result of using unsmoothed data. Other more pronounced differences between the theoretical and observational results are due to other factors. One such factor is the vertical processes neglected in the theoretical solution. Compare, for example, the curves of the theoretical and observational results at each of the three locations selected from areas of upwelling: on the Equator (Figure 70 , upper right), off the Coast of California (Figure 7I, upper left), and in the Gulf of Alaska (Figure 71 , lower right). The observations show a decrease in the total heat storage during months of upwelling at each location. For example, the sharp drop in total heat storage in the Gulf of Alaska during May to July is very apparent (Tully, 1964). Off the Coast of California March is a month of strong upwelling, (Sverdrup and Fleming, 1941) and the observed total heat storage is decreasing in March. On the Equator, vertical circulation is increased during August (Knauss, 1961) and the total heat storage also declines during August. In each of these cases, the theoretical results do not show a similar decrease in total heat storage during these months. The point is that the theoretical results cannot be made to agree well with the observed monthly total heat storage in areas where vertical advection and mixing through the 250 meter level are important. In the areas of the North Pacific where the vertical processes are probably negligible, as in the 
South Equatorial Current (Figure 70, lower right) and in the North Pacific Current (Figure 71, upper right), the agreement between the observed and theoretical monthly total heat storage is quite good.

D. HEAT STORAGE ANOMALIES. The final theoretical solution was used to examine the behavior of heat storage anomalies in the North Pacific Ocean. Anomalies were generated in two ways. First, hypothetical anomalies simulating abnormal changes in the net surface heat exchange were added to the numerical solution. Second, the circulation in the North Pacific was increased or decreased. In each case the numerical solution was iterated through one or more annual cycles and the growth, movement, interaction, and decay of the anomalies were followed.

1. Magnitude and Location of Hypothetical Anomalies. Experimentation showed that the initial locations chosen for adding local positive or negative heat storage anomalies simulating an abnormal net surface heat exchange could be selected so that at some later stage in the time stepping process the hypothetical anomalies would simulate anomalies that have been observed in the North Pacific Ocean. (Namias, 1959, 1963, 1965 and U.S. Department of the Interior, Fish and Wild Iife Service, 1947 to the present). These initial locations generally corresponded to the locations previously noted where anomalous areas of total heat storage are observed. These 
areas are east of Japan in the Kuroshio, in the Equatorial North Pacific, and in the Eastern Tropical Pacific. Each anomaly simulating an abnormal change in the net surface heat exchange was added to the initial heat storage field for up to 30 days at the start of the iteration process. The anomalous input was then stopped and the iteration was continued for one to three annual cycles. At monthly intervals the theoretical heat storage field without anomalies was subtracted from the heat storage field being computed and the result plotted to show the progress of the anomalies.

The magnitude chosen for each hypothetical anomaly was dependent upon two criteria. The first criterion involved the location where the anomaly was to be added. The observed annual amplitude of the net surface heat exchange at the location in question was used to determine the maximum size of anomaly. The maximum was $50 \%$ of the local annual amplitude. This percentage was arbitrarily selected based upon. the magnitude of the observed transient total heat storage variations (Figures 24 to 35 ). Setting an upper limit on the size of the anomaly insured that an unrealistic anomaly was not added to the heat storage field.

The second criterion used to establish the magnitude of the hypothetical anomalies limited their minimum size. The minimum size is dependent upon the round-off error in the solution. As discussed earlier, the actual numerical 
solution contains some round-off error. Estimates of the magnitude of the error can be calculated. Taylor's expansion is used to develop the finite difference operators representing the terms in the heat conservation equation (Salvadori and Baron, 196I, p. 67). Finite difference theory specifies that the fourth-order terms in this expansion can be considered the error in the numerical solution. Estimates of the size of the error can be calculated using the results of the observed total heat storage. Using the data for the maximum north-south and east-west gradient observed (in the Kuroshio) the maximum

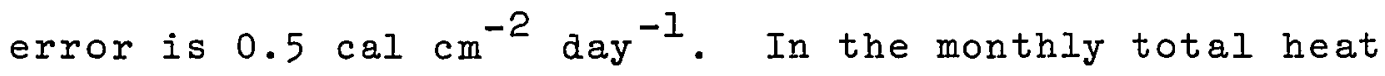
storage fields (Figures 24 to 35 ) the horizontal gradients throughout the majority of the Pacific are much less than in the Kuroshio and, therefore, the error is correspondingly much lower.

\section{Behavior of Hypothetical Anomalies. Many} hypothetical anomalies were tested but only a portion of the results will be discussed. Some examples were selected that typify the initial locations chosen, and the seasonal growth movement and decay of most anomalies tested. Figures 72 and 73 show composite maps of these examples. The figures show the initial location and strength (in cal $\mathrm{cm}^{-2} \mathrm{day}^{-1}$ acting for 21 days) of each hypothetical anomaly. The subsequent behavior of each anomaly is shown in six month steps until the magnitude of the anomaly decays 
to less than $0.5 \mathrm{kcal} \mathrm{cm}^{-2}$.

Ten hypothetical anomalies were added to the North Pacific at the locations shown in Figures 72 and 73 . Each anomaly was applied for the first 21 days of the iterative process. Namias (1953 and 1959) suggests that anomalies in the surface temperature of the ocean may result from increased insulation due to a lack of cloud cover, abnormal wind velocities causing an increase (or decrease) in the rate of evaporation at the surface, or an abnormal shift in the wind direction causing a unique Ekman drift that brings cold (or warm) water into an area. However, his evidence suggests that abnormal wind components are the primary cause for surface temperature anomalies with the winds retaining their abnormal character for up to a month. Therefore, positive and negative anomalies were investigated and the initial duration of each anomaly was arbitrarily set at three weeks. The initial strength of each anomaly is obtained by taking the product of the anomalous surface heat exchange and the duration of the initial anomalous input. For example, the anomaly (Kuroshio) in Figure 72 is initially $-2.9 \mathrm{kcal} \mathrm{cm}^{-2}$ (-140 kcal $\mathrm{cm}^{-2} \mathrm{day}^{-1} \times 21$ days).

Each anomaly shown in Figures 72 and 73 behaves in a somewhat predictable manner. Each moves with the circulation in the direction dictated by the local velocity field. The two anomalies added just northeast of Japan move 
eastward across the Pacific. The anomalies added in the Tropical Pacific move generally westward, and the anomalies added in the Gulf of Alaska move westward along the Alaskan Coast.

As each hypothetical anomaly moves it also diffuses over a larger area. The rate at which each anomaly diffuses differs depending upon its location. The negative anomaly

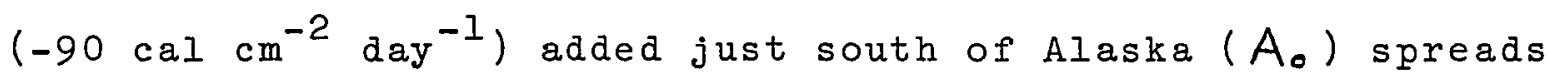
as it moves westward in the Gulf of Alaska. In six months it has decreased in strength from almost $-2 \mathrm{kcal}^{-2}$ to between -0.5 and $0.6 \mathrm{kcal} \mathrm{cm}^{-2}$. At twelve months just a small portion of the anomaly remains equal to $0.5 \mathrm{kcal}$ $\mathrm{cm}^{-2}$. This rapid decay is the result of the greater mixing at high latitudes. Similarly, the positive anomaly $\left(+140 \mathrm{cal} \mathrm{cm}^{-2} \mathrm{day}^{-1}\right)$ starting northeast of $\mathrm{Japan}\left(O_{0}\right)$ moves toward the Aleutian Islands. By the end of the first year it has spread so that its initial intensity of almost

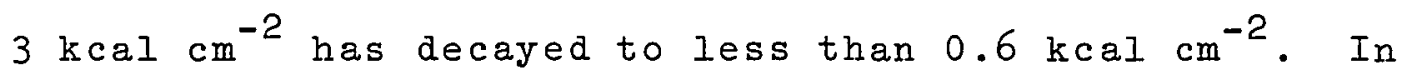

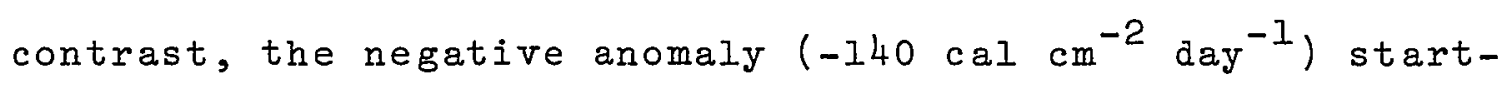
ing northeast of Japan $\left(K_{0}\right)$ with the same initial strength can be followed to the area east of the Hawaiian Islands eighteen months later. The three anomalies added in the Eastern Tropical Pacific ( $H_{0}, C_{0}$ and $E_{0}$ ) can also be followed for twelve to eighteen months. The anomaly initially located east of Hawaii ( $H_{0}=-70 \mathrm{cal} \mathrm{cm}^{-2} \mathrm{day}^{-1}$ ) spreads rapidly during the first six months. In moving 
south this anomaly enters an area where the circulation divides into an eastward and westward flow at approximately $10^{\circ}$ to $20^{\circ}$ North latitude (see Figure 63). This circulation is primarily responsible for the rapid spread of this anomaly during the first six months. In the next year, this large anomaly then moves westward, essentially retaining its strength and configuration $\left(H_{1 z}\right)$ because the mixing at this latitude is weak. However, in the following six months, the anomaly begins moving northwest during which time it decays to less than $-0.5 \mathrm{kcal} \mathrm{cm}^{-2}$.

An anomaly was added west of Panama $\left(E_{0}=-80 \mathrm{cal} \mathrm{cm}^{-2}\right.$ day $^{-1}$ ) at the latitude of the Equatorial Countercurrent $\left(6^{\circ}-8^{\circ}\right.$ North latitude). In the first six months this anomaly spreads north and south. In the next six months the anomaly splits into two smaller anomalies each slightly greater than $-0.5 \mathrm{kcal} \mathrm{cm}^{-2}$. The portion closest to the Equator cannot be followed past twelve months, but the portion that moved northward continues westward for eighteen months. At this latitude (approximately $10^{\circ}$ North) the westward component of the velocity field increases from Panama to south of the Hawaiian Islands. The rapid progress of the anomaly $\left(E_{18}\right)$ is due to this increased westward velocity.

Hypothetical anomalies shown in Figure 73 vere initially placed off Vancouver Island $\left(V_{0}=+60 \mathrm{cal} \mathrm{cm}^{-2} \mathrm{day}^{-1}\right)$ and off the California Coast $\left(C_{0}=-50 \mathrm{cal} \mathrm{cm}^{-2} \mathrm{day}^{-1}\right)$. In 
six months these anomalies move along the coast, but remain within $600 \mathrm{~km}$ to $1000 \mathrm{~km}$ of the coast. The positive anomaly initially off Vancouver Island moves northwest and decays to less than $0.7 \mathrm{kcal} \mathrm{cm}^{-2}$ in six months. The anomaly continues to decay such that it cannot be followed for twelve months. The negative anomaly initially off the California Coast moves southward and diffuses over a larger area. At twelve months it has reached the southern end of Baja California. Note that the anomaly initially starting in this area $\left(C_{0}=-80 \mathrm{kcal} \mathrm{cm}^{-2}\right)$ also moves southeast along the coastline of Mexico and Central America. At six months $\left(C_{6}\right)$ it has combined with the anomaly, and by twelve months $\left(C_{12}\right)$ it has continued along the coastline to approximately $14^{\circ}$ North latitude. Therefore, anomalies added to the model initially as far north as California move into the Eastern Tropical and Equatorial Pacific in eighteen to twenty-four months. The large anomaly added east of $\operatorname{Japan}\left(J_{0}=280 \mathrm{cal}\right.$ $\mathrm{cm}^{-2}$ day $^{-1}$ ) moves eastward and can be followed to the area east of the Hawaiian Islands during the next twenty-four months. At twelve months $\left(J_{12}\right)$ a small portion of the large anomaly is shown separating and by eighteen months ( $\left.J_{18}\right)$ this small portion has moved northwest back toward Japan. This small anomaly is moving around the gyre center shown in Figure 63 just southeast of Japan. Another anomaly is also shown in Figure 73 approaching Japan from the south. 
This anomaly originated twelve months earlier east of Guam Island.

In summary, each anomaly moves with the prevailing circulation. Those anomalies that are carried into the cyclonic gyres north of $40^{\circ}$ North latitude dissipate within one year. Their identity is lost primarily because of the greater mixing at higher latitudes. Thos anomalies that move with the anticyclonic gyres in the Central North Pacific retain their identity up to twenty-four months, particularly if they are in the Tropical Pacific. Though hypothetical anomalies were added to all areas of the North Pacific the only anomalies that retained some identity past a year were those that moved into the Eastern Tropical Pacific. The low rate of mixing and weak circulation in the Eastern Tropical Pacific are primarily responsible. In general, the circulation decreases from west to east across the Pacific. The weakeast circulation is in an area extending approximately $1000 \mathrm{~km}$ off the North American Coast from $45^{\circ}$ to $10^{\circ}$ North latitude. The work of Namias (1953, 1959) and the monthly average and anomaly charts published by the U.S. Fish and Wildlife Service (initiated in 1947) show that extensive anomalies of surface temperature are found in this area of the North Pacific. During 1957 and 1958 the surface water in the Northeast Pacific appeared to move through a warming cycle (Namias, 1959). The data from the U.S. Department of the Interior for 
the Northeast Pacific (Report Number 385, pp. 21-56) and the Eastern Tropical Pacific (Report Number 442, pp. 22-57) show these areas were both anomalously warm and cold during 1947 to 1958 . The results here show that anomalies in these areas could have originated within the area or they may have originated as far west as in the Kuroshio just off Japan.

3. Effect of Increasing or Decreasing the Circulation. Long term heat storage anomalies may result from changes in the oceanic circulation. Namias (1953) and McGary (1958) examined the effect of large-scale anomalous atmospheric circulation on the oceanic circulation. They conclude that the change in the atmospheric circulation generally has to persist for more than one month to affect the ocean circulation. A number of changes in the strength of the circulation in each gyre of the North Pacific were tried to determine the consequences of increasing or decreasing the circulation for as long as one year. As in the preceeding discussion of hypothetical anomalies, all of the results cannot be shown here; therefore, two results were chosen. Figures 74 and 75 respectively show the consequences of increasing or decreasing the circulation throughout the entire North Pacific ocean by $10 \%$. In each figure the total heat storage field previously computed for the end of the year has been subtracted from the new heat storage field, and 
only the difference is shown in each figure.

Figure 74 clearly shows that increasing the circulation $10 \%$ for one year results in an increase up to $23 \mathrm{kcal} \mathrm{cm}^{-2}$ of heat advected into the area east of Japan. This heat was lost from the Western Tropical Pacific, primarily from

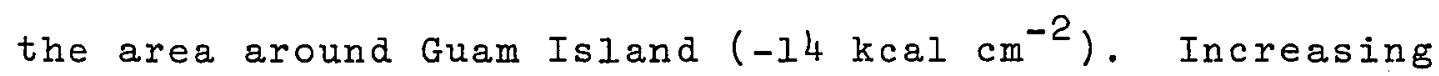
the circulation also results in a slight accumulation of heat in the entire Northeast Pacific due to an increase in warm advection. Note that this increase in warm advection affects just a narrow zone across the Pacific at approximately $45^{\circ}$ North latitude. South of approximately $40^{\circ}$ North latitude there is a net loss of heat during the year of anomalous circulation. The North Pacific Anticyclonic gyre also gains heat in a small area approximately 1000 $\mathrm{km}$ west of the Hawaiian Islands. This small local gain of $8 \mathrm{kcal} \mathrm{cm}^{-2}$ primarily results from changes in the East Pacific Anticyclonic gyre (see Figure 63).

The changes in the total heat storage field during the year show the slow development of the above large areas of heat surplus and heat deficit. In February the Western Pacific from $12^{\circ}$ to $42^{\circ}$ North latitude begins showing a surplus of heat $\left(9 \mathrm{kcal} \mathrm{cm}^{-2}\right)$. A large area of heat surplus also forms in the Central Pacific ( $2 \mathrm{kcal} \mathrm{cm}^{-2}$ ) and Eastern Pacific ( $3 \mathrm{kcal} \mathrm{cm}^{-2}$ ) with a branch of this area at $20^{\circ}$ North latitude extending westward almost to Guam Island. By July, the area east of Japan has accumulated more heat, with a high of $22 \mathrm{kcal}^{-2}$ developing 
just off the Coast of Japan. In July the large surplus previously located in the Central Pacific has moved westward, joining another area of heat surplus southeast of the Aleutian Islands. The long branch previously extending westward at $20^{\circ}$ North latitude from the Eastern Pacific has moved back east of the Hawaiian Islands leaving a small area of heat surplus west of the Hawaiian Islands and an area of heat deficit around Guam Island. Figure 74 shows the result six months later. By January the area of heat surplus east of Japan has increased and the high (23 kcal $\mathrm{cm}^{-2}$ ) has moved eastward. Between Japan and Taiwan the heat surplus that was in this area until september has changed to a heat deficit. The large area of heat surplus originated in the Central Pacific has moved into the Northeast Pacific, and the heat deficit around Guam has increased.

Large positive heat anomalies have been observed in the Northeast Pacific (Namias, 1959). The above results indicate that these large anomalies could develop from changes in the circulation strength. When compared to local hypothetical anomalies these large anomalies of heat surplus or deficit are considerably greater in size and they do not dissipate as rapidly.

Figure 75 shows the results of decreasing the circulation $10 \%$. The area east of Japan shows a deficit of total heat storage as high as $-20 \mathrm{kcal} \mathrm{cm}^{-2}$, and an accumulation 


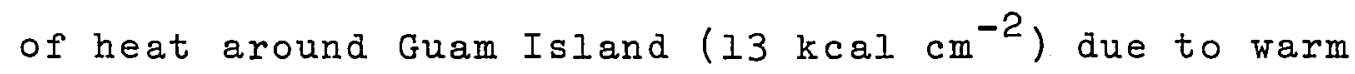
advection from the Eastern Pacific. Decreasing the circulation in the Equatorial region also results in a deficit of total heat storage in this area. Slowing the Equatorial Countercurrent decreases the amount of heat carried east. The result is a narrow zone of heat deficit extending from the Philippine Islands almost to the Galapagos Islands. Decreasing the circulation also leads to a narrow zone of heat deficit extending across the Pacific at $45^{\circ}$ North latitude and a deficit of total heat storage throughout the major portion of the Northeast Pacific. The monthly development of the areas of heat deficit and surplus is as discussed when increasing the circulation, but with the areas of surplus and deficit reversed. 


\section{SUMMARY AND CONCLUSIONS}

The results presented in the first part of this work gave a quantitative description of the seasonal heat storage in the 0 to 250 meter surface layer of the North Pacific Ocean. The data are examined to find the mixed layer depth and to determine how it varies seasonally. Using the mixed layer depth, the 0 to 250 meter surface layer was divided into a mixed and thermocline layer, and the monthly heat storage, the annual average heat storage, and the annul amplitude were found and briefly discussed for each layer. The total heat storage in the 0 to 250 meter surface layer was found and discussed. The results were presented in maps covering the North Pacific Ocean.

The seasonal change in the mixed layer depth was found to be greatest in high latitudes, particularly in the Gulf of Alaska and the Bering Sea (approximately 180 meters), while the seasonal change was least in the Eastern Tropical Pacific ( 10 meters). During the period from December to April the mixed layer depth is greater than 100 meters over most of the Pacific North of $30^{\circ}$ North latitude. From May to september a shallow mixed layer (20 meters to 40 meters) develops North of $30^{\circ}$ latitude. 
This layer begins developing in the Western Central North Pacific and spreads throughout most of the North Pacific by July. During October the shallow mixed layer begins deepening north of the Alaskan Peninsula and by November has increased to approximately 80 meters throughout the Pacific North of $30^{\circ}$ North latitude. In the Western Equatorial North Pacific the seasonal change in the mixed layer depth is slight (20 to 40 meters). However, the seasonal change occurring in the Central and Eastern Equatorial Pacific is greater ( 40 to 94 meters). The mxed layer depth is greatest here ( 140 meters) in September, when the mixed layer depth in most of the Pacific north of $10^{\circ}$ North latitude is shallowest. The annual average mixed layer depth ranges from 15 meters off the Coast of Panama to 121 meters in the Bering sea. The overall geographic mean of the annual average mixed layer depth is 75 meters. The annual average mixed layer depth in the Central Pacific is slightly shallower (approximately 65 meters), and is greater in high and low latitudes (approximately 100 meters).

The descriptive results show that the greatest amount of heat is stored every month in the Western Tropical Pacific (approximately $610 \mathrm{kcal} \mathrm{cm}^{-2}$ ). The total heat storage decreases eastward and northward from this area, with the minimum amount of heat storage found in the Bering Sea (approximately $40 \mathrm{kcal} \mathrm{cm}^{-2}$ ). On the average, the 
maximum total heat storage is reached between september and November and the minimum is found between January and April. The strong east-west orientation of the heat storage contours throughout most of the North Pacific shows that the ocean responds strongly to the annual wave of heating and cooling at the surface. The annual amplitude of the variation in total heat storage is least in the Western Tropical Pacific (usually less than $7 \mathrm{kcal} \mathrm{cm}^{-2}$ ). The annual amplitude increases to 10 to $30 \mathrm{kcal}^{-2}$ in the Eastern Tropical Pacific and at high latitudes, and is greatest just southwest of Japan (up to $90 \mathrm{kcal} \mathrm{cm}^{-2}$ ). Other areas where the annual change in total heat is greater than $50 \mathrm{kcal} \mathrm{cm}^{-2}$ are found south and north of the Hawaiian Islands, on the Equator, and off the Coast of Alaska.

A comparison of the annual phase of the total heat storage and the net surface heat exchange shows that the lag of the total heat storage behind the net surface heat exchange in the Pacific increases from approximately one month at the Equator to approximately two and one-half months at $35^{\circ}$ to $45^{\circ}$ North latitude. Farther north the phase lag again decreases. This deviation from a 3 months phase lag is attributed to the seasonal redistribution of heat in the North Pacific by advection. A comparison of the local annual amplitude of total heat storage with the annual amplitude of the nt surface heat exchange shows that, on the average, advection and mixing combined are equal to 
or greater in importance than the heat exchange at the surface in determining the local thermal structure. On the average, throughout the North Pacific, the annual amplitude of the total heat storage is 2.2 times the annual amplitude of the net surface heat exchange. In the simple case, using sinusoids to approximate each process, the annual amplitude of combined advection and mixing was approximately 1.4 times greater than the annual amplitude of the net surface heat exchange. The simple analysis shows that, on the average, combined advection and mixing lead the net surface heat exchange by 2 months. The result is that the annual amplitude of the total heat storage is amplified over most of the North Pacific by advection. The contribution to the local change in total heat storage due to horizontal mixing was computed. Mixing was found to contribute from 10 to $38 \%$ of the local monthly change in total heat storage where the Kuroshio and Oyashio currents meet east of Japan. Other areas where mixing is important are located west of Vancouver Island and south of the Aleutian Islands. Elsewhere in the North Pacific, mixing contributes generally less than $10 \%$ to the local monthly change in total heat storage. On the average for the entire North Pacific mixing contributes $8 \%$, advection $54 \%$, and the net surface heat exchange $38 \%$ to the local change in total heat storage. The heat conservation equation was used to find the 
monthly contribution to the local change in total heat storage due to advection. The equation was first simplified to two dimensions by assuming that the turbulent downward flux of heat is balanced by vertical advection of cold water. The monthly contribution due to horizontal mixing and to the net surface heat exchange were then subtracted from the local change in total heat storage, to obtain the monthly contribution due to advection. The results show that, on the average, the North Pacific in the area from Taiwan to approximately $4000 \mathrm{~km}$ east of Japan, the Bering Sea, and in the Gulf of Alaska gains up to $424 \mathrm{cal} \mathrm{cm}^{-2} \mathrm{day}^{-1}$ due to advection. A large area east of the Hawaiian Islands also gains a slight amount

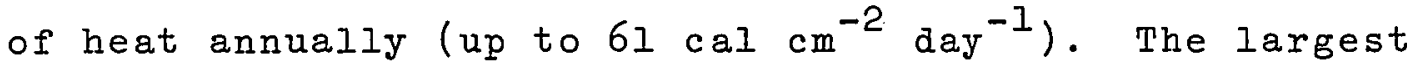
heat losses due to advection are off the East Coast of

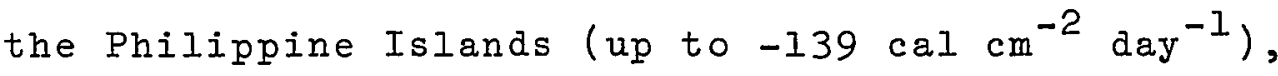

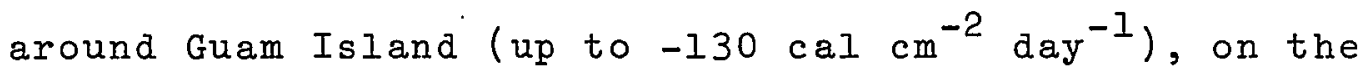

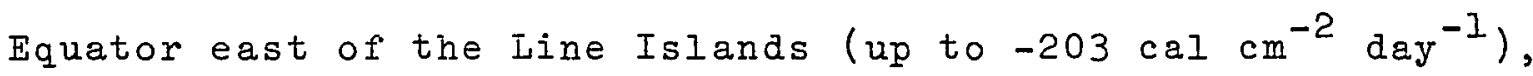
and off the coast of Mexico and Central America (up to $-186 \mathrm{cal} \mathrm{cm}^{-2} \mathrm{day}^{-1}$ ).

Advection can vary considerably from month to month. During the year areas of high heat gain and loss are found throughout the North Pacific. These areas are found between Taiwan and Japan, in the Kuroshio, in the Gulf of Alaska close to the coastline, around the Hawaiian Islands, on the Equator and just east of the Philippine 
Islands. Upwelling may contribute to the heat loss in some of these areas. High losses are found in the Gulf of Alaska during July, off the California Coast from March to May, off the coast of Central America during October and November, and on the Equator from July to November. The monthly results show that areas such as that north of Taiwan, may accumulate heat for a number of months and release this heat in subsequent months. The advection can be in or out of phase with the local net surface heat exchange. If in phase the local heat storage is considerably amplified, as northeast of the Hawaiian Islands. If out of phase the annual amplitude of the local heat storage is decreased, as west of Vancouver Island. If the advection leads the local net surface heat exchange by $41 / 2$ to $71 / 2$ months, the annual amplitude of the total heat storage and the amplitude of the net surface heat exchange can be close to equal, even though the amount of heat advected is high. This is the case just off the coast of Japan.

In general, advection is responsible for heat transfer from the Eastern and Western Tropical Pacific to the Northwest Pacific. The heat loss in low latitudes occurs in two ways. Heat leaves the western side of the North Pacific from approximately Guam Island to the Philippine Islands, and cold water enters the Eastern Pacific in the area from Midway Island to the California 
Coast. The largest heat gain in high latitudes occurs in the Kuroshio south of $35^{\circ}$ North Iatitude. This heat apparently is distributed in subsequent months throughout the Northwest Pacific.

A theoretical model of the seasonal changes in total heat storage throughout the North Pacific was developed using the two-dimensional heat conservation equation. The purpose of the model was to gain more insight into the mixing and advection processes in the North Pacific and to determine how well the two-dimensional heat conservation equation models the 0 to 250 meter surface layer of the North Pacific. The model was developed by specifying the mixing coefficient and an initial heat storage field, using a stream function go give the horizontal velocities and time stepping the equation in daily steps through an annual cycle. The mixing coefficient and the stream function were altered and the time stepping repeated until the best agreement was obtained between the theoretical and observed total heat storage.

The results show good agreement between the theoretical and observed annual amplitude and phase of total heat storage was obtained over most of the North Pacific Ocean. This suggests that the vertical processes of mixing and advection are very small over the majority of the North Pacific and can essentially be neglected compared to the local seasonal changes in total heat storage. The 
discrepancy existing between the observations and the total heat storage predicted by the theoretical model gives some information on the areas where vertical processes are probably important. Upwelling, for example, in the Gulf of Alaska, off the coast of California, off Central America, and on the Equator is probably responsible for the discrepancies existing between the theoretical and observed results in these areas. These discrepancies range from $22 \mathrm{kcal} \mathrm{cm}^{-2}$ (off the coast of California) to $11 \mathrm{kcal} \mathrm{cm}^{-2}$ (off the coast of Alaska). The discrepancy existing on the western side of the Pacific was attributed to a loss of heat to greater depths. Heat is probably mixing downward in the area from Taiwan to Japan.

Information on the importance of horizontal mixing and the mean horizontal velocity field in the North Pacific was gained from the theoretical model. A variable mixing coefficient was found to be preferable to a constant mixing coefficient in improving the agreement between the observed and theoretical monthly total heat storage, when using a constant mixing coefficient. The coefficient used increases by a factor of 11 from $1 \times 10^{6} \mathrm{~cm}^{2} \mathrm{sec}^{-1}$ at $8^{\circ}$ North to $60^{\circ}$ North latitude. A maximum volume transport of $42 \times 10^{6} \mathrm{~m}^{3} \mathrm{sec}^{-1}$ was required for the advective transport of heat to higher latitudes in the North Pacific Anticyclonic gyre. In adition, an East Pacific gyre of $32 \times 10^{6} \mathrm{~m}^{3} \mathrm{sec}^{-1}$ located southeast of the 
Hawaiian Islands was found necessary to improve the agreement in the Eastern North Pacific.

The theoretical model was used to examine the consequences of adding hypothetical heat storage anomalies to the solution and of altering the strength of the horizontal circulation. Anomalies simulating an abnormal period of net surface heat exchange were added in numerous places throughout the North Pacific and were followed until each anomaly decayed to less than $0.5 \mathrm{kcal} \mathrm{cm}^{-2}$. The results show that each anomaly moves with the prevailing circulation. Those anomalies carried into the Pacific north of approximately $40^{\circ}$ North latitude dissipate quickly due to horizontal mixing. Those carried south can be followed for many months. For example, anomalies originating in the Kuroshio can be followed to the Eastern Central Pacific. Anomalies originating in or moving into the Eastern Pacific retained their identity longest. This is primarily due to the weak model circulation in the Eastern Pacific.

Both increasing and decreasing the circulation in the North Pacific primarily affected the Western Pacific. For example, increasing the circulation $10 \%$ for one year leads to a: large area of heat surplus (up to $23 \mathrm{kcal} \mathrm{cm}^{-2}$ ) that extends from Japan $3000 \mathrm{~km}$ eastward. In addition, a heat deficit (up to $-14 \mathrm{kcal} \mathrm{cm}^{-2}$ ) results in low latitudes in the area from the Philippine Islands to the Marshall Islands. 
A slight heat surplus also develops in the Equatorial Pacific and in the Gulf of Alaska. The heat surplus anomaly that developed in the Gulf of Alaska in one year was much larger in size and more persistent than that caused by any simulated surface heat exchange anomaly. In general, large anomalous areas of total heat storage were easily generated by changes in the strength of the circulation. Similar large anomalous areas were more difficult to develop even using large simulated surface heat exchange anomalies. Surface heat exchange anomalies tended to dissipate in the Gulf of Alaska during one year. Increasing the circulation, however, leads to the development of a large anomaly in one to three months that seems to be maintained by the increased circulation during the remaining months of the year. 
V. APPENDIX

131 


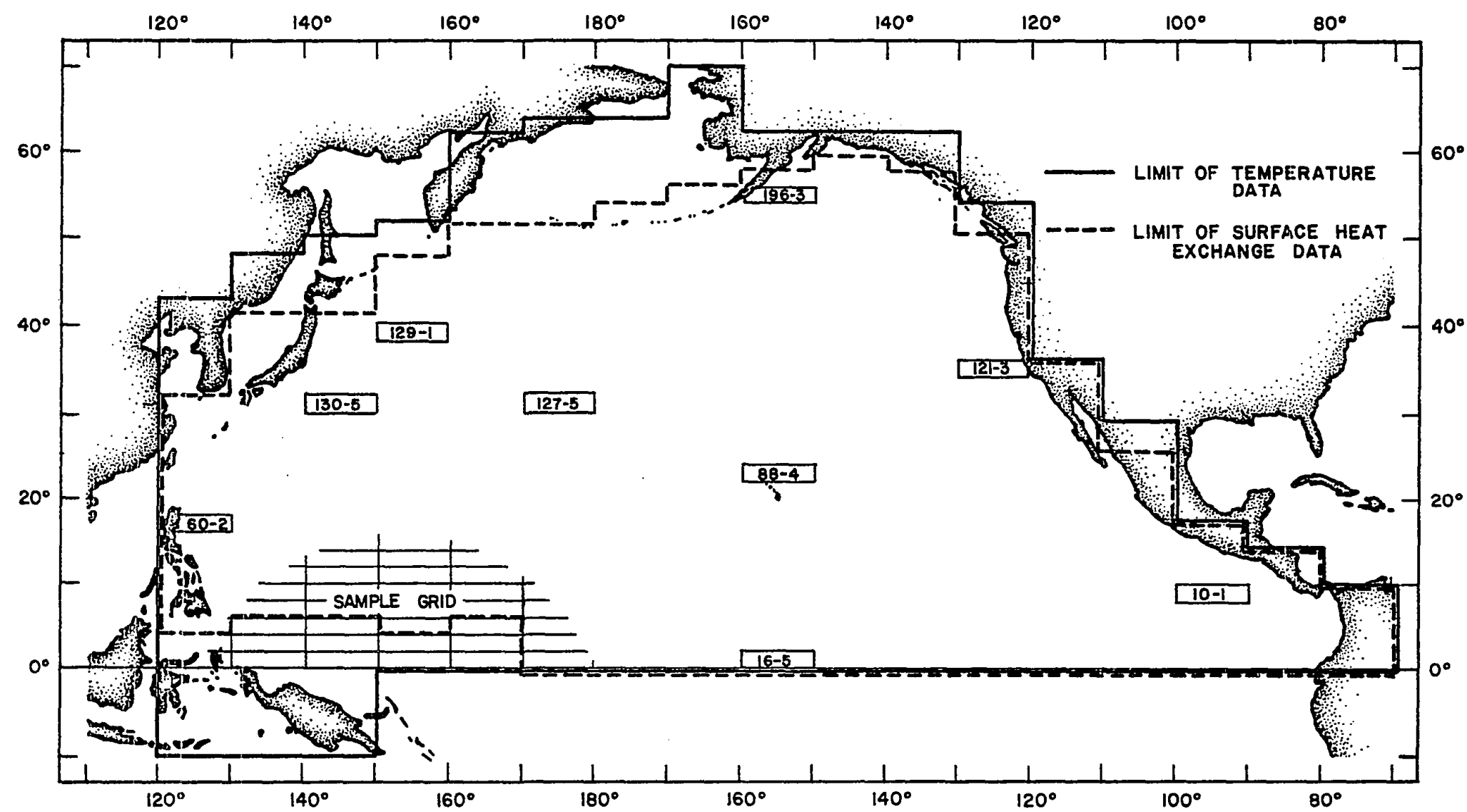

Figure 1 Reference Map. The Figure shows the limit of the temperature and surface heat exchange data, a sample of the grid used for the data reduction and the theoretical model, and the location of nine areas referred to in the text (see Figures 22, 23, 70 and 71). 


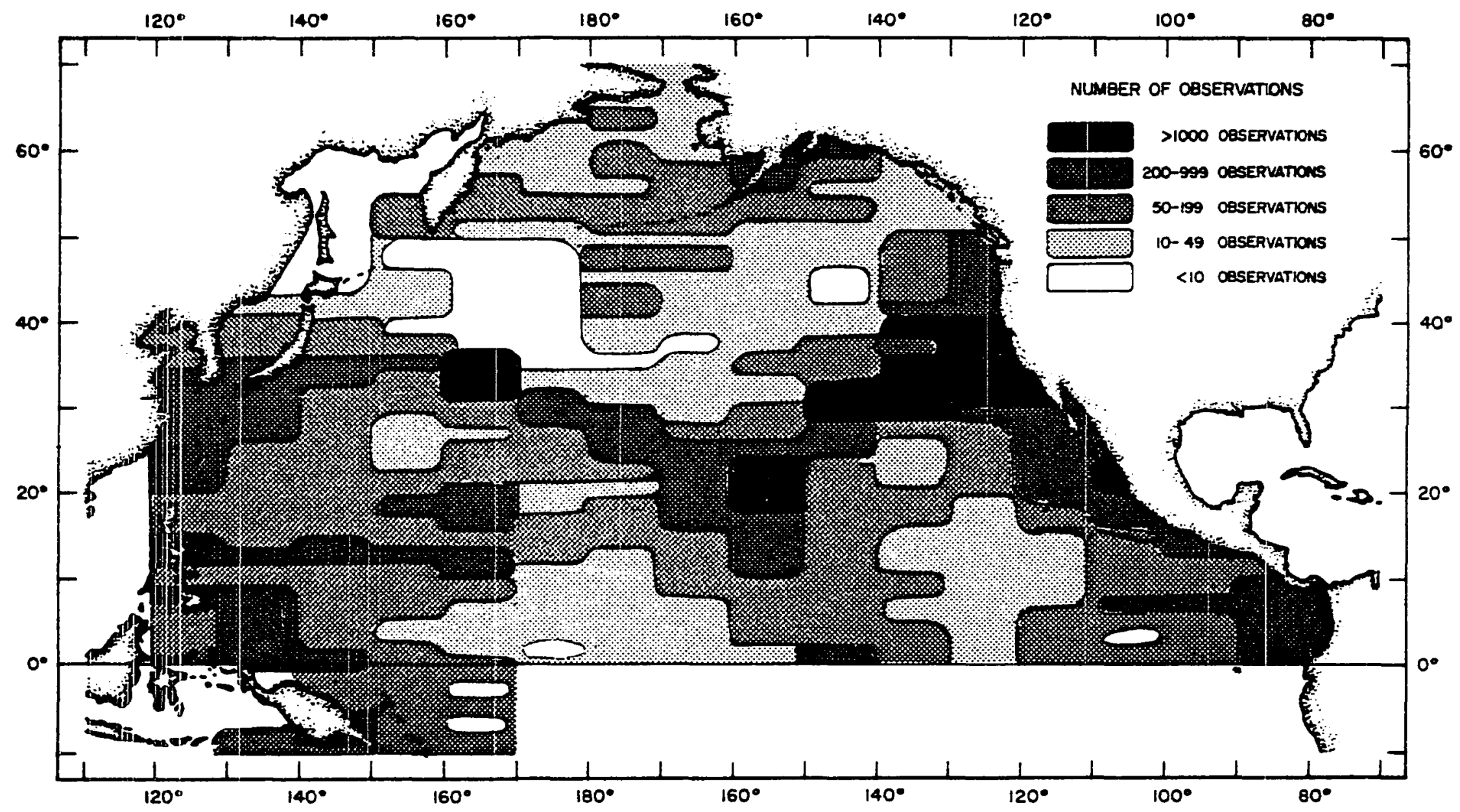

Figure 2 Spatial Coverage of the Temperature Data. 


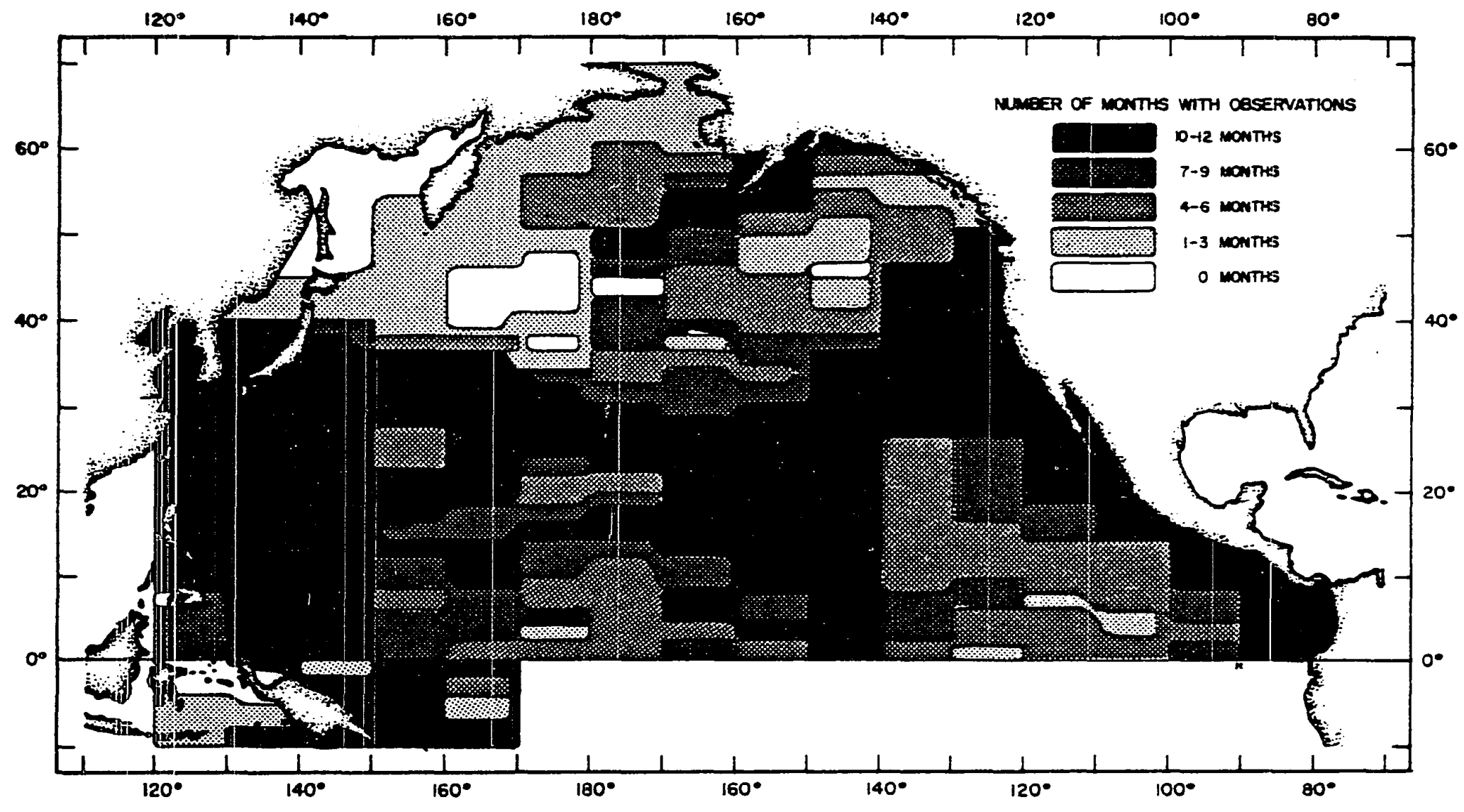

Figure 3 Temporal Coverage of the Temperature Data. 


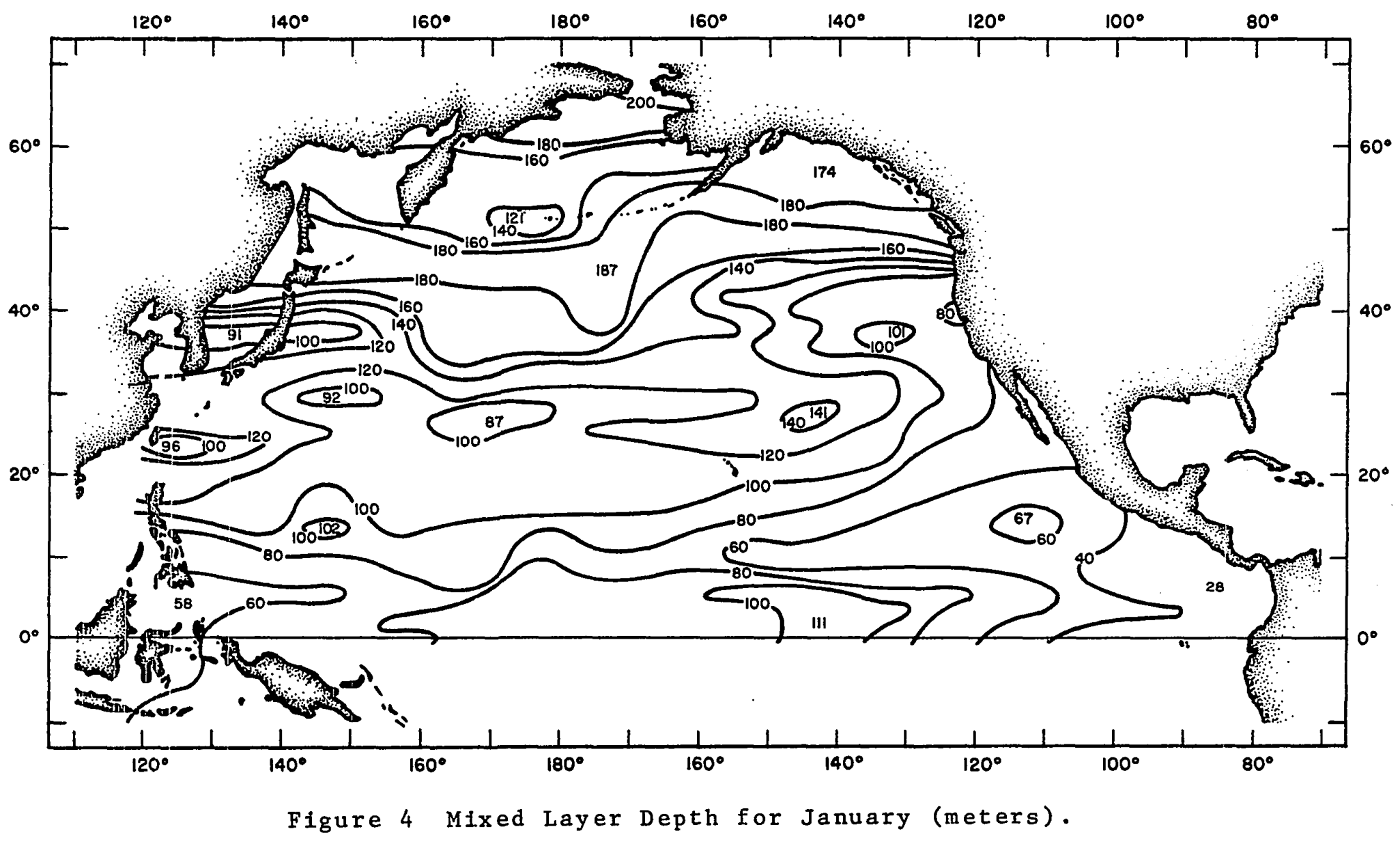

$\stackrel{\omega}{w}$ 






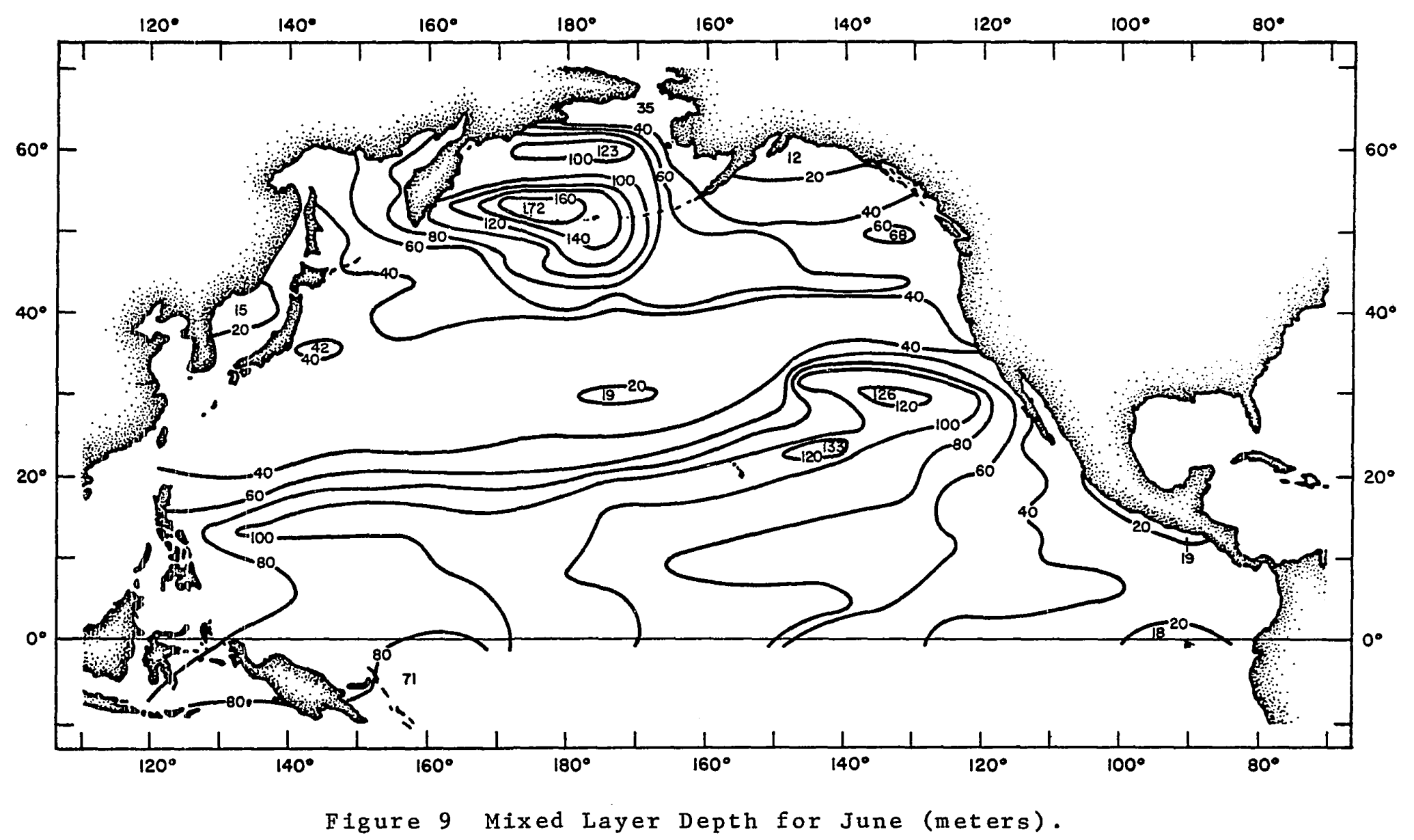





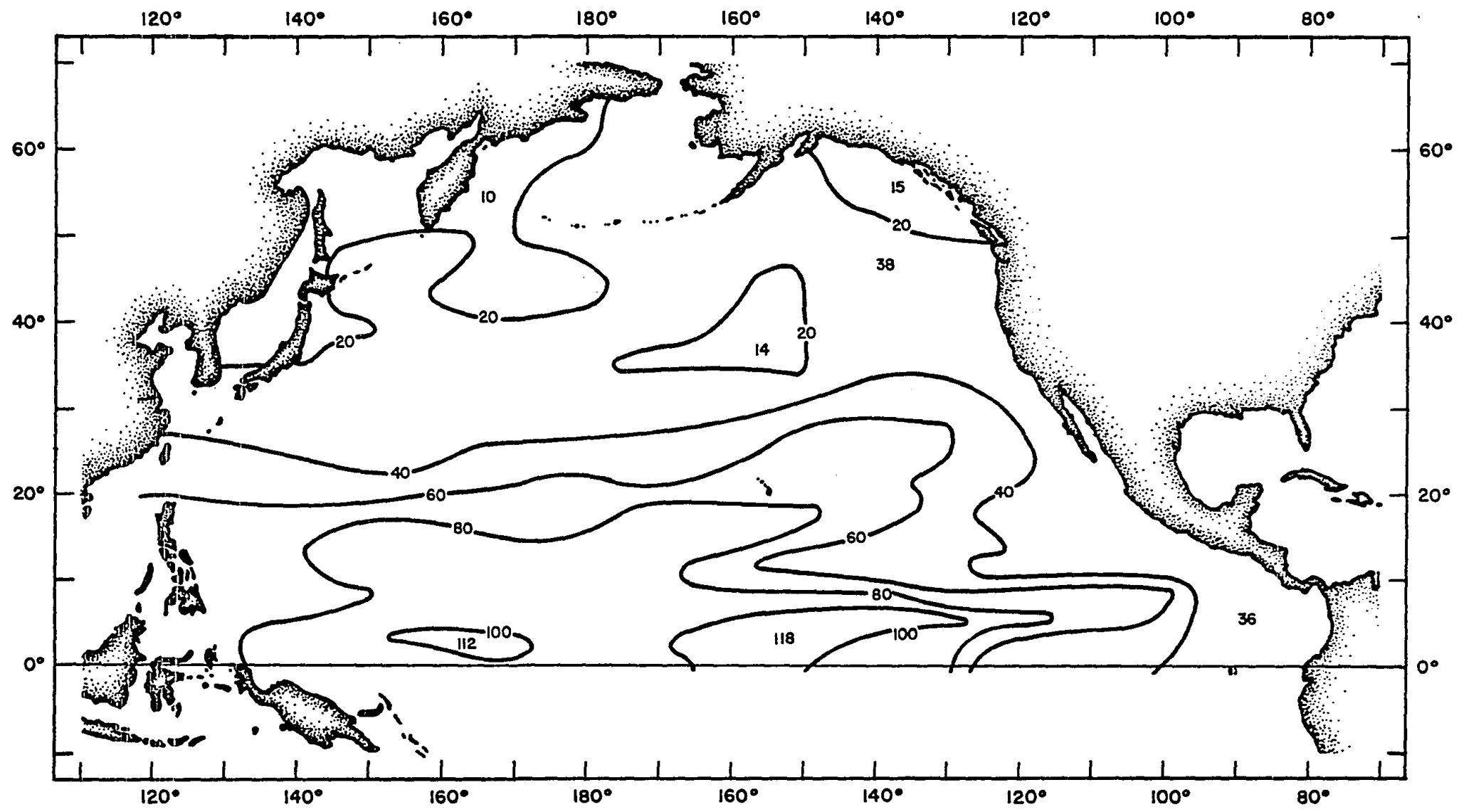

Figure 11 Mixed Layer Depth for August (meters).

$\stackrel{\leftarrow}{N}$ 


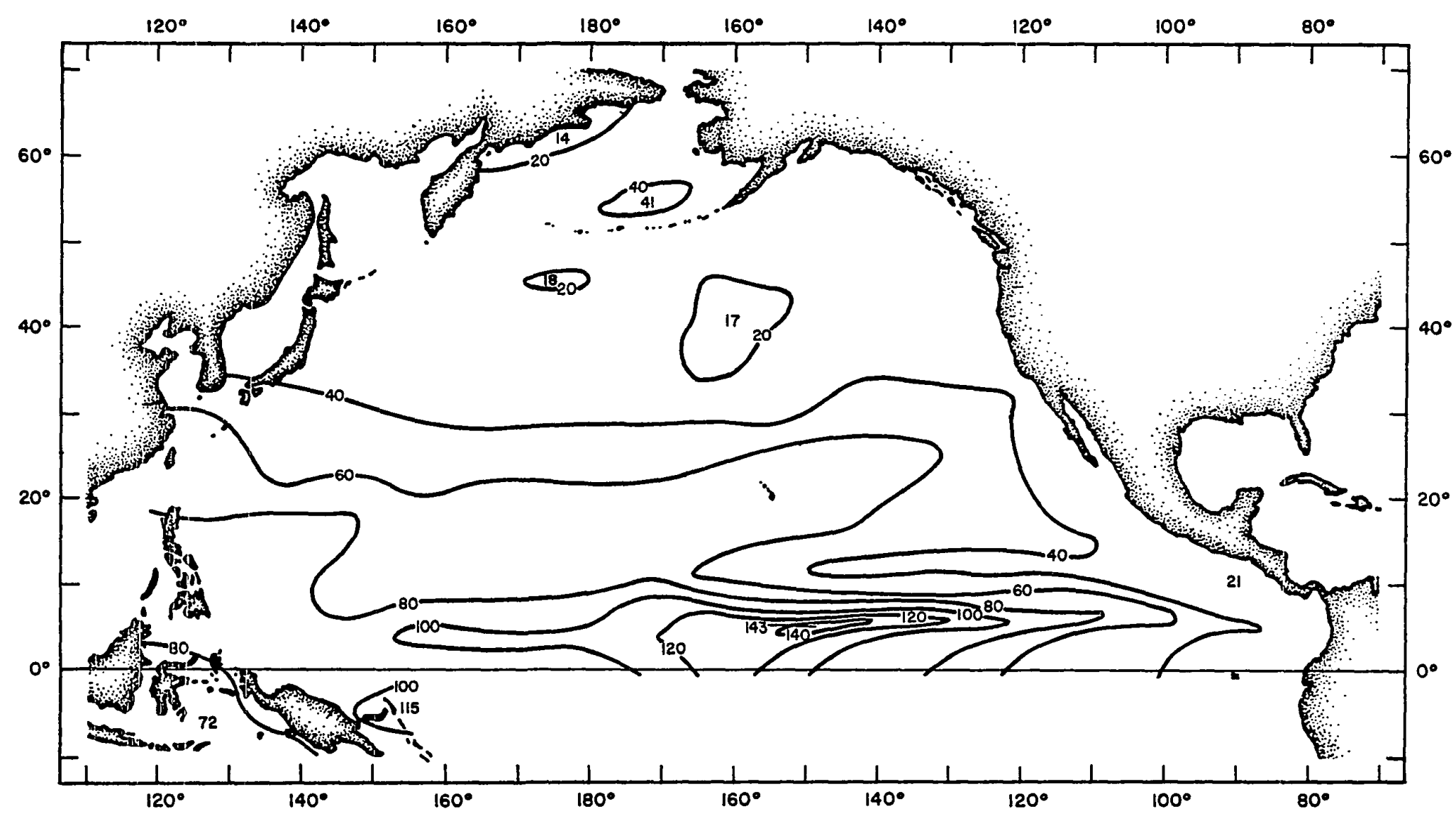

Figure 12 Mixed Layer Depth for September (meters). 


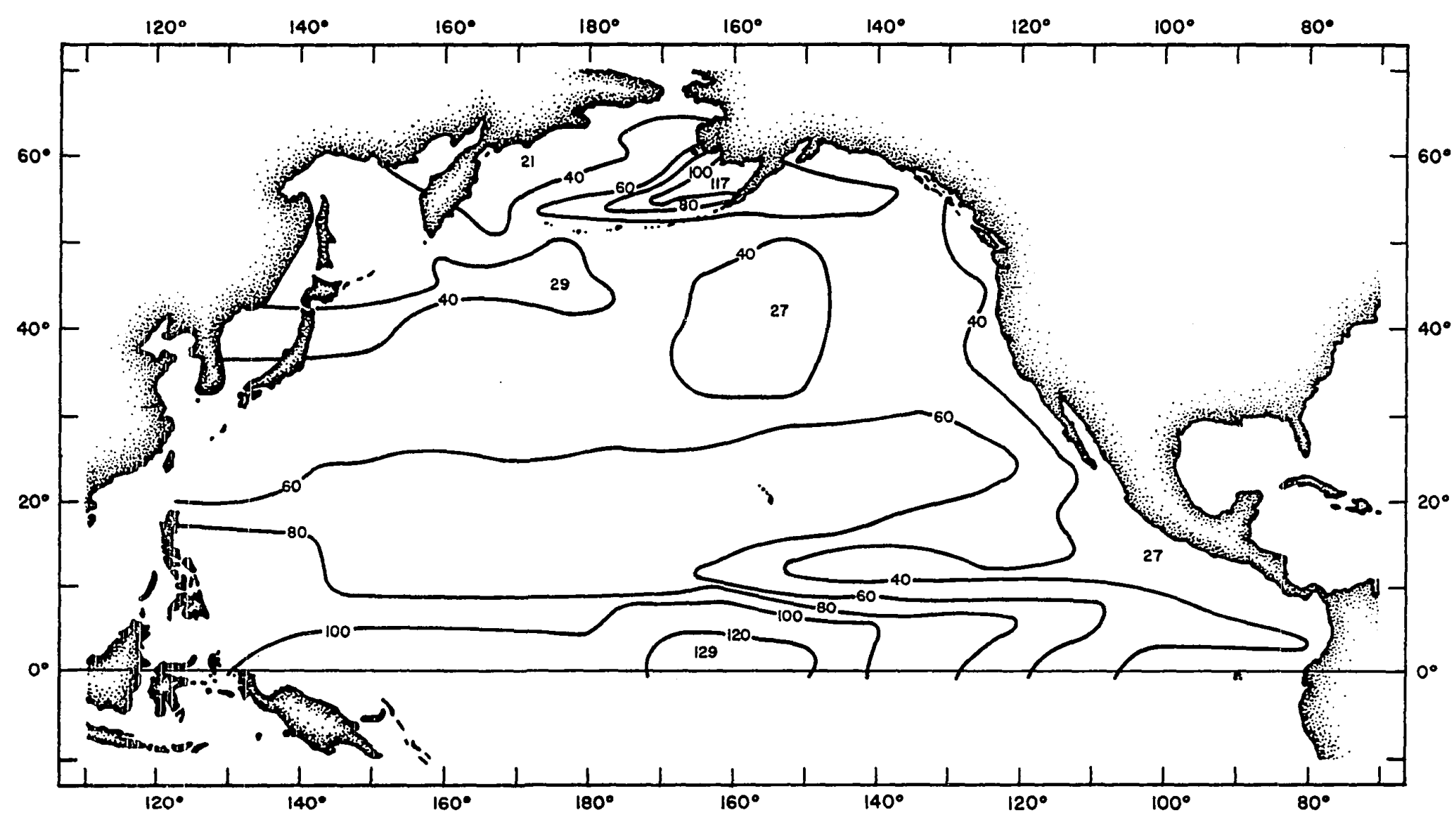

Figure 13 Mixed Layer Depth for October (meters). 




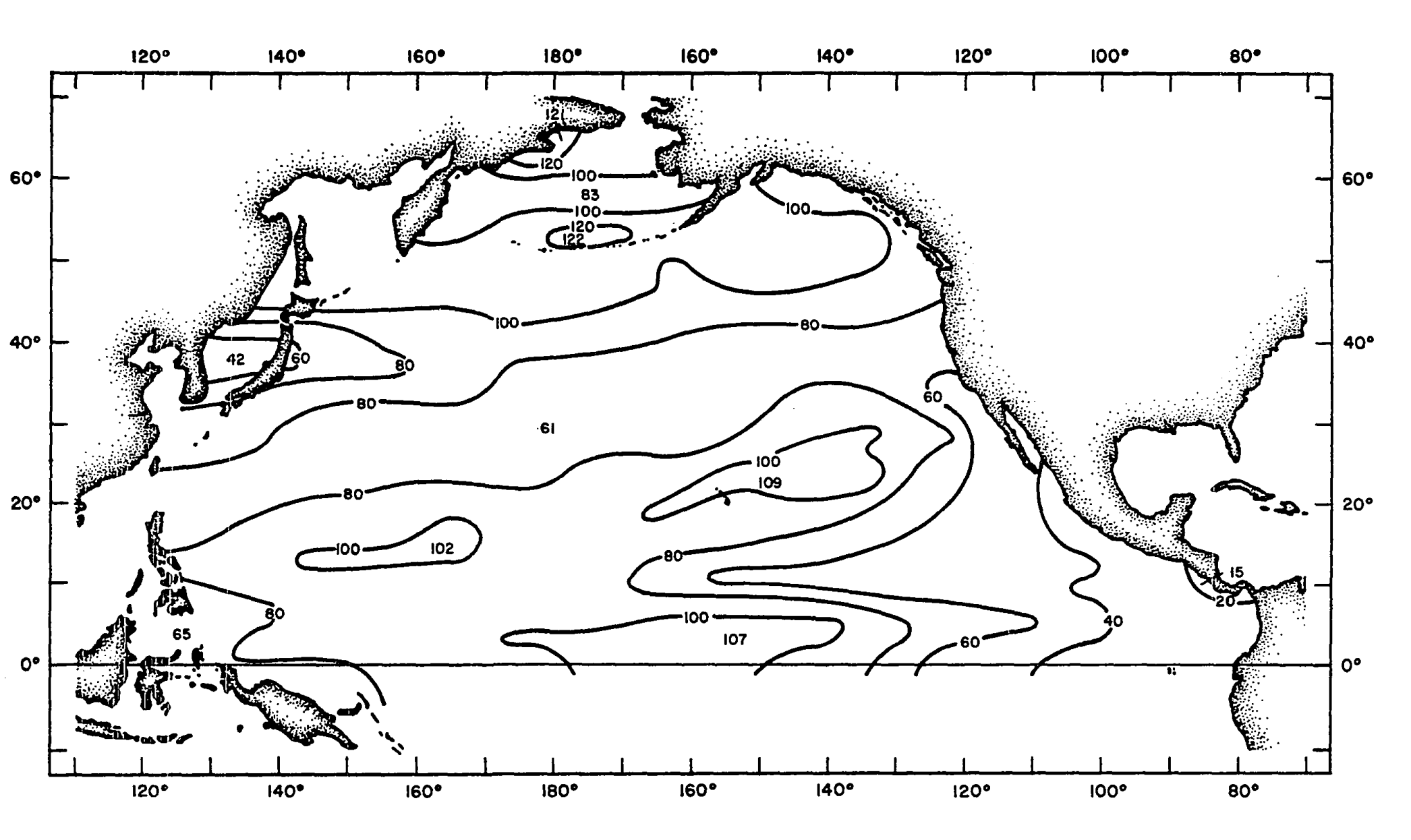




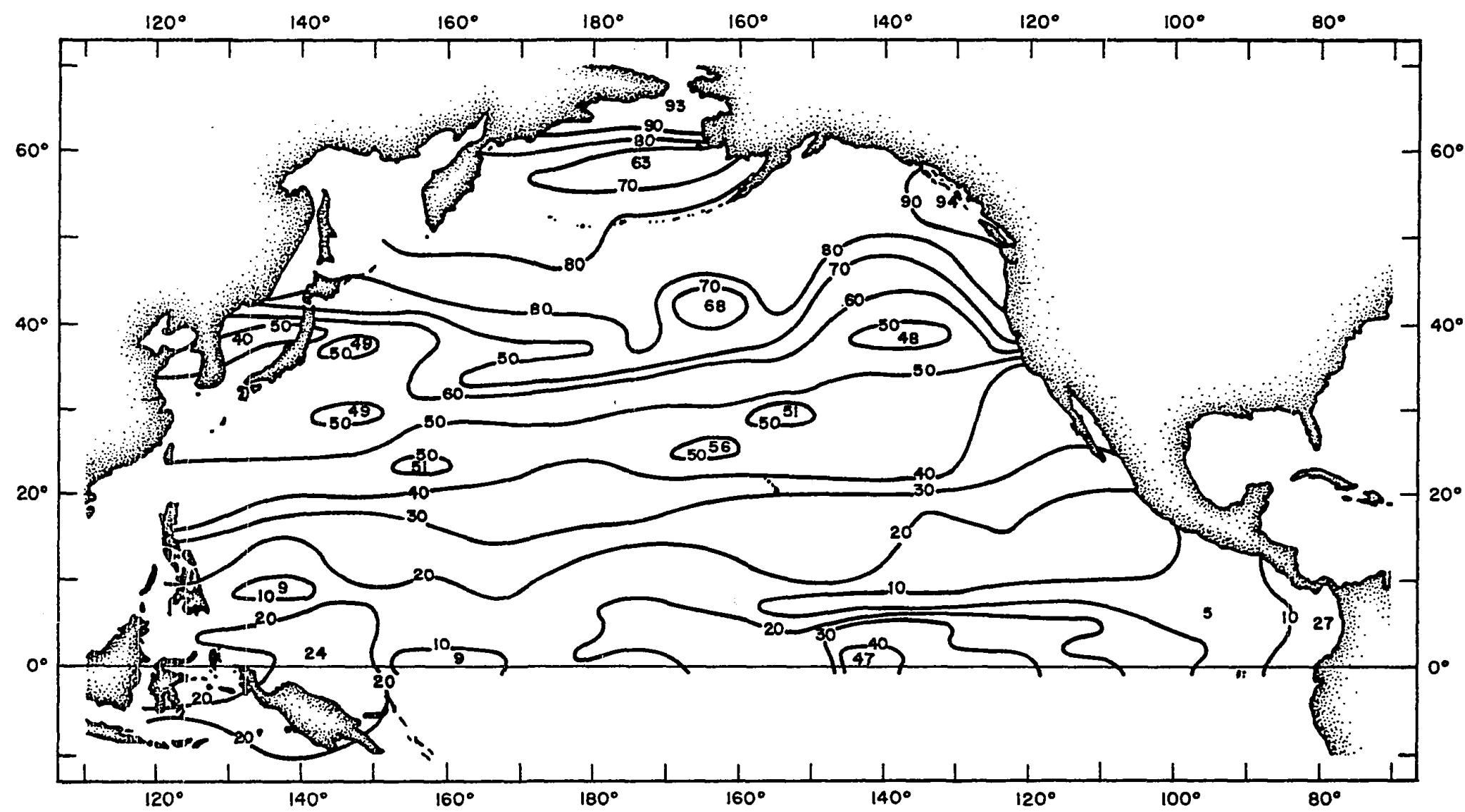

Figure 17 Annual Amplitude of the Mixed Layer Depth (meters). 
<smiles>CCCCCCCCCCCC</smiles> 


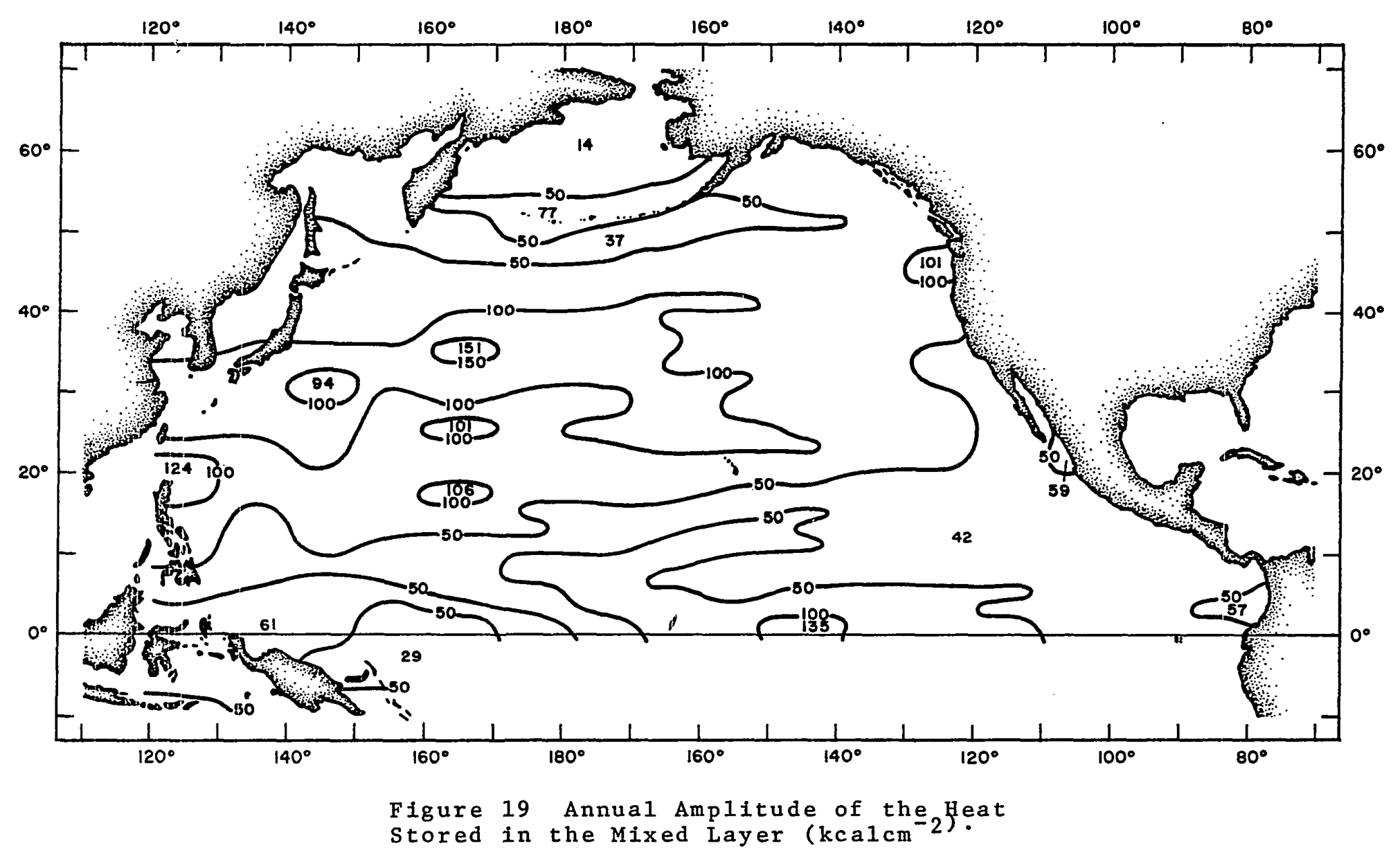




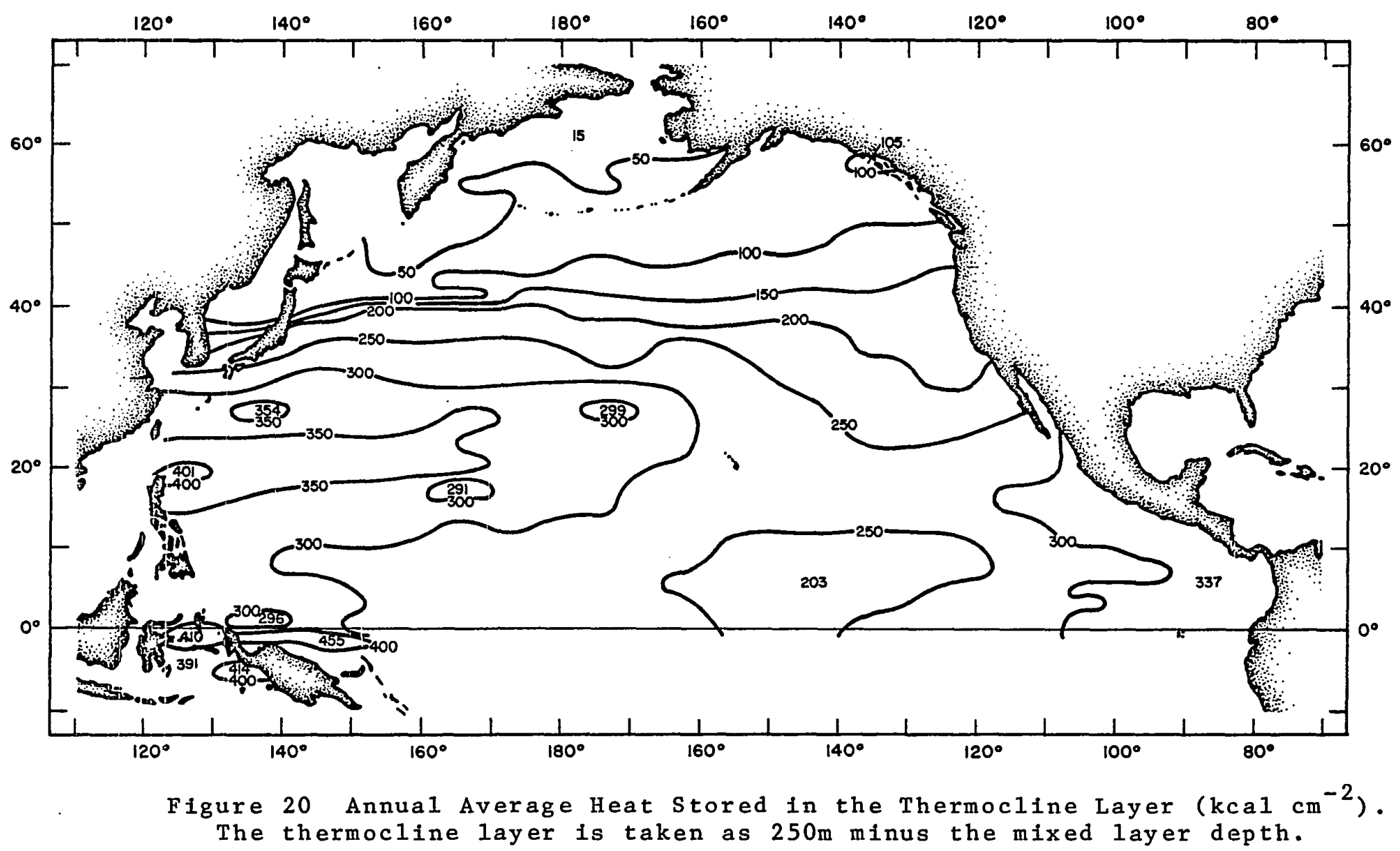




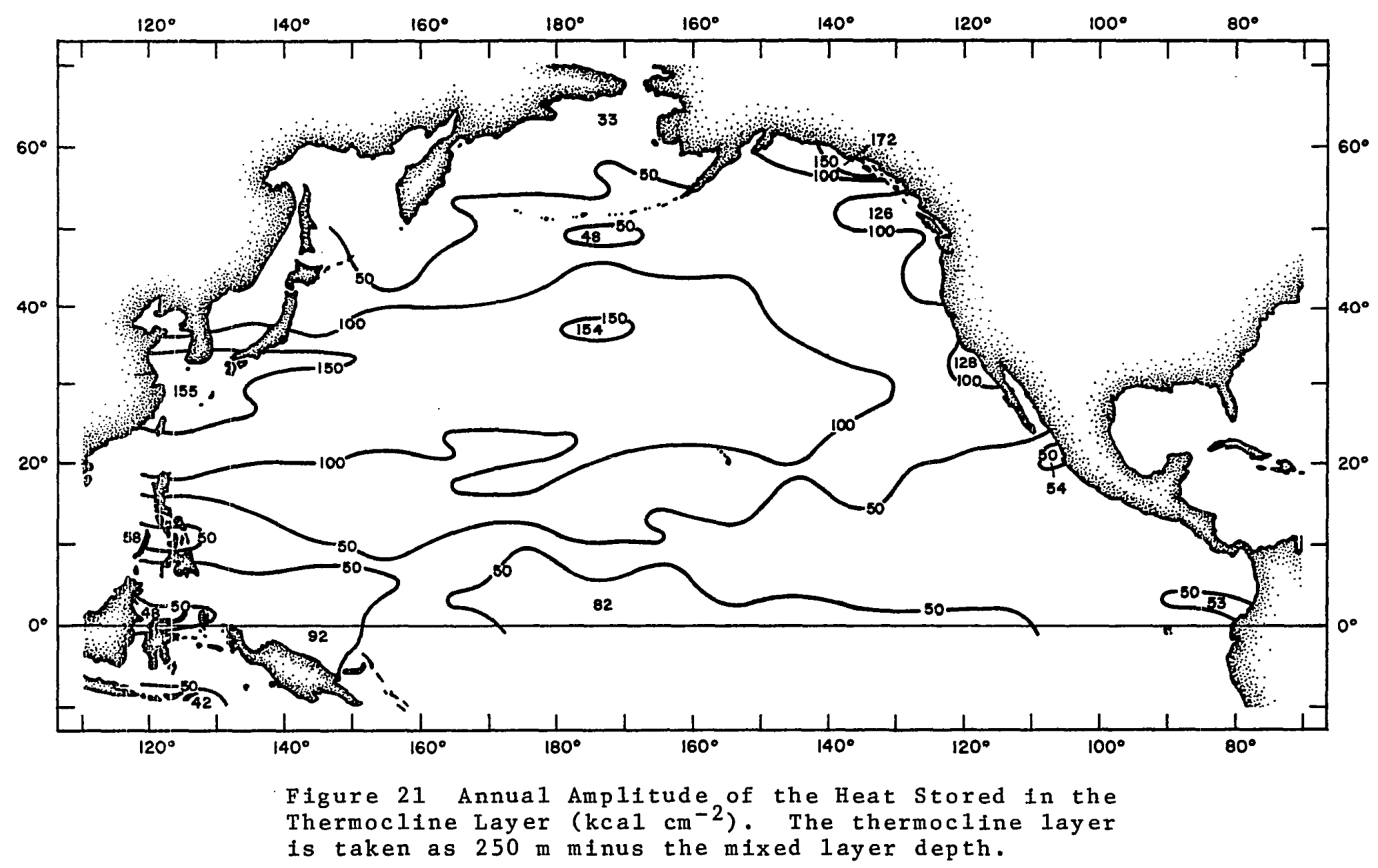



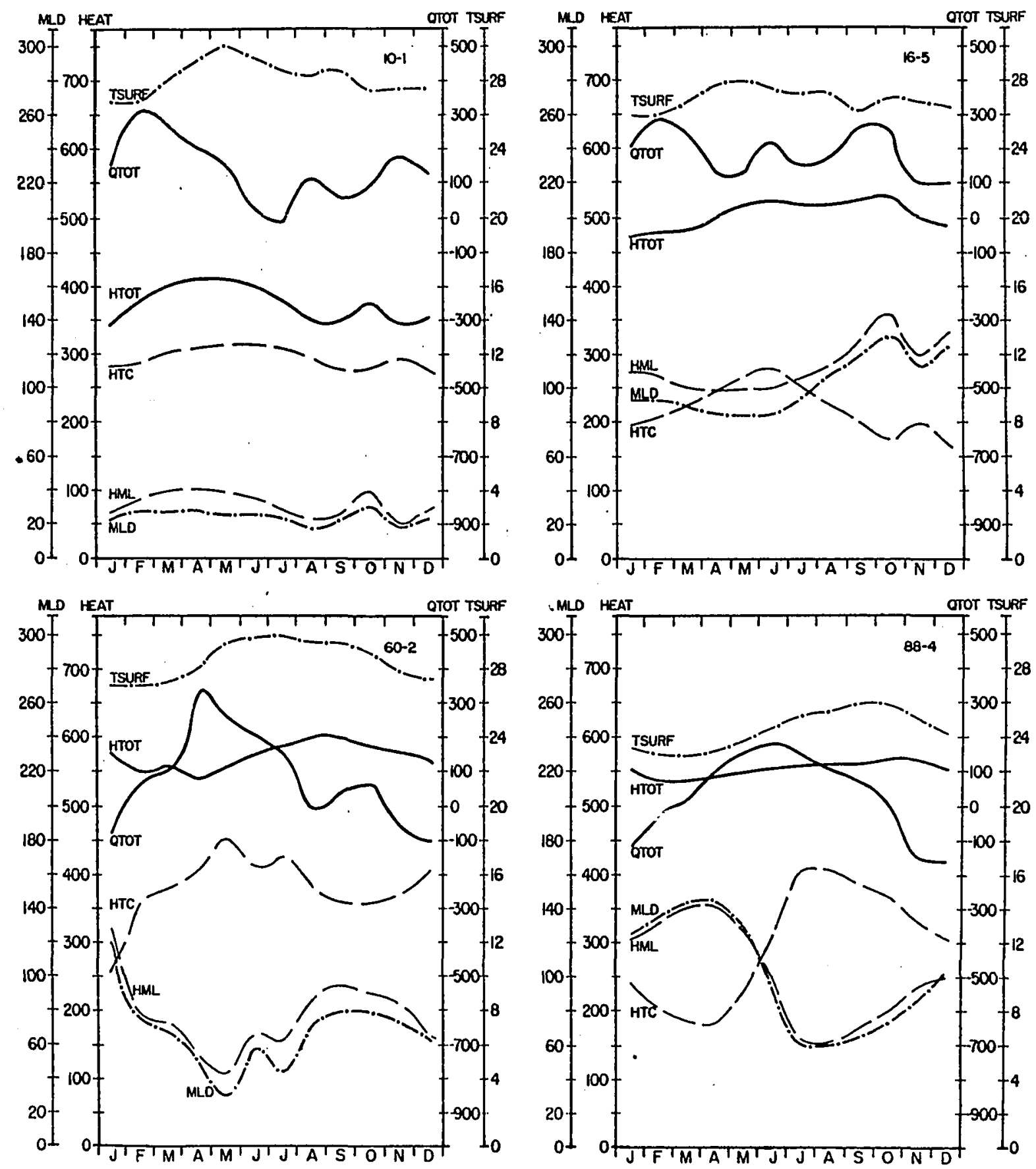

Figure 22 Seasonal Total Heat Storage, Heat in the Mixed Layer, Heat in the Thermocline Layer, Mixed Layer Depth, Surface Temperature, and Net Surface Heat Exchange. HTOT is in the total heat storage (0-250m surface layer); HML the heat in the mixed layer, and HTC the heat in the thermocline layer all in $\mathrm{kcal} \mathrm{cm}^{-2}$ (heat axis): QTOT is the net surface heat exchange in cal $\mathrm{cm}^{-2} \mathrm{day}^{-1}$. TSURF is the surface temperature in ${ }^{\circ} \mathrm{C}$. MLD is the mixed layer depth in meters: The location of each area is shown in Figure 1; 10-1 west of Central America, 16-5 Central Equatorial Pacific, 60-2 East of the Philippines, 88-4 north of Hawail. 

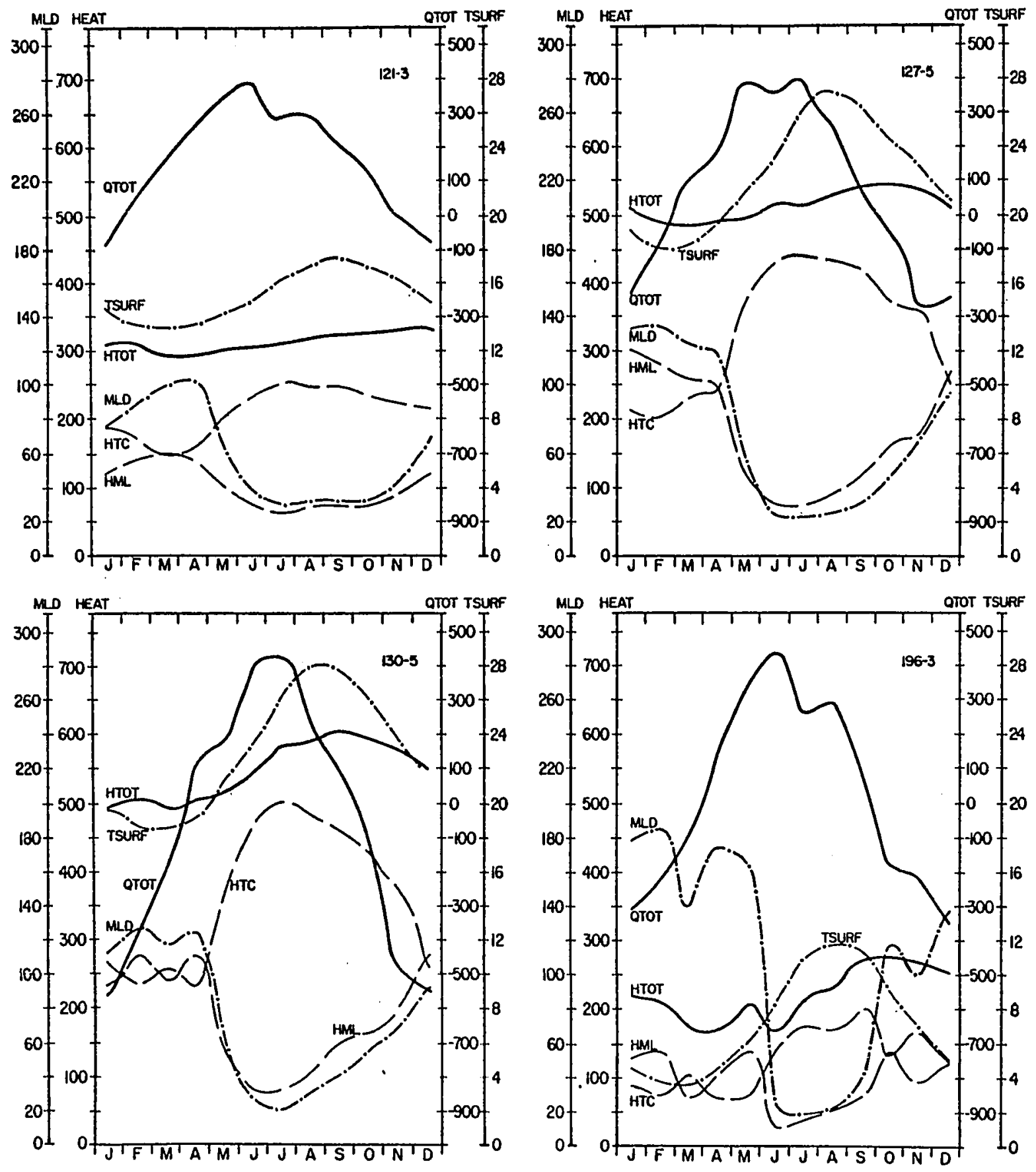

Figure 23 Seasonal Total Heat Storage, Heat in the Mixed Layer, Heat in the Thermocline Layer, Mixed Layer Depth, Surface Temperature, and Net Surface Heat Exchange. HTOT is in the total heat storage (0-250m surface layer); HML the heat in the mixed layer, and HTC the heat in the thermocline layer all in kcal $\mathrm{cm}^{-2}$ (heat axis) $\mathrm{QTOT}$ is the net surface heat exchange in cal $\mathrm{cm}^{-2}$ day-i. TSURF is the surface temperature in ${ }^{\circ} \mathrm{C}$. MLD is the mixed layer depth in meters. The location of each area is shown in Figure 1; 121-3 West of California, 127-5 Central North Pacific, 130-5 East of Japan, 196-3 South of Alaska. 


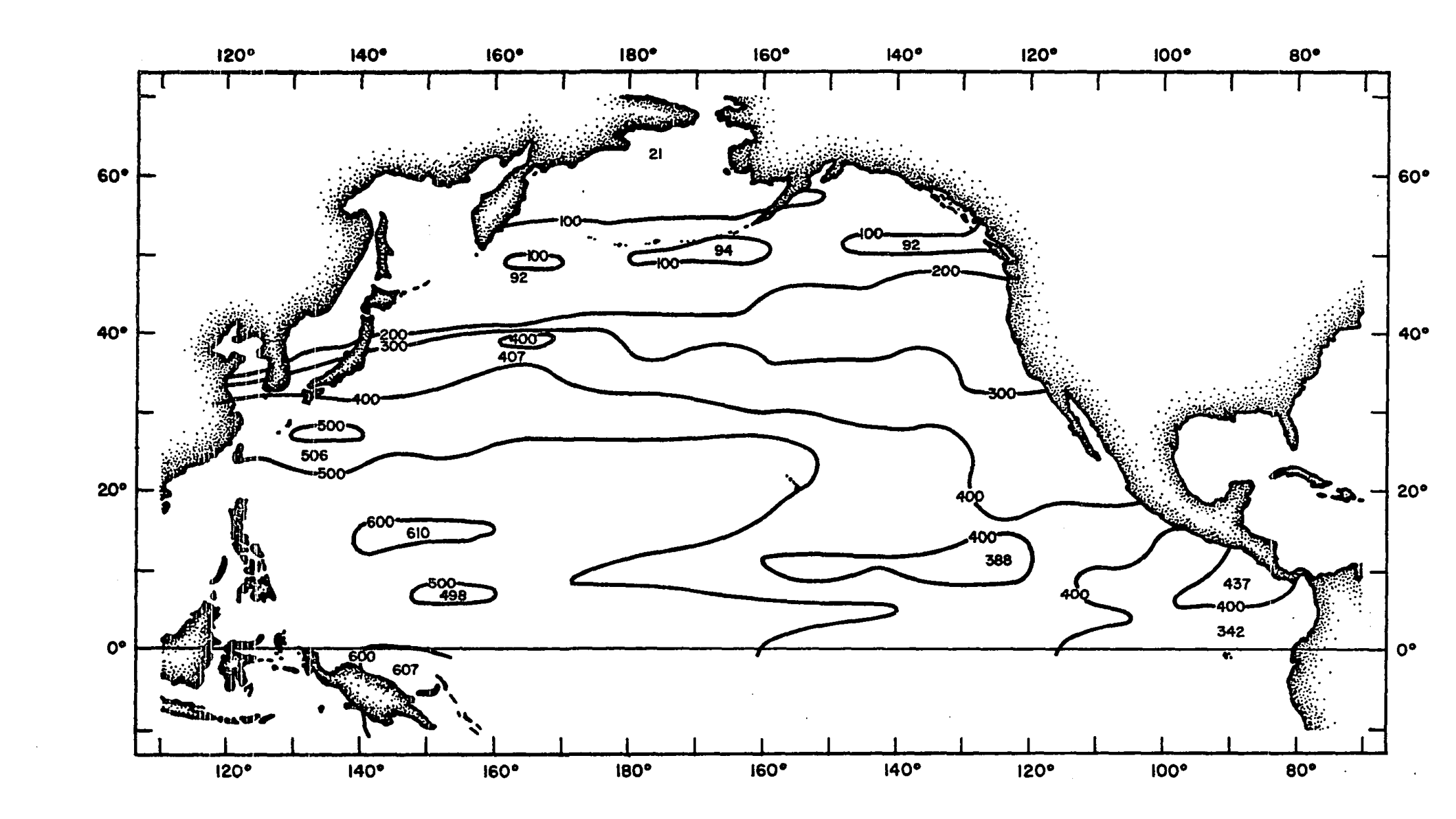




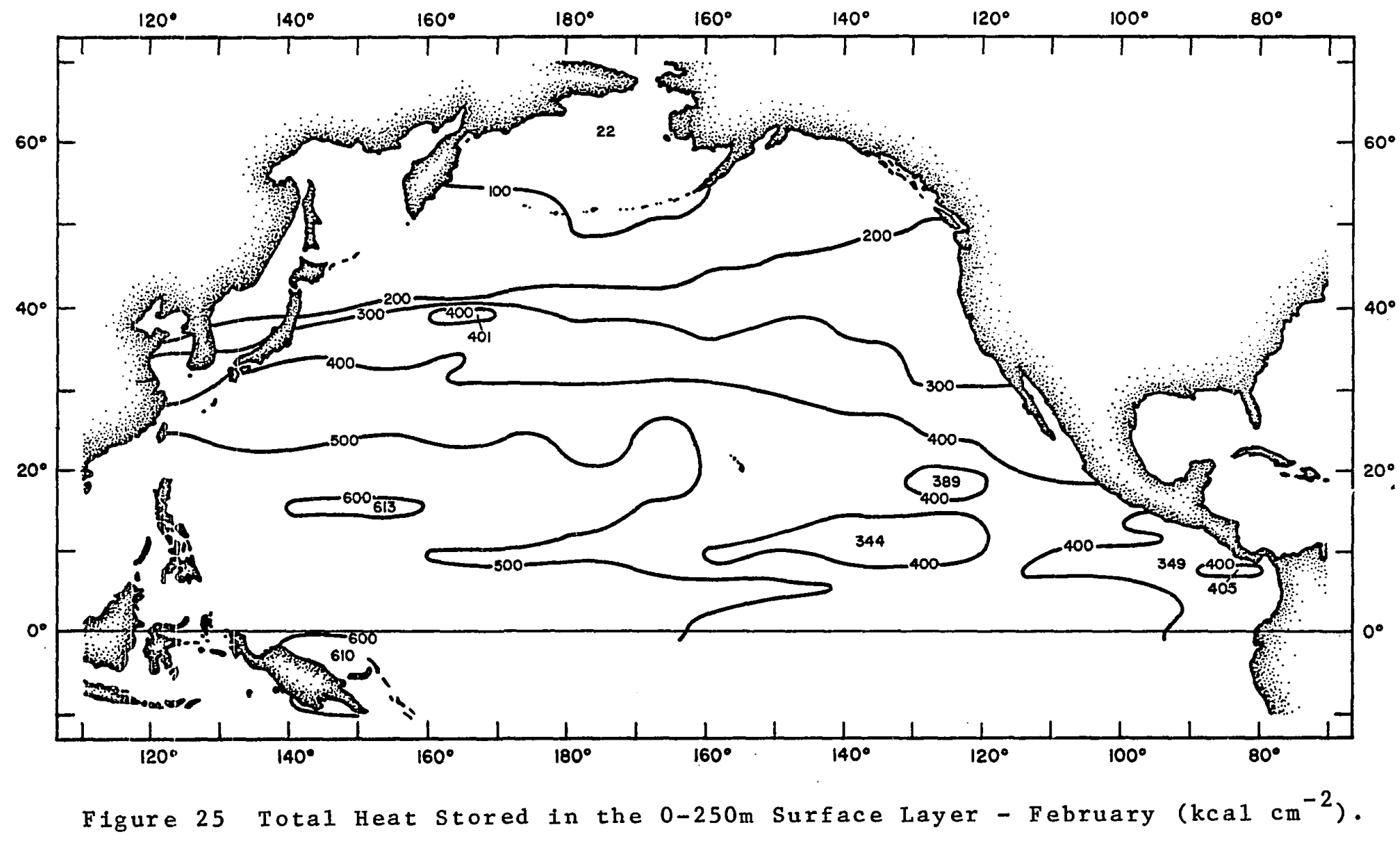


<smiles>C[Si]1CCCCC1</smiles> 
<smiles>C1CCCCCCCCCCCCCCCC1</smiles> 



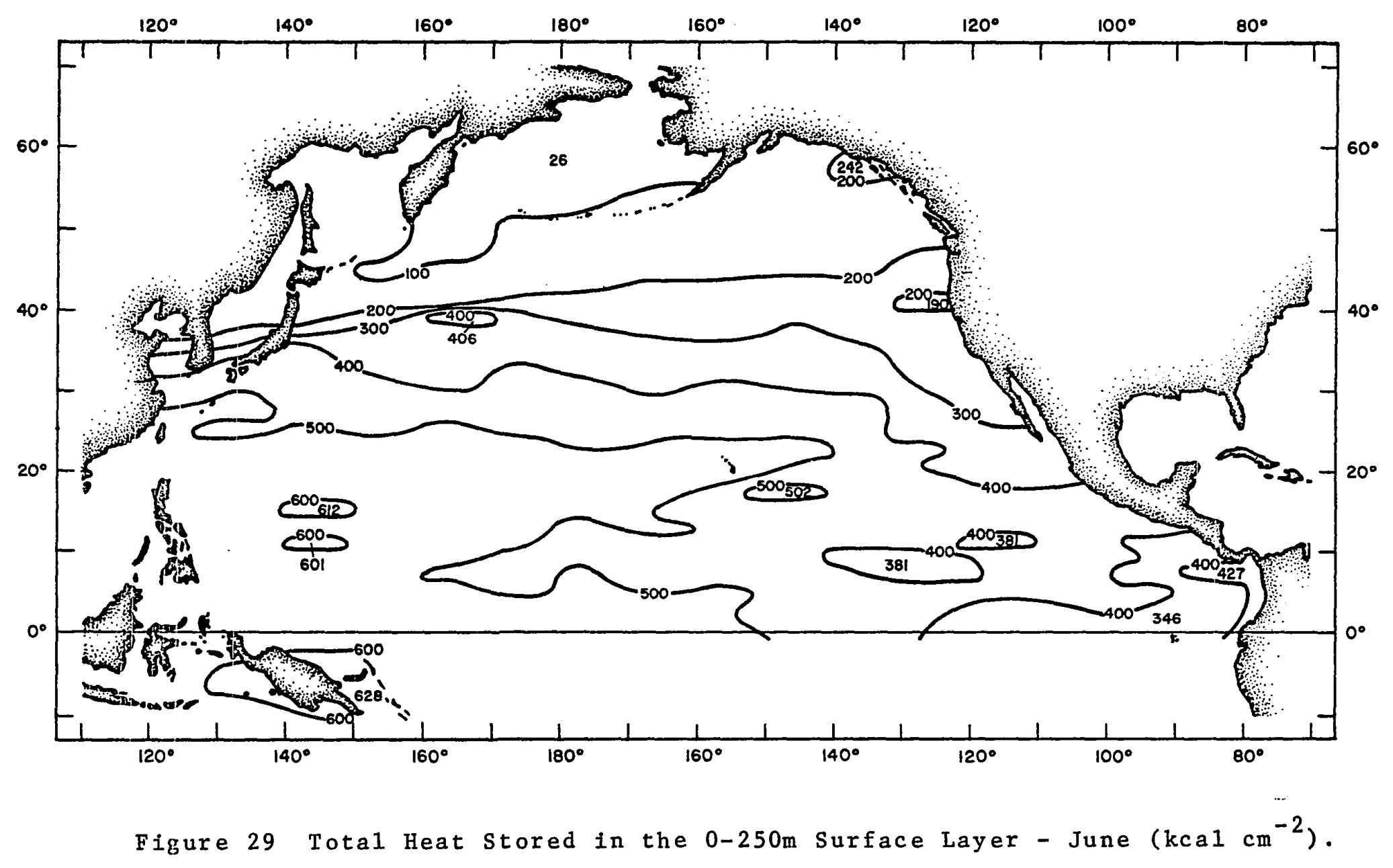




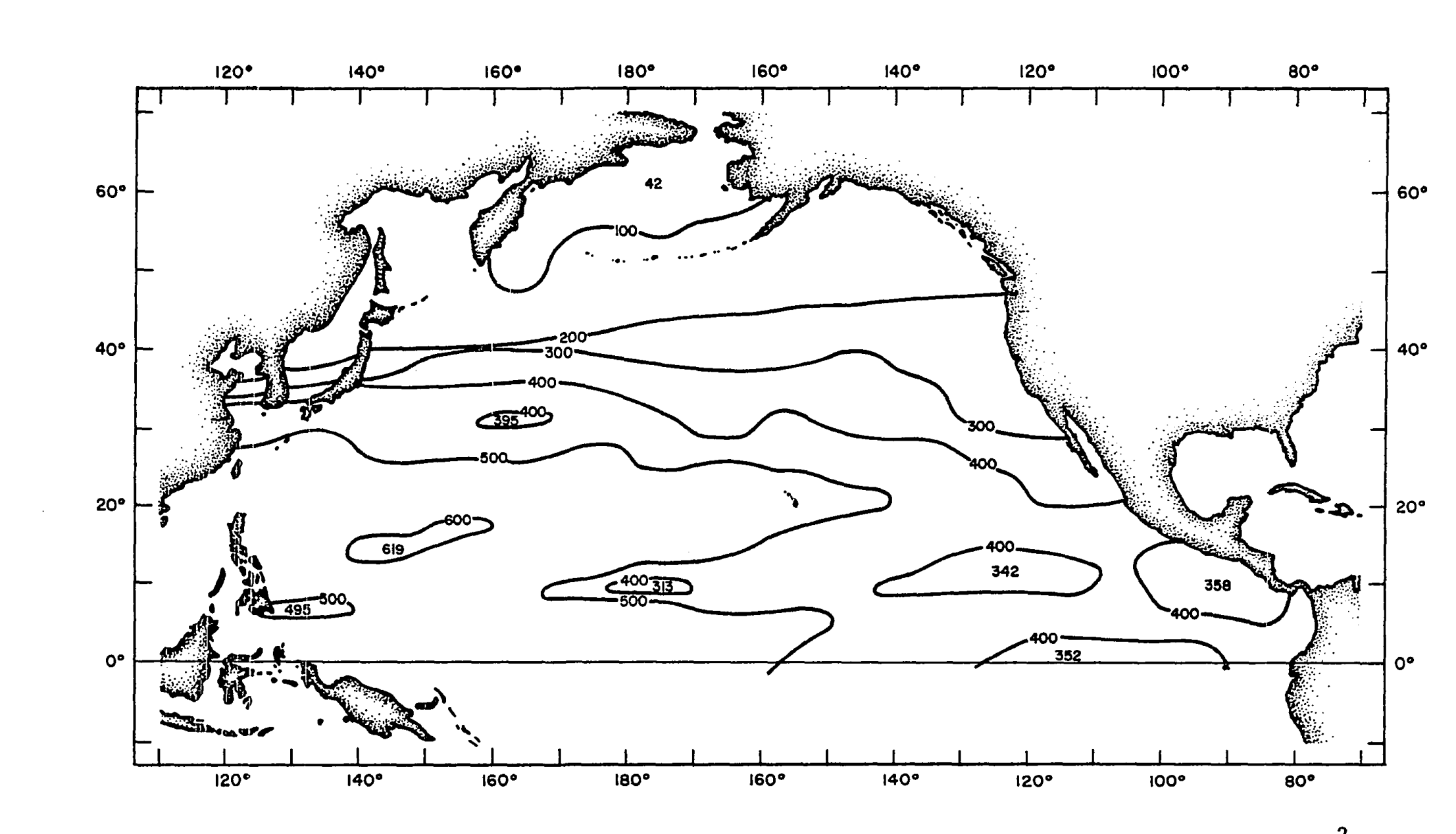





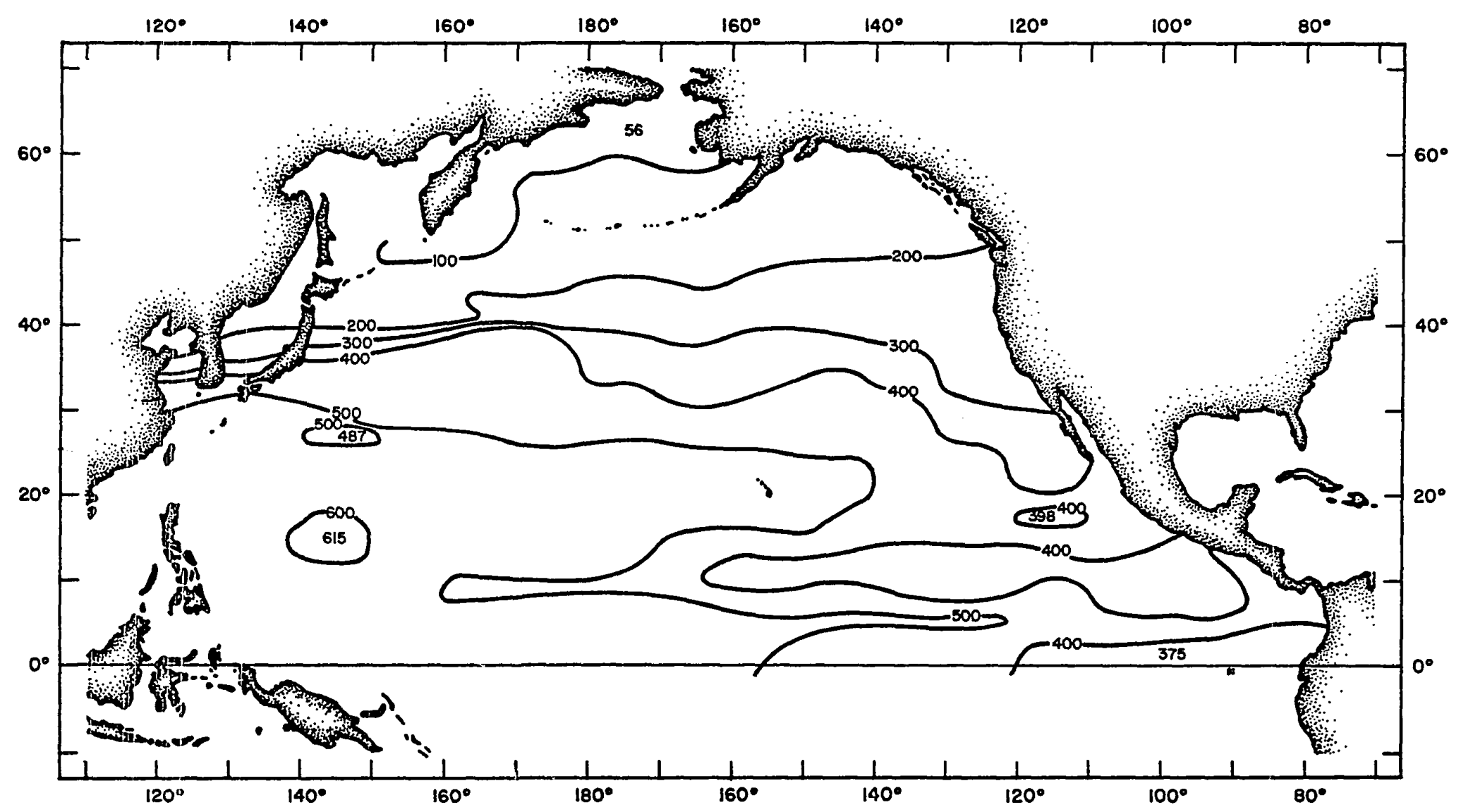

Figure 32 Total Heat Stored in the $0-250 \mathrm{~m}$ Surface Layer - September (kcal $\left.\mathrm{cm}^{-2}\right)$. 


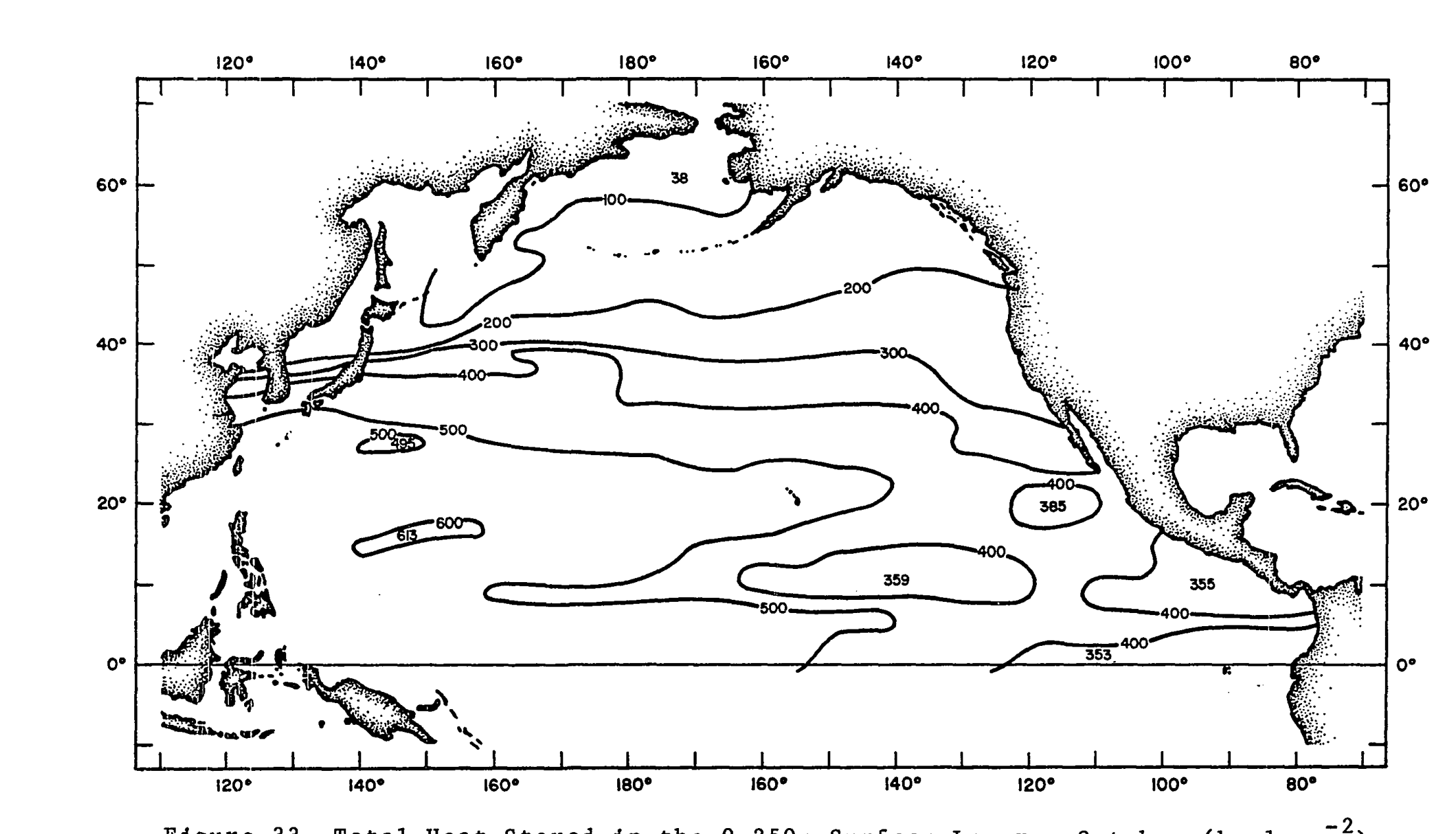






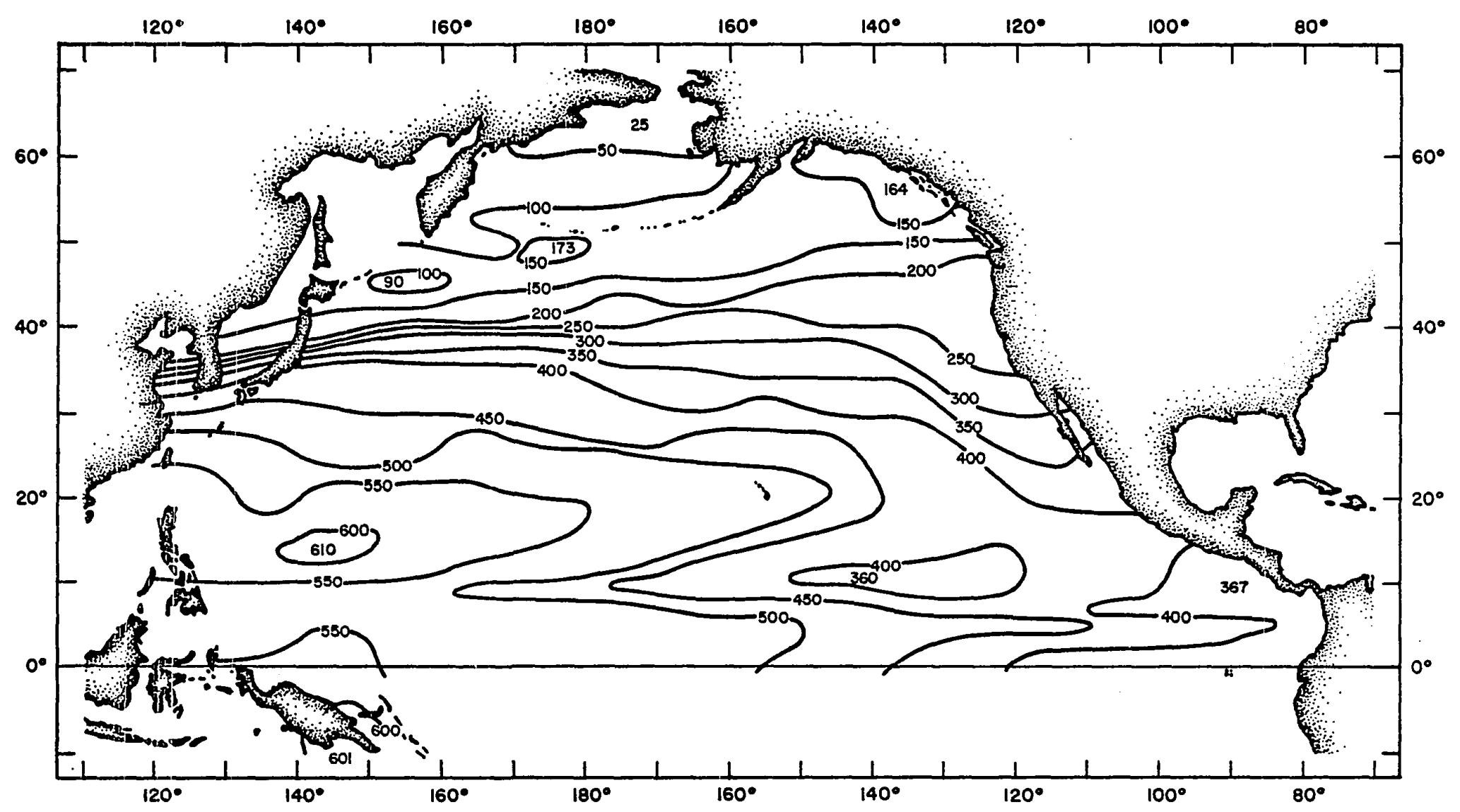

Figure 36 Annual Average Total Heat Stored

in the $0-250 \mathrm{~m}$ Surface Layer (kcal $\left.\mathrm{cm}^{-2}\right)$. 
<smiles>C1C2C3C4C1C1C2C3C41</smiles> 


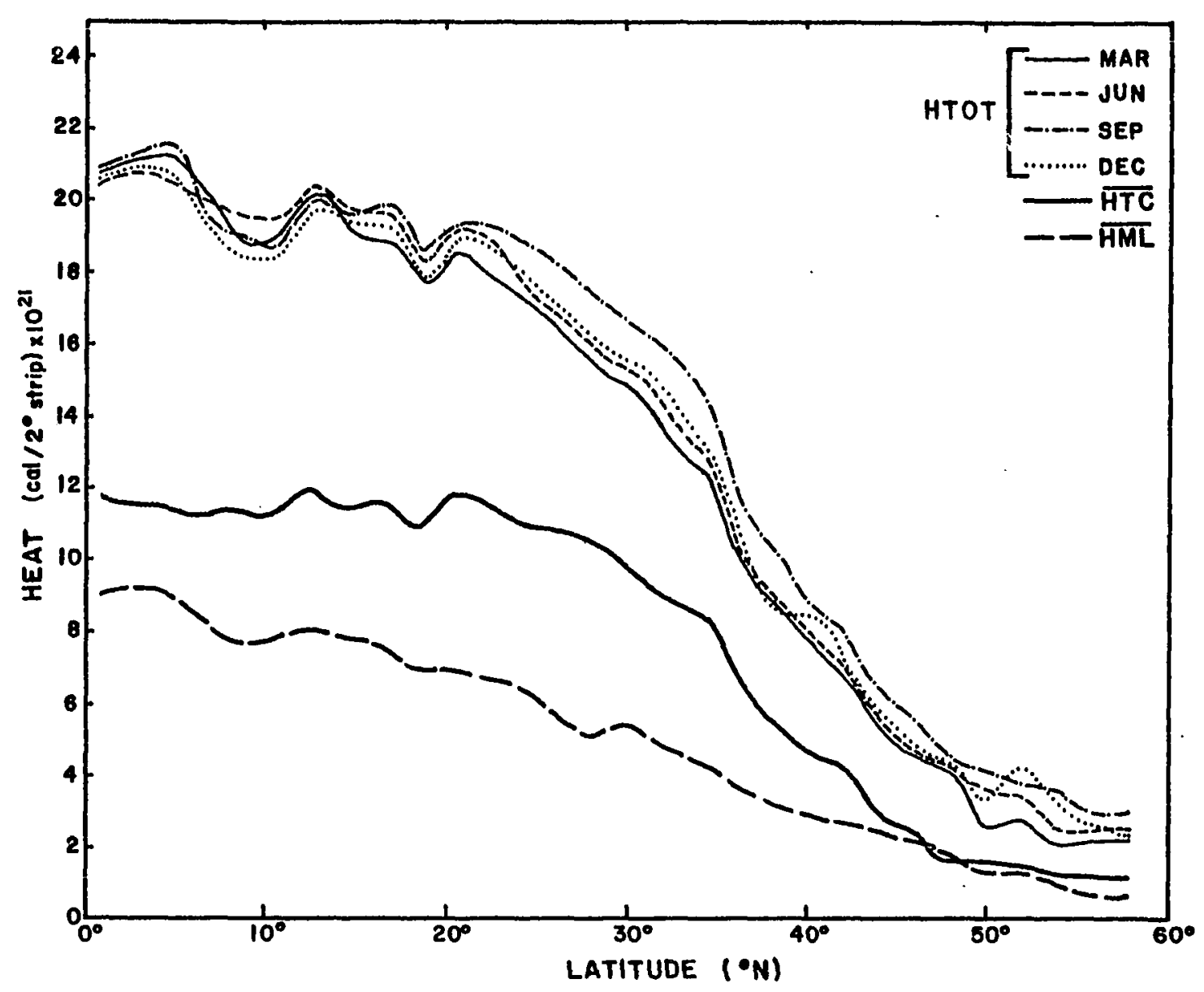

Figure 38 Summation by $2^{\circ}$ strips of Latitude of the Total Heat Storage, Heat Stored in the Mixed Layer, and Heat Stored in the Thermocline Layer. The Thermocline layer is taken as $250 \mathrm{~m}$ minus the mixed layer depth. The total heat storage for the months of March, June, September and December is shown (HTOT) along with the annual average heat stored in the mixed (HML) and thermocline layer (HTC). 


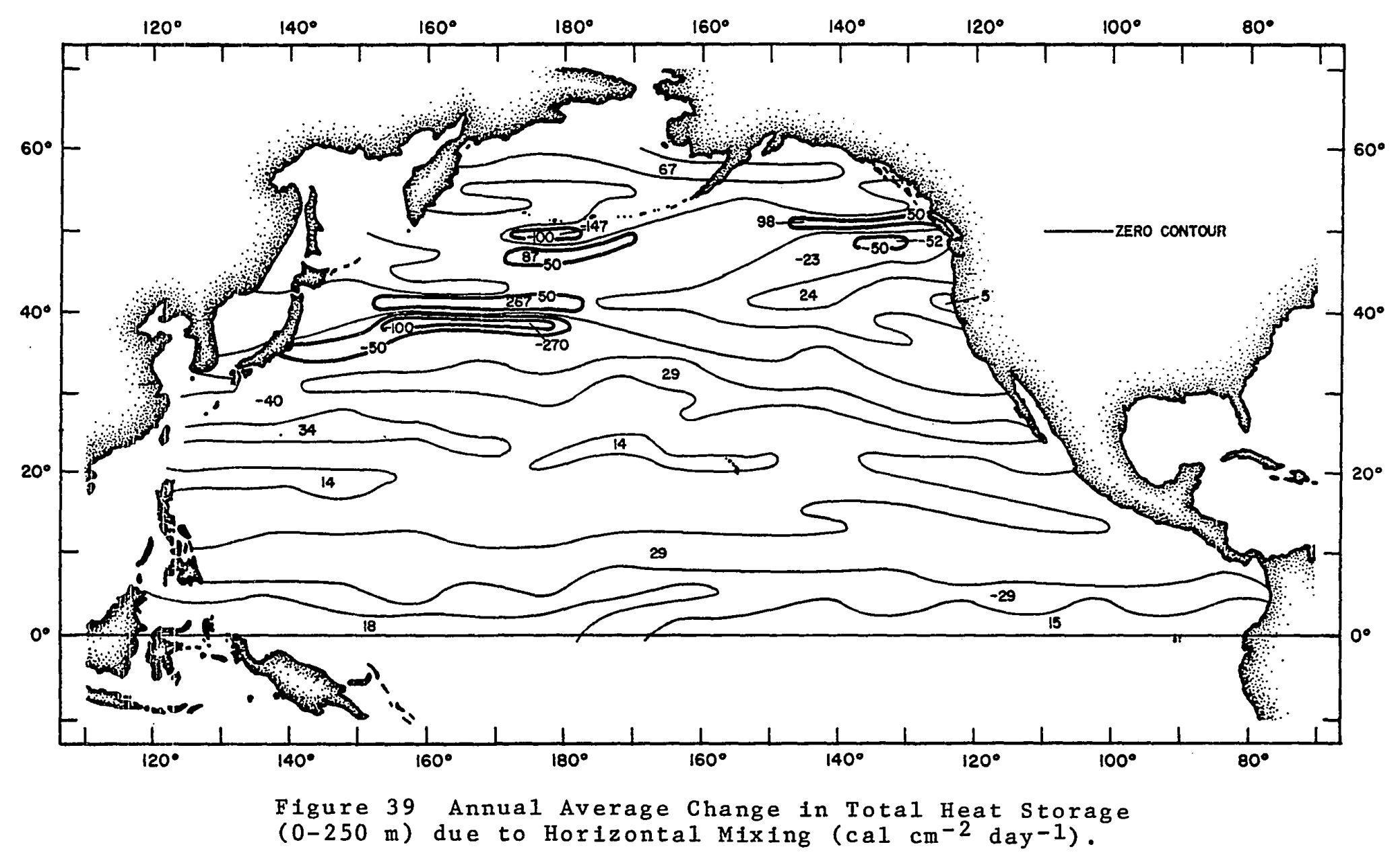





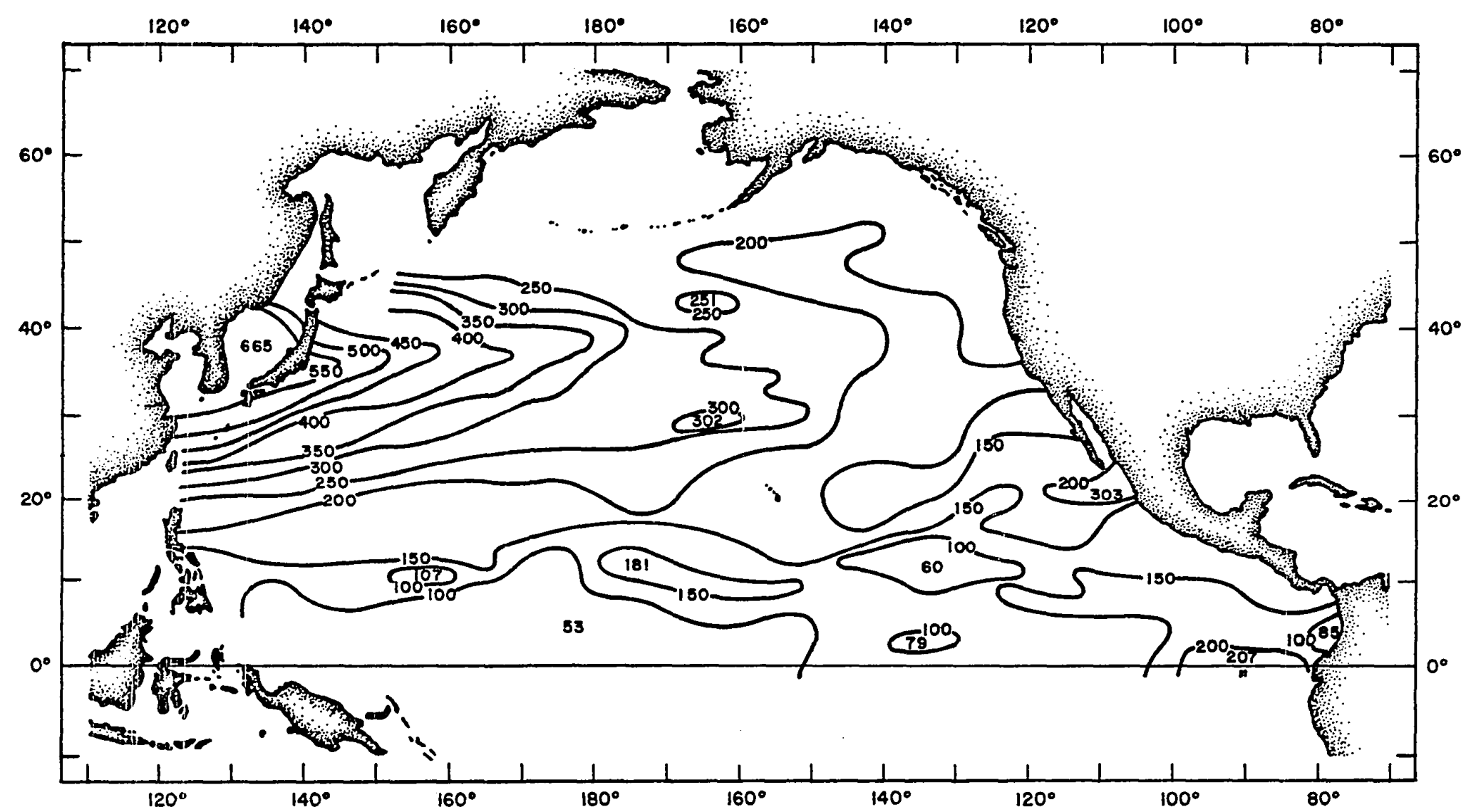

Figure 41 Annual Amplitude of the Net Surface

Heat Exchange (cal $\mathrm{cm}^{-2} \mathrm{day}^{-1}$ ). 


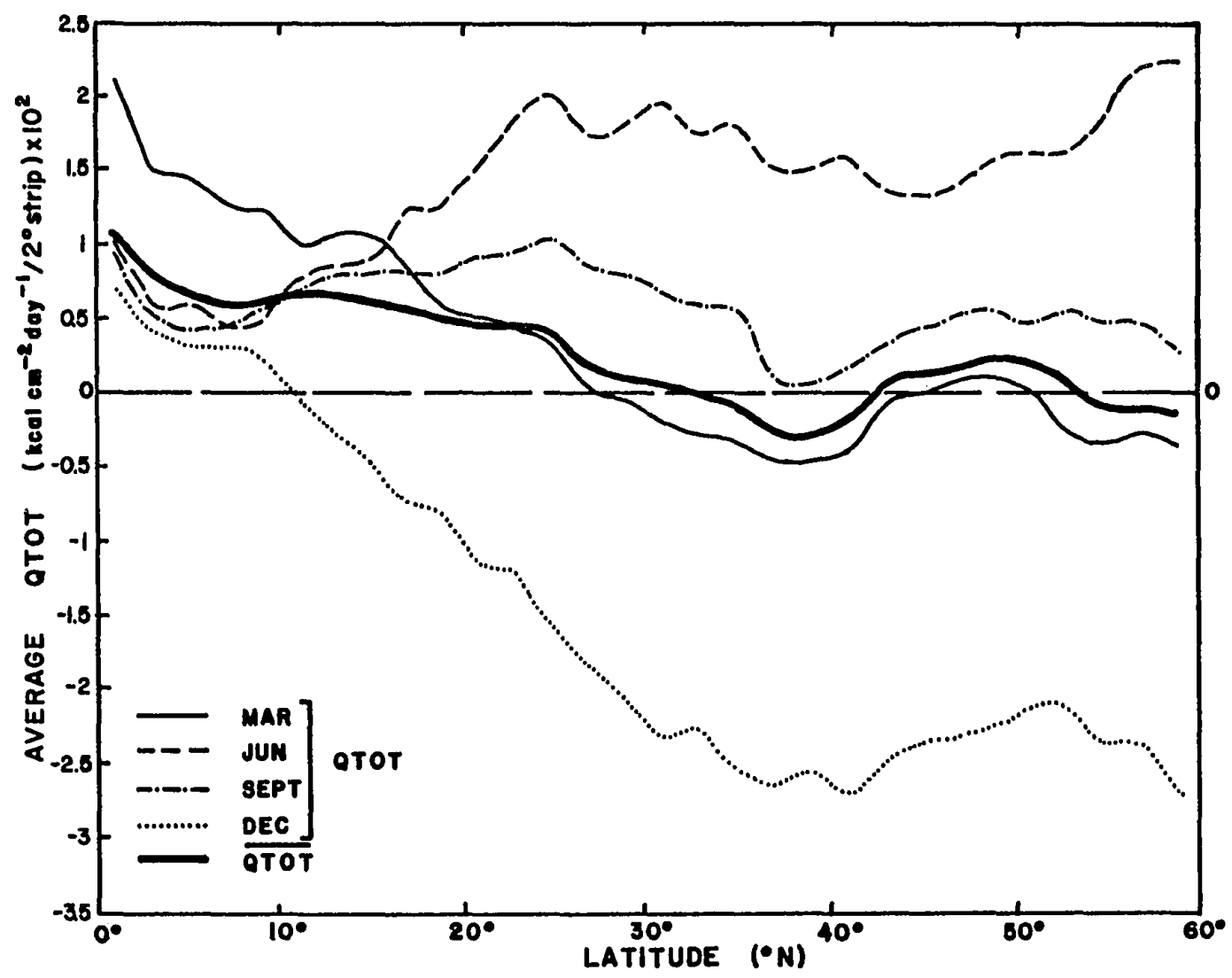

Figure 42 Average by $2^{\circ}$ of Latitude of the Net Surface Heat Exchange (QTOT) from the Equator to $60^{\circ}$ North latitude for the months of March, June, September and December. QTOT is the annual average. 


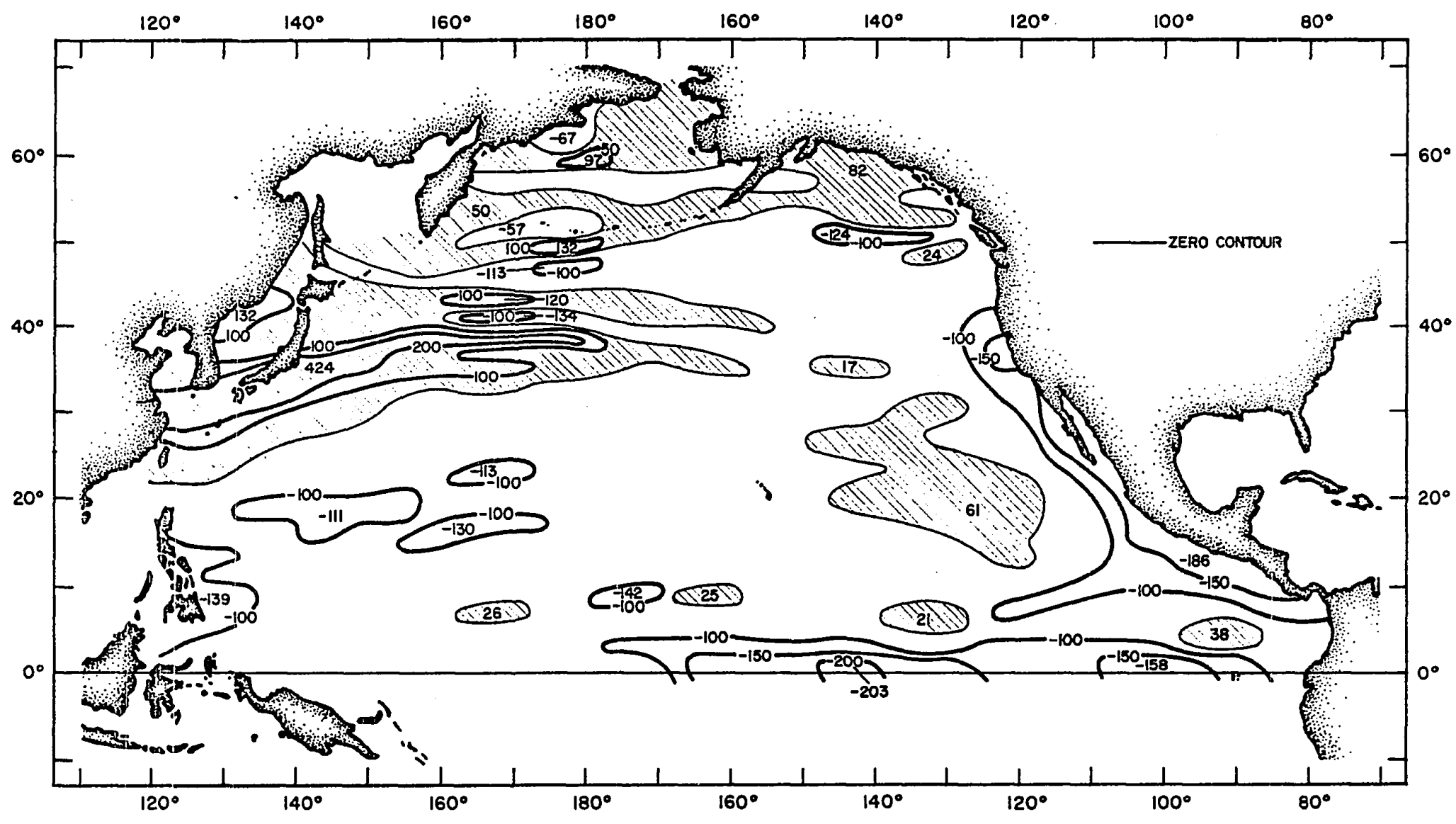

Figure 43 Annual Average Change in Total Heat Storage $(0-250 \mathrm{~m})$ due to Advection ( $\left.\mathrm{ca} 1 \mathrm{~cm}^{-2} \mathrm{day}^{-1}\right)$. 



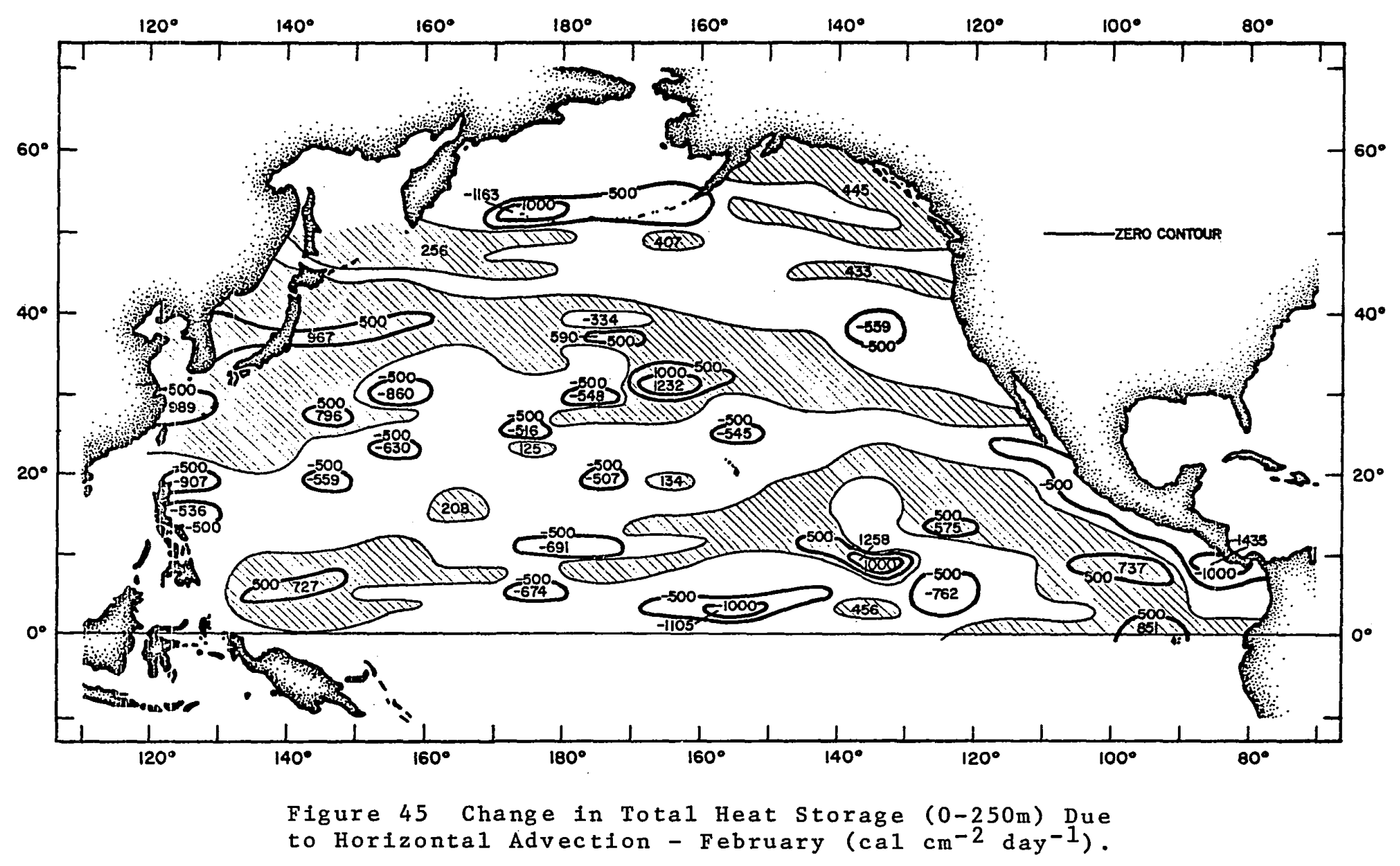




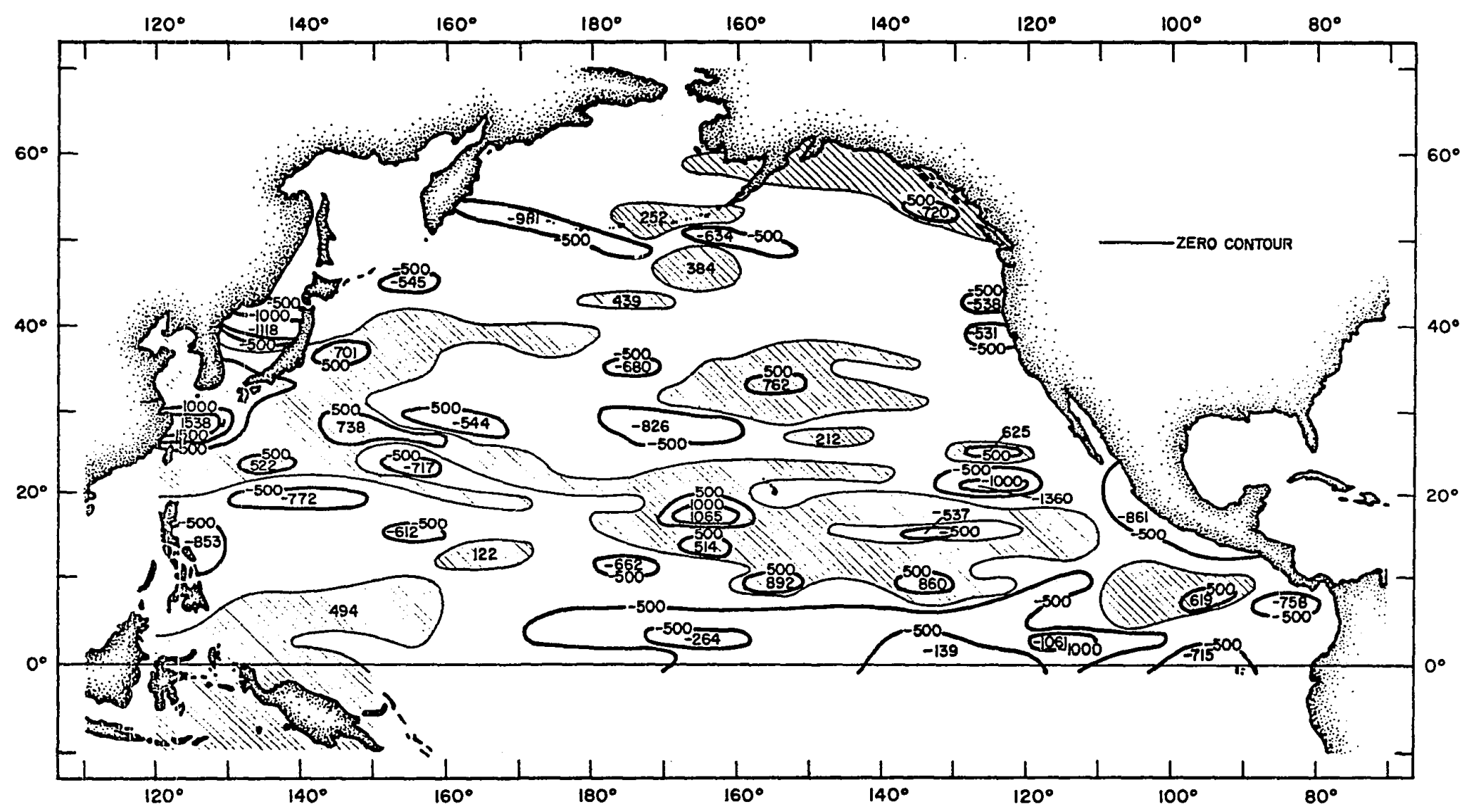

Figure 46 Change in Total Heat Storage $(0-250 \mathrm{~m})$ Due to Horizontal Advection - March (cal $\left.\mathrm{cm}^{-2} \mathrm{day}-1\right)$. 


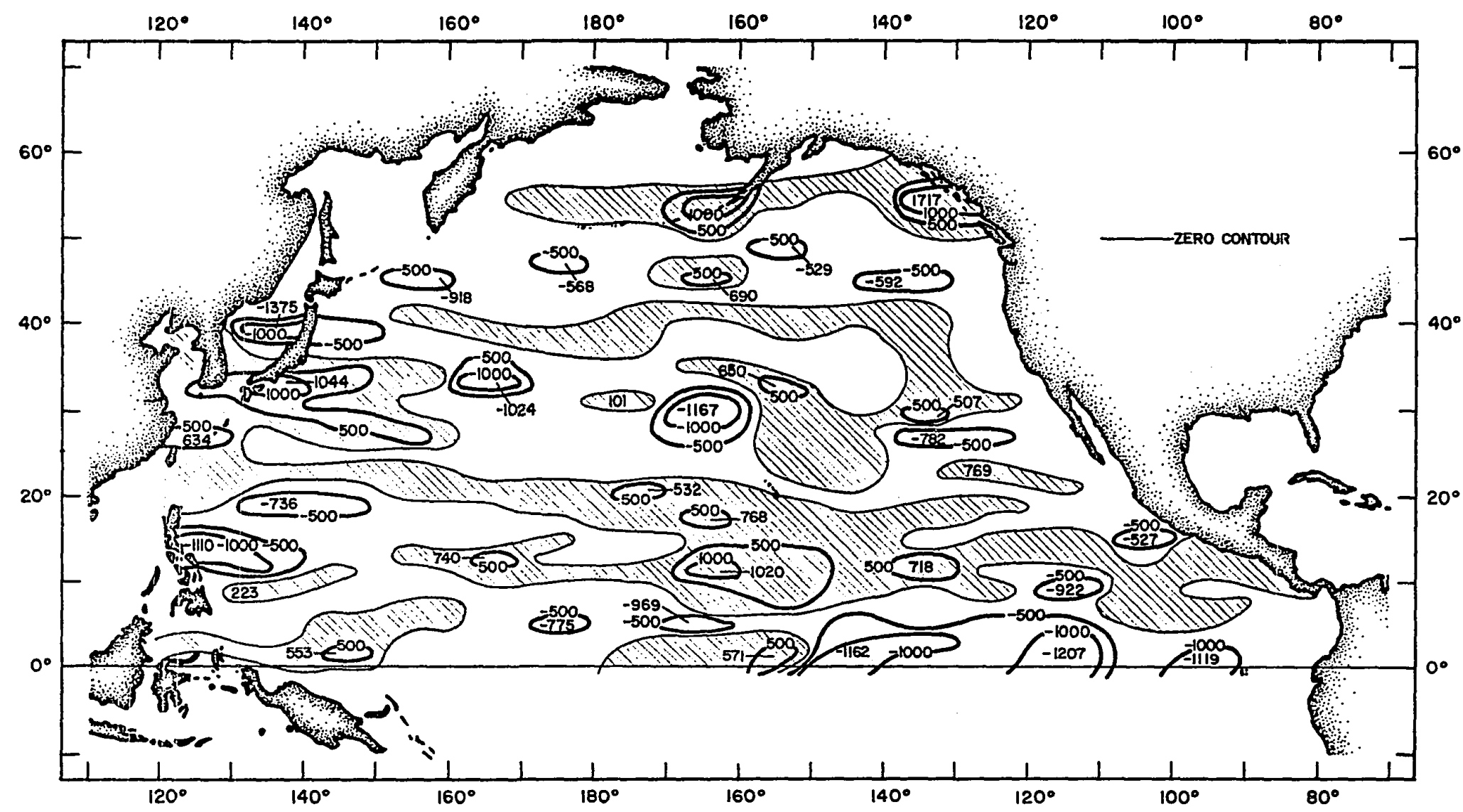

Figure 47 Change in Total Heat Storage $(0-250 \mathrm{~m})$

Due to Horizontal Advection - April ( $\left.\mathrm{cal} \mathrm{cm}^{-2} \mathrm{day}^{-1}\right)$. 


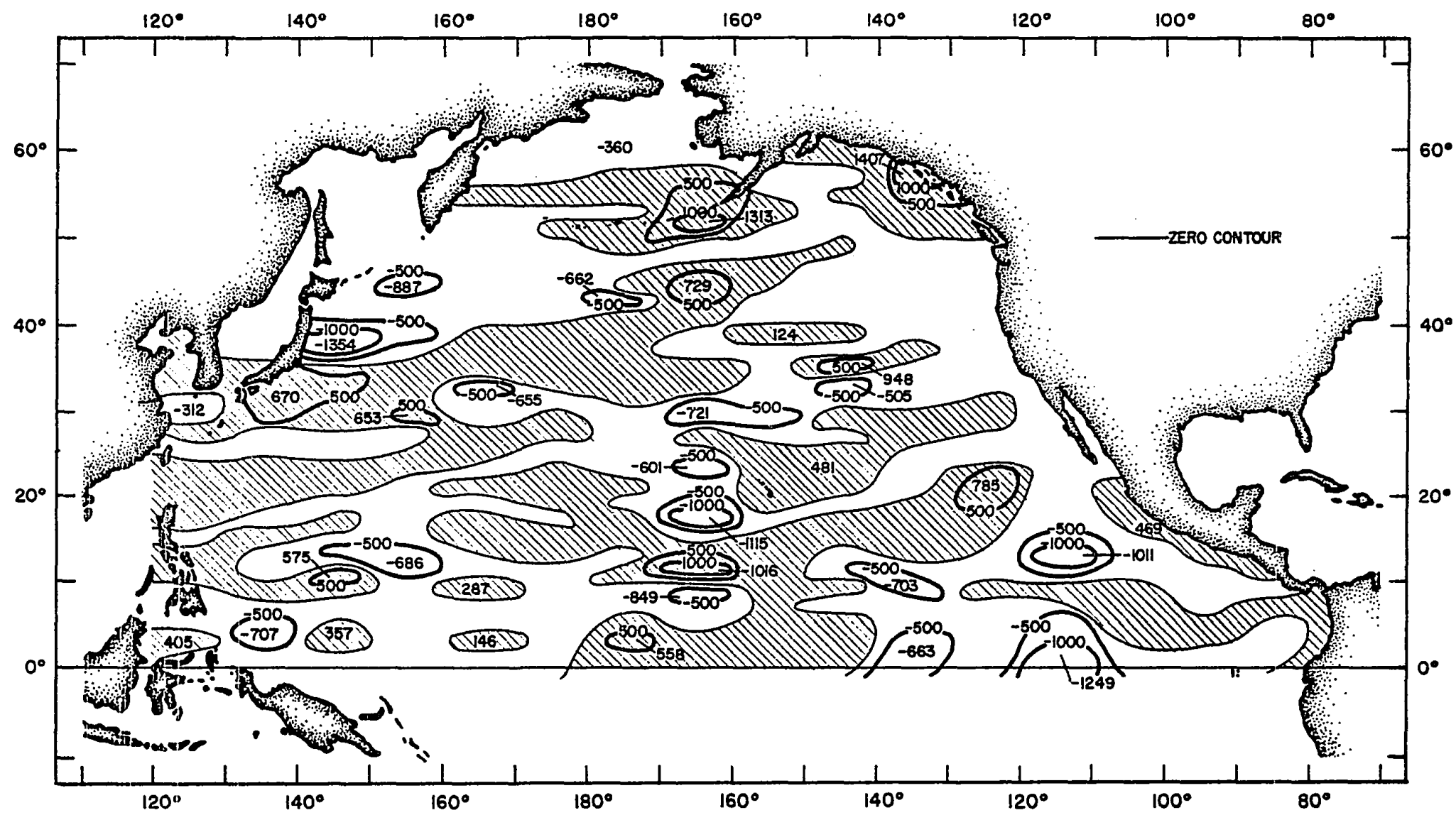

Figure 48 Change in Total Heat storage $(0-250 \mathrm{~m})$

Due to Horizontal Advection - May ( $\mathrm{cal}^{\mathrm{cm}} \mathrm{cm}^{-2} \mathrm{day}^{-1}$ ). 


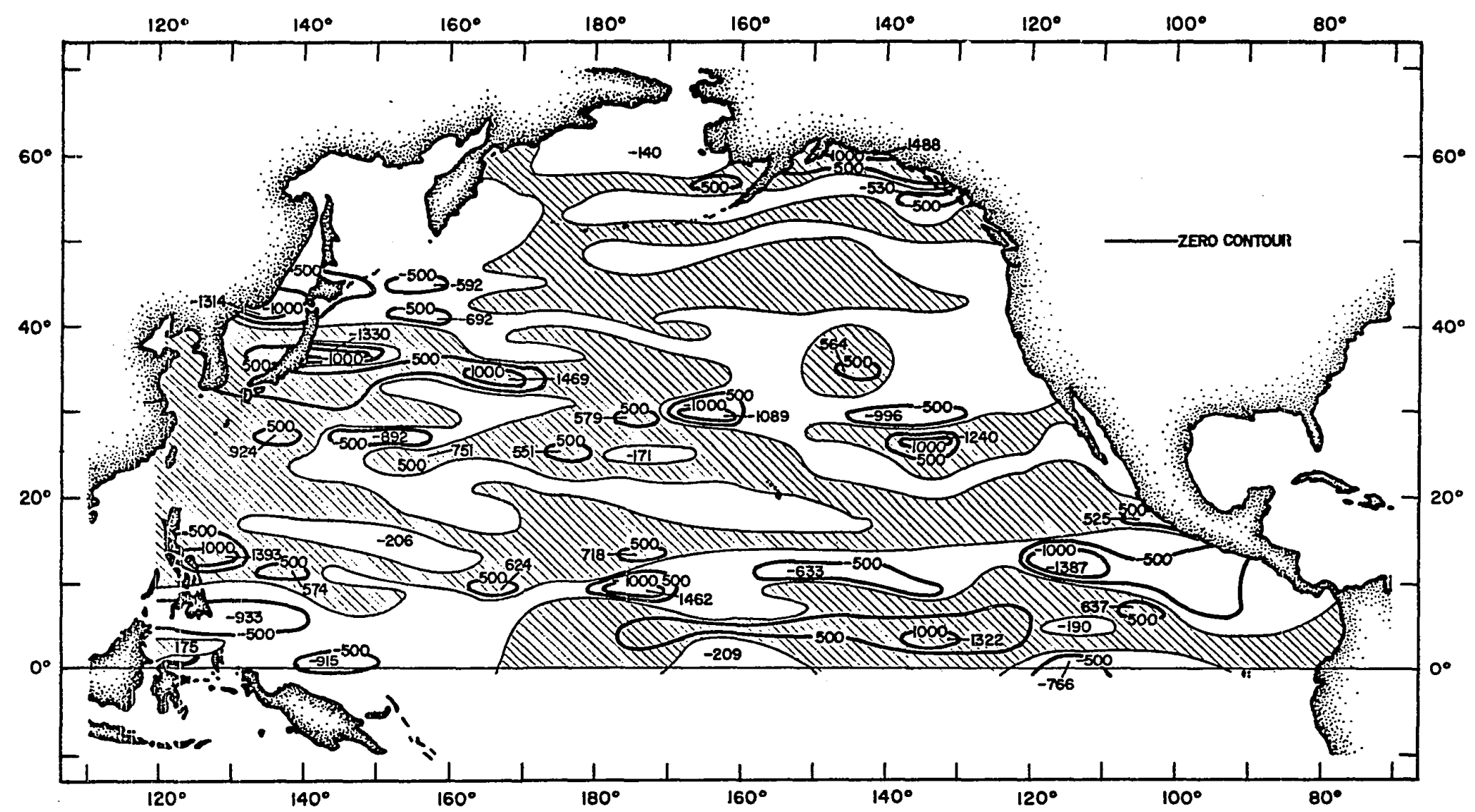

Figure 49 Change in Total Heat Storage $(0-250 \mathrm{~m})$

Due to Horizontal Advection - June (cal $\left.\mathrm{cm}^{-2} \mathrm{day}-1\right)$. 


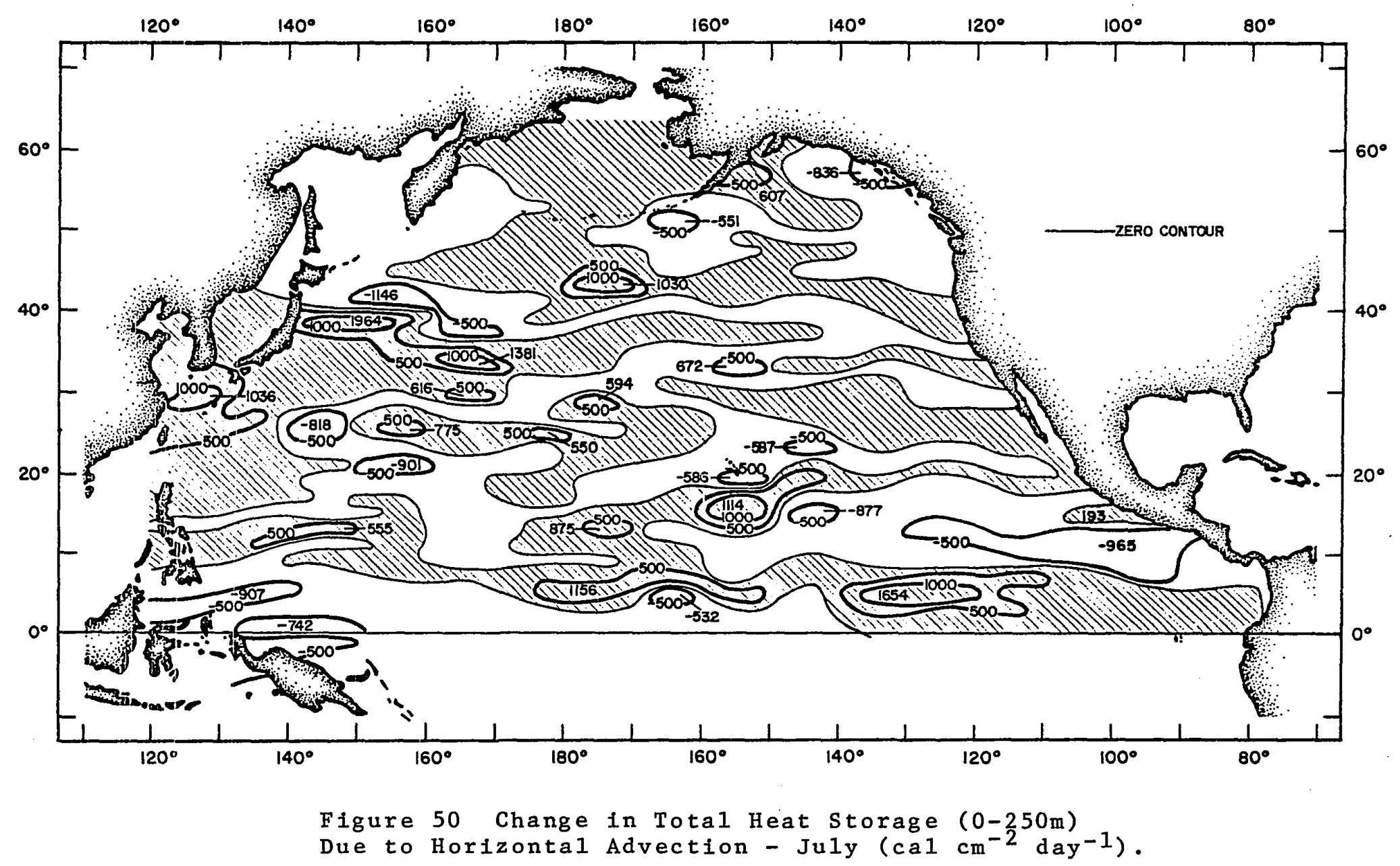




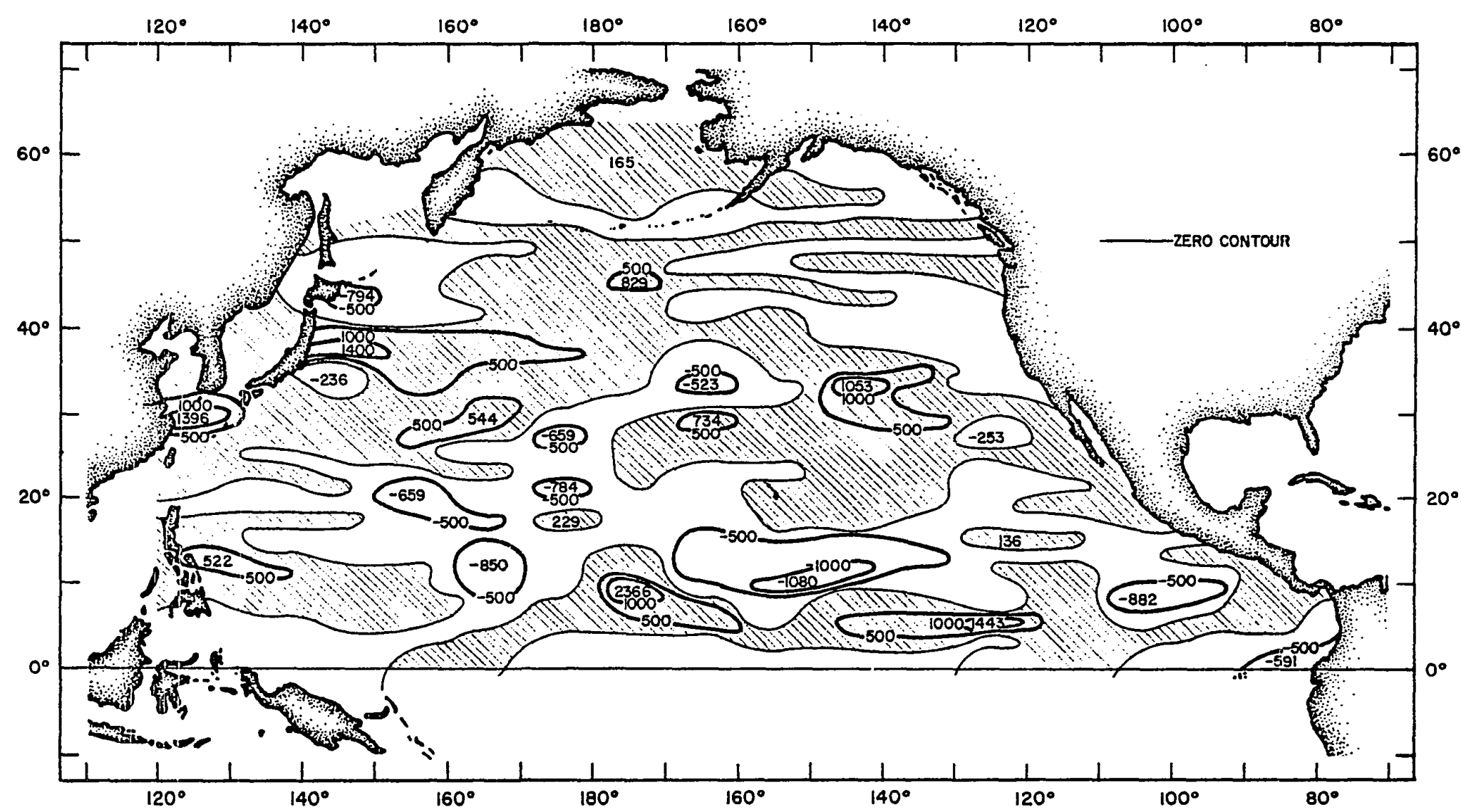

Figure 51 Change in Total Heat Storage (0-250m) Due to Horizontal Advection - August (cal $\mathrm{cm}^{-2} \mathrm{day}^{-1}$ ). 


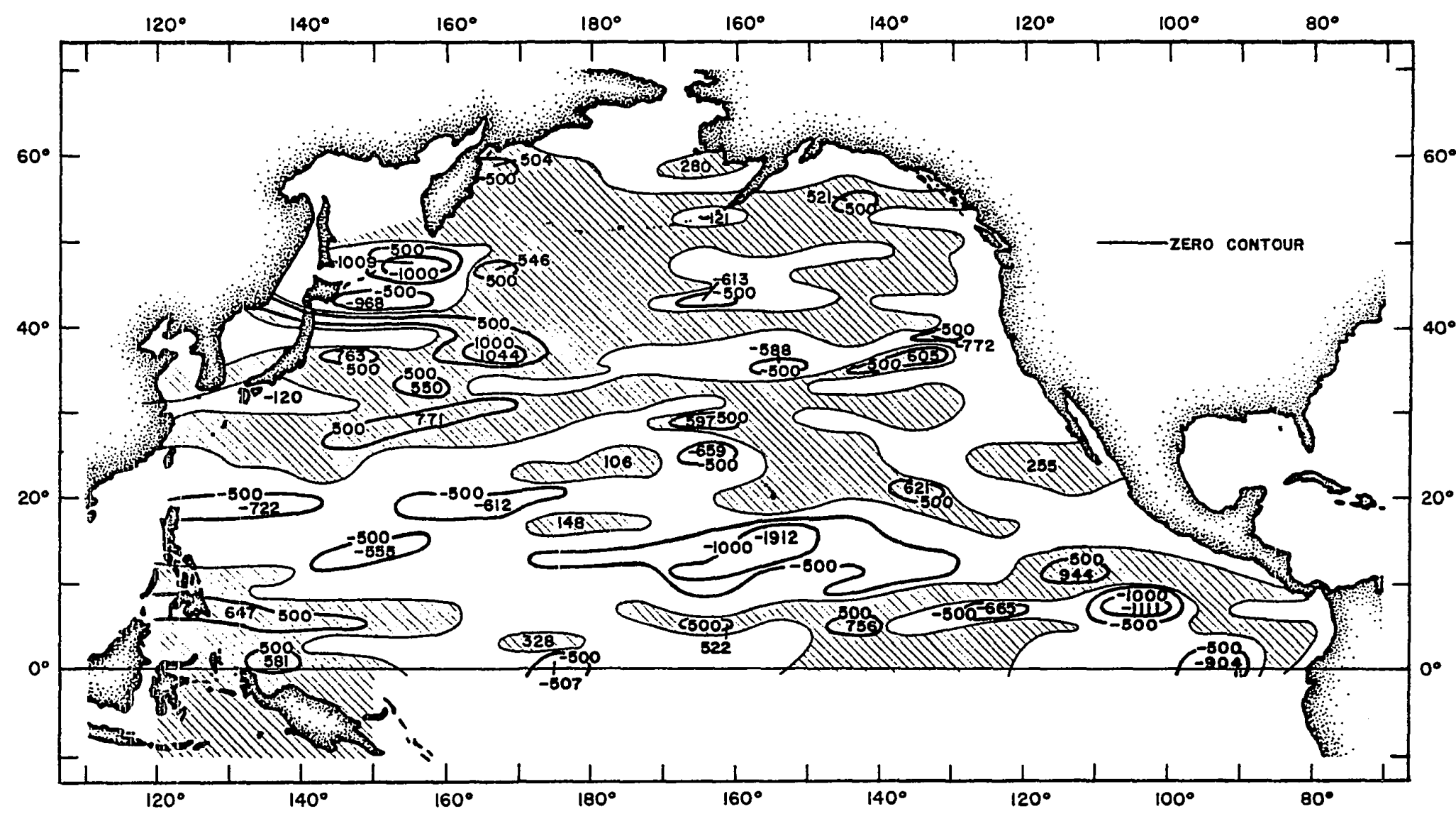

Figure 52 Change in Total Heat Storage $(0-250 \mathrm{~m})$ Due

to Horizontal Advection - September (cal $\mathrm{cm}^{-2} \mathrm{day}^{-1}$ ). 


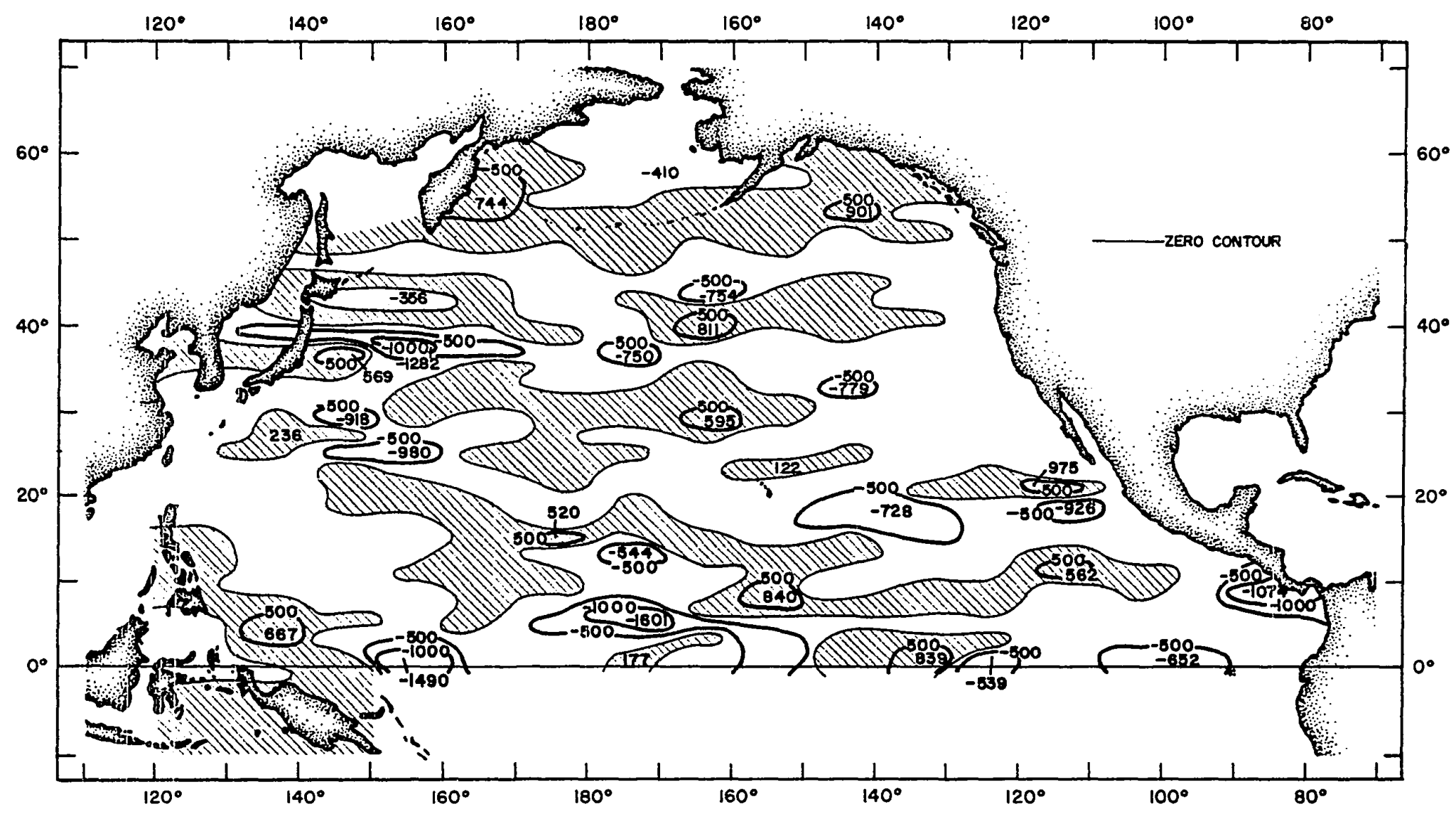

Figure 53 Change in Total Heat Storage $(0-250 \mathrm{~m})$ Due

to Horizontal Advection - october (cal $\left.\mathrm{cm}^{-2} \mathrm{day}^{-1}\right)$. 


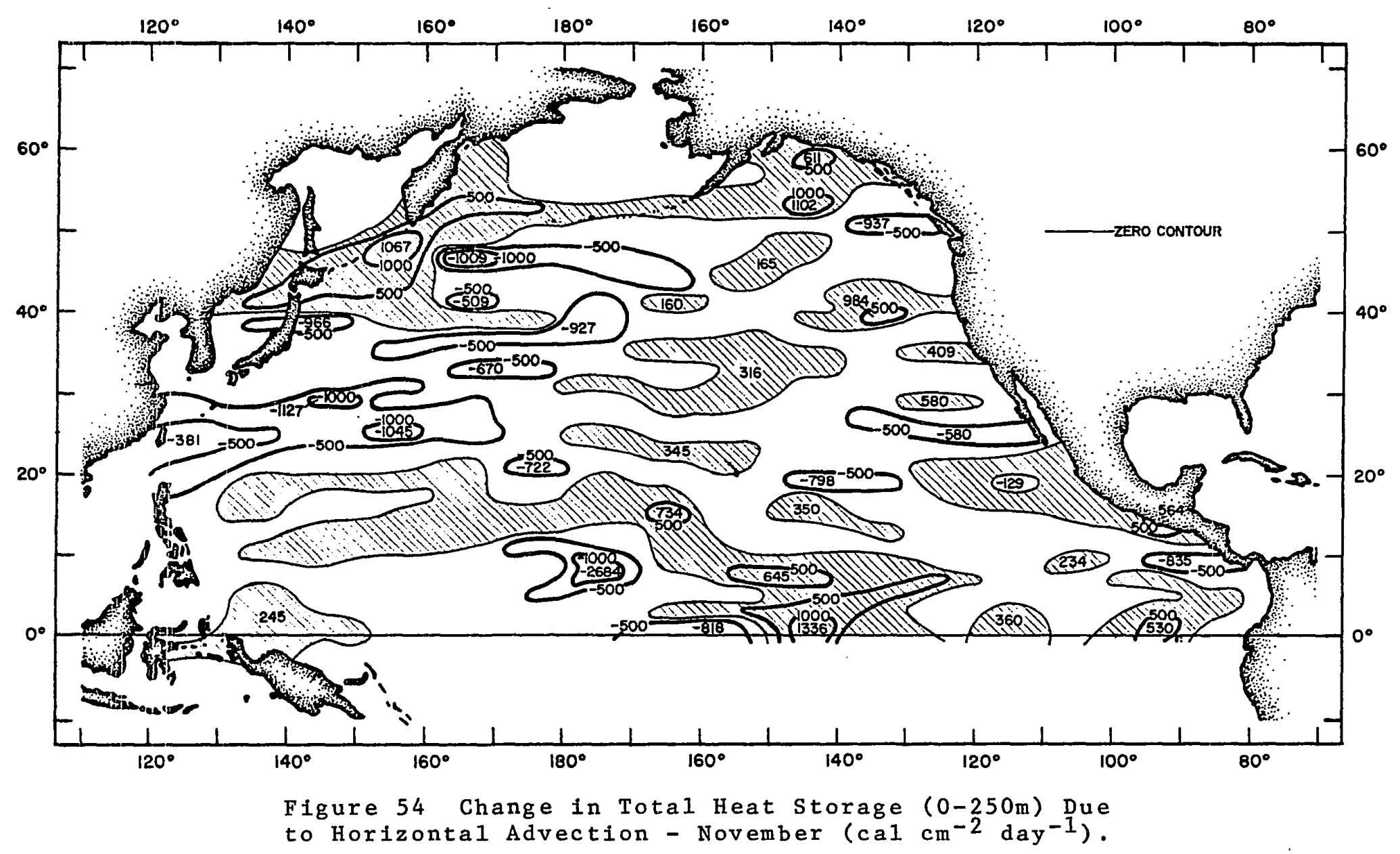




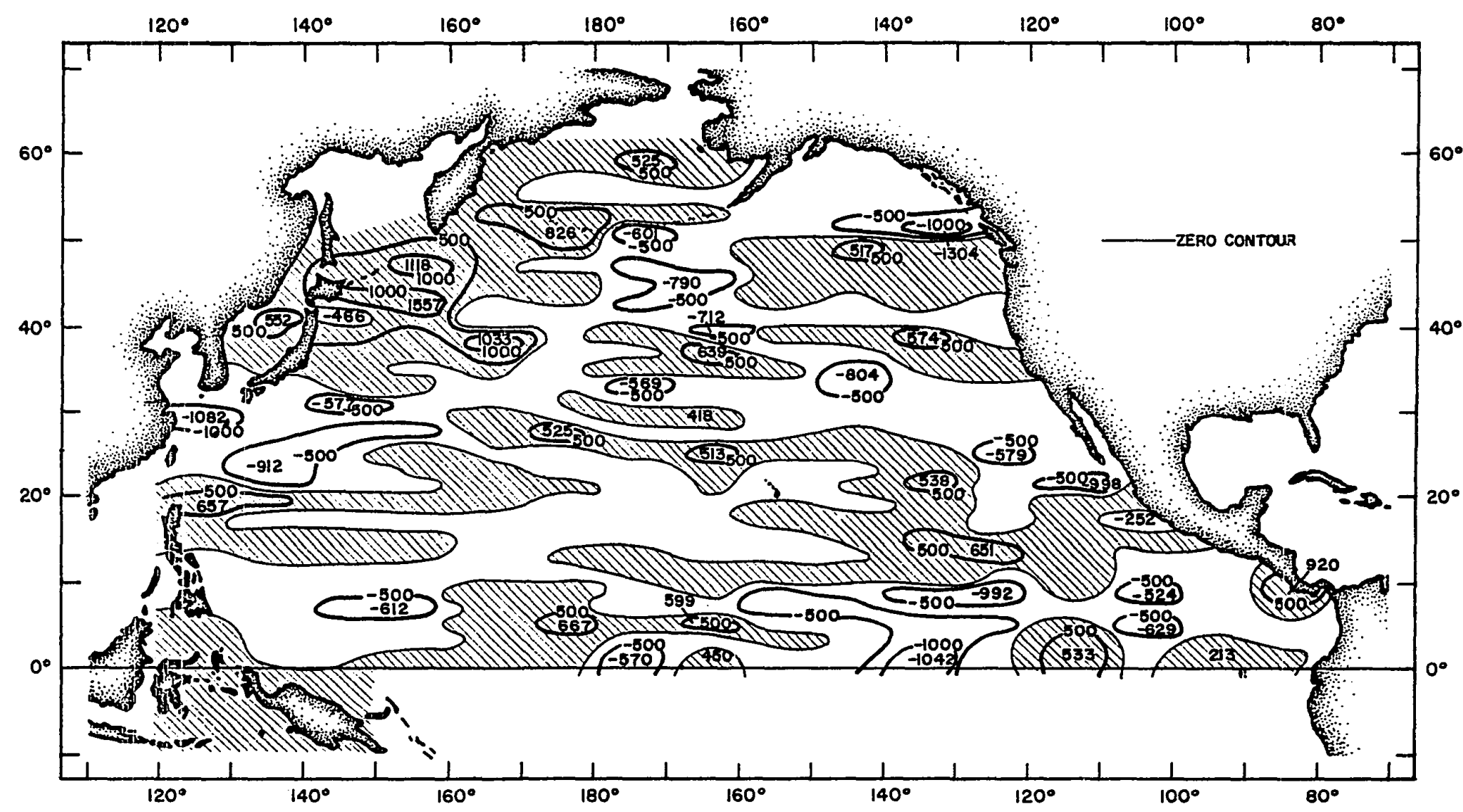

Figure 55 Change in Total Heat Storage $(0-250$ n $)$ Pue 


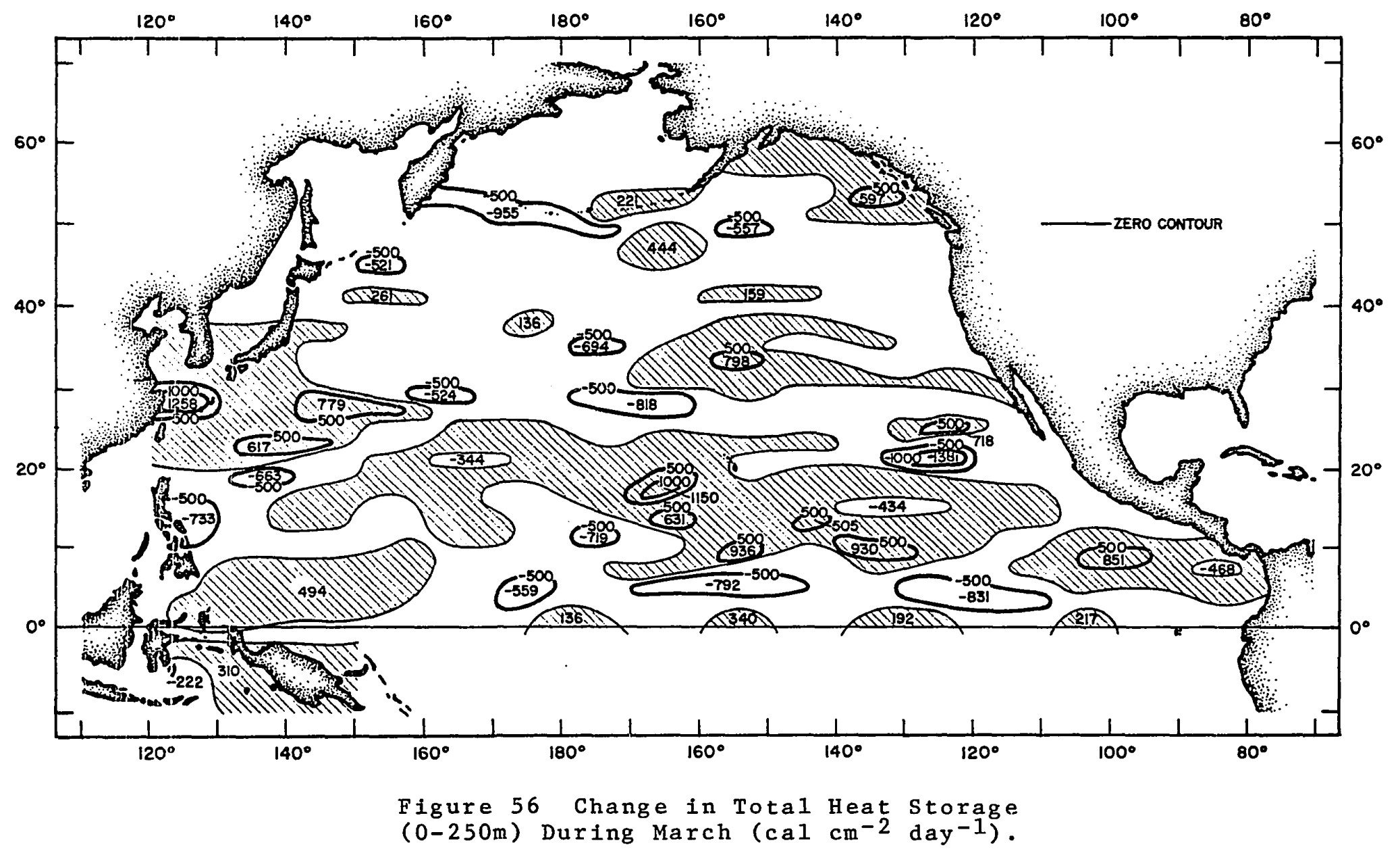




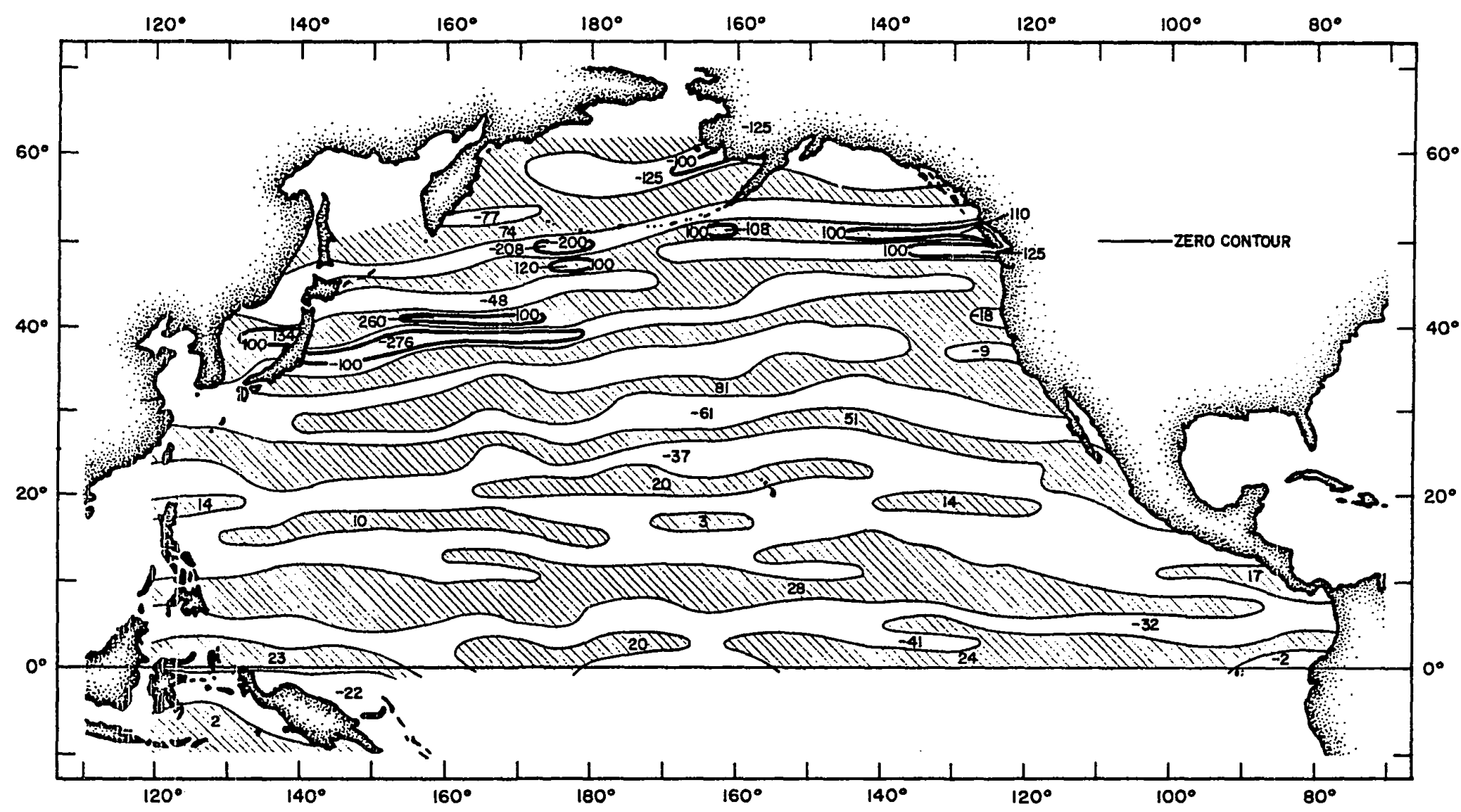

Figure 57 Change in Total Heat storage $(0-250 \mathrm{~m})$

Due to Horizontal Mixing - March (cal $\mathrm{cm}^{-2} \mathrm{day}^{-1}$ ). 


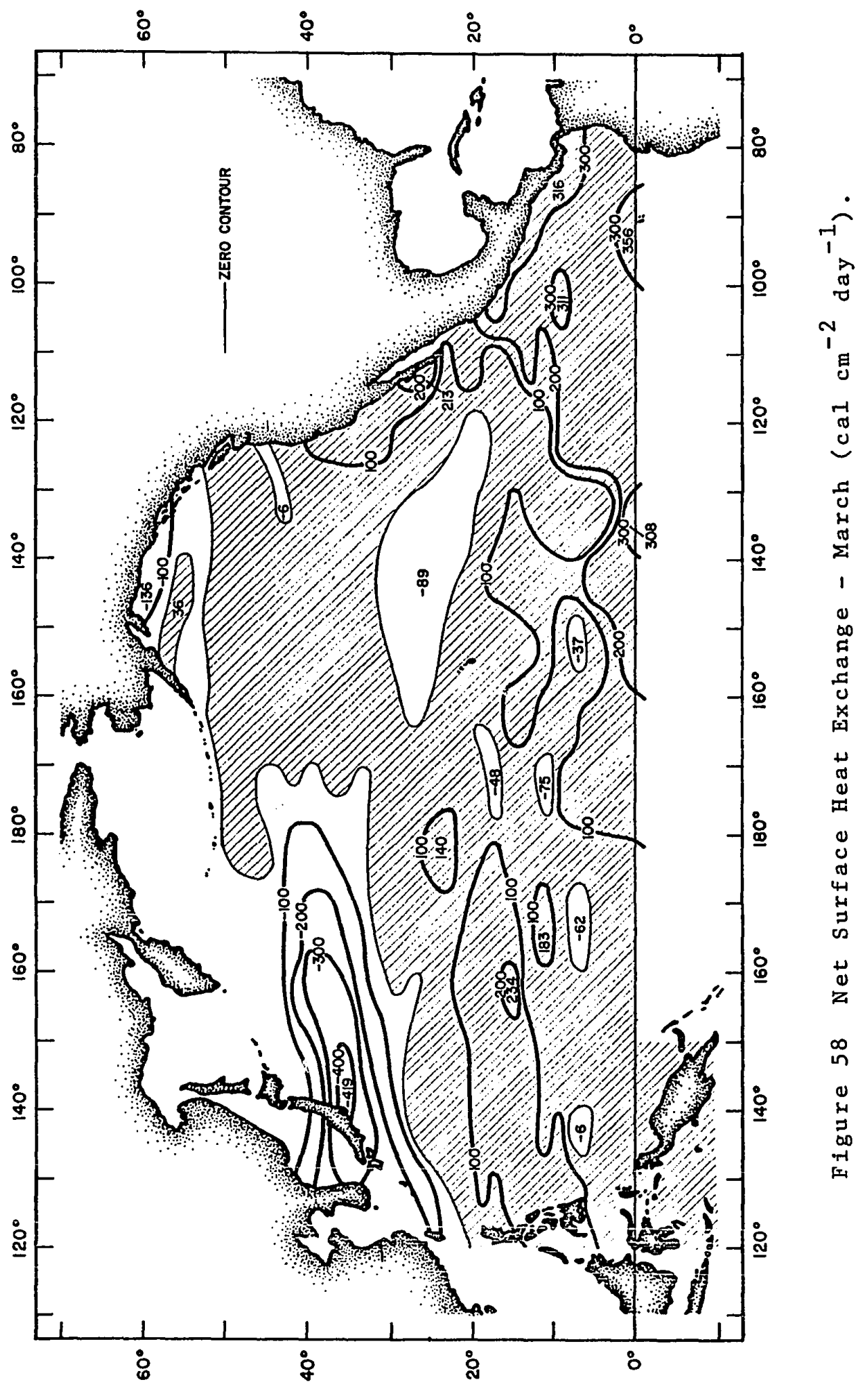




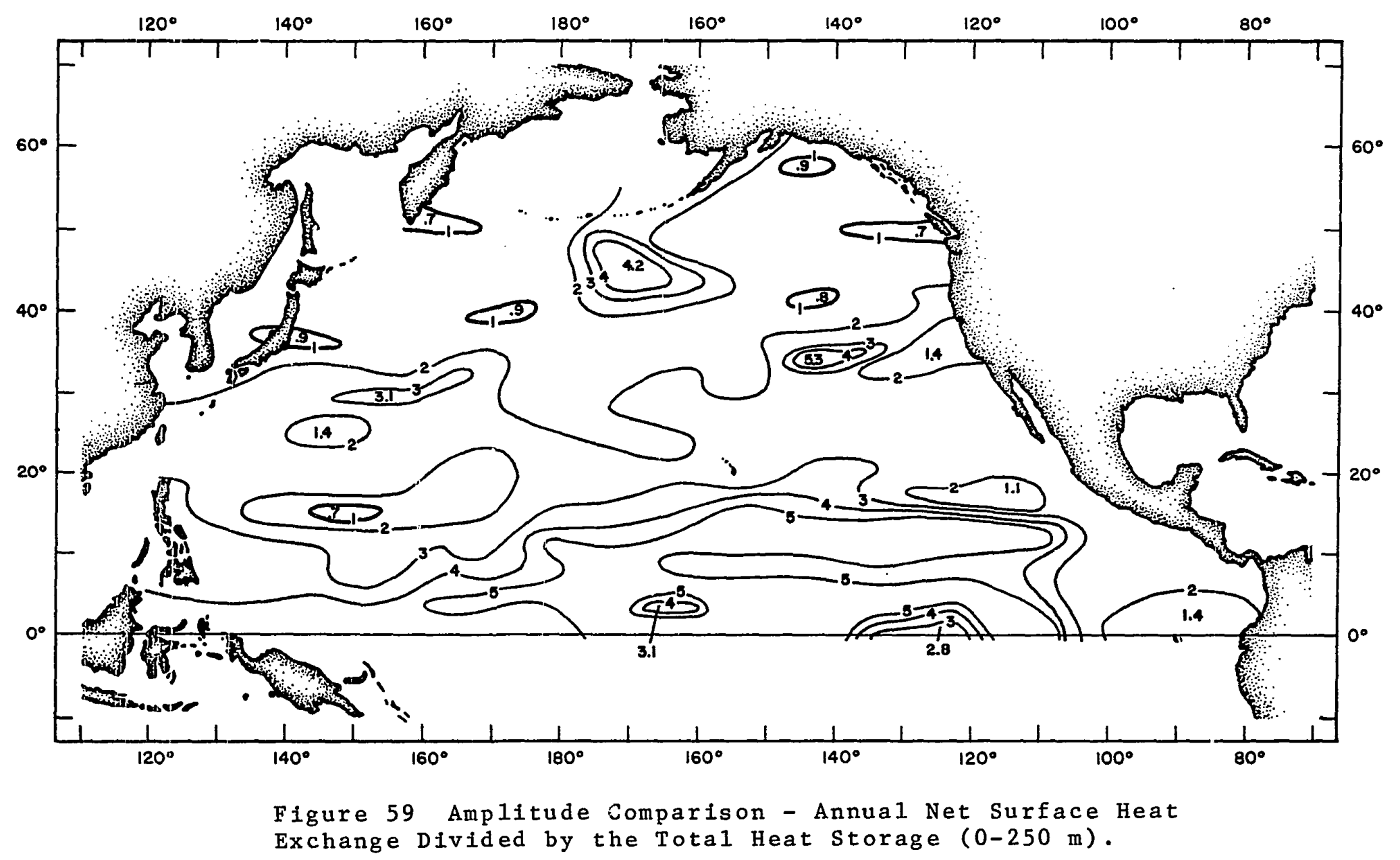




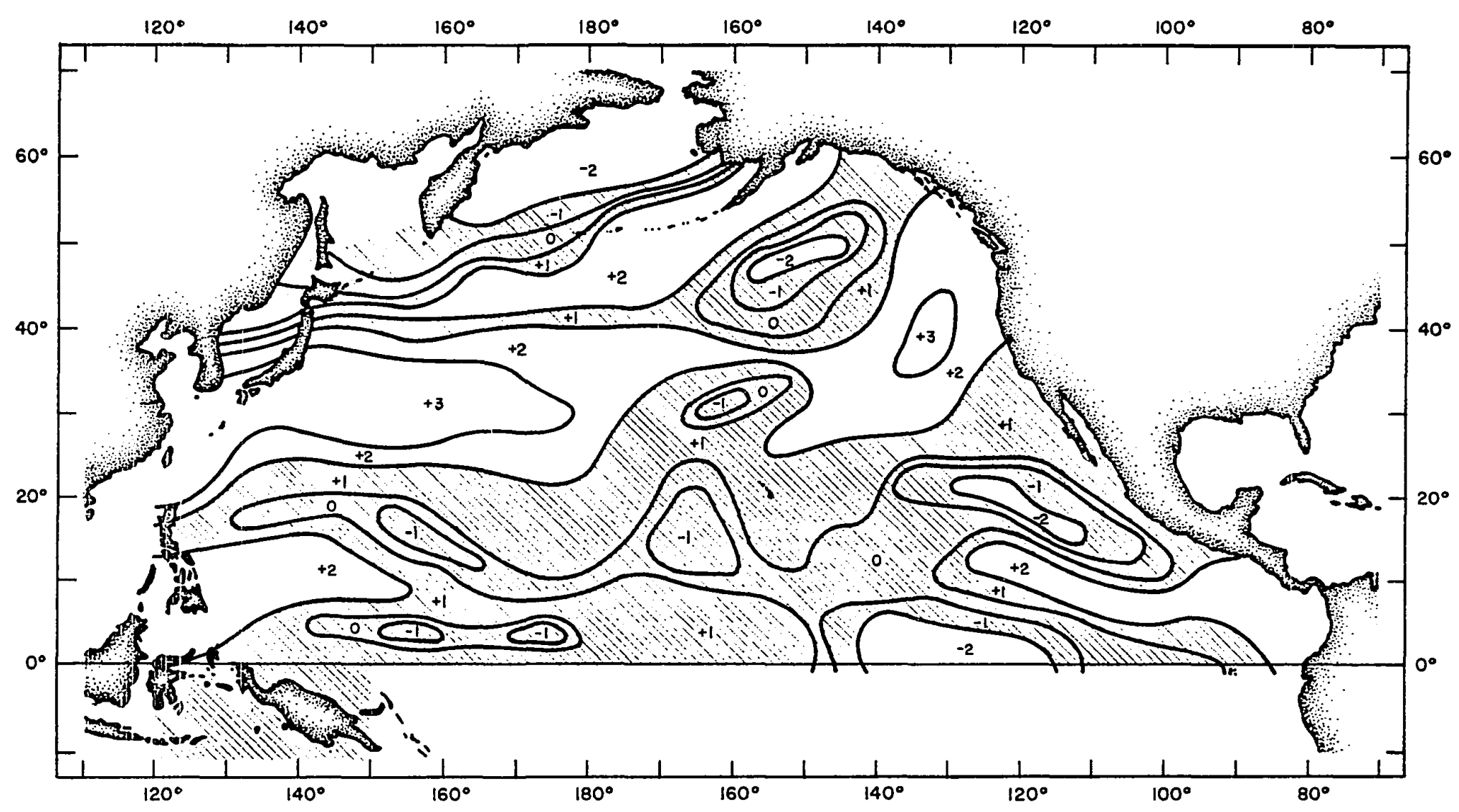

Figure 60 Phase Comparison - Month of Maximum Total Heat Storage $(0-250 \mathrm{~m})$ minus Month of Maximum Net Surface Heat Exchange (months). Positive values show the annual maxima of total heat storage lags the annual maxima of the net surface heat exchange. 


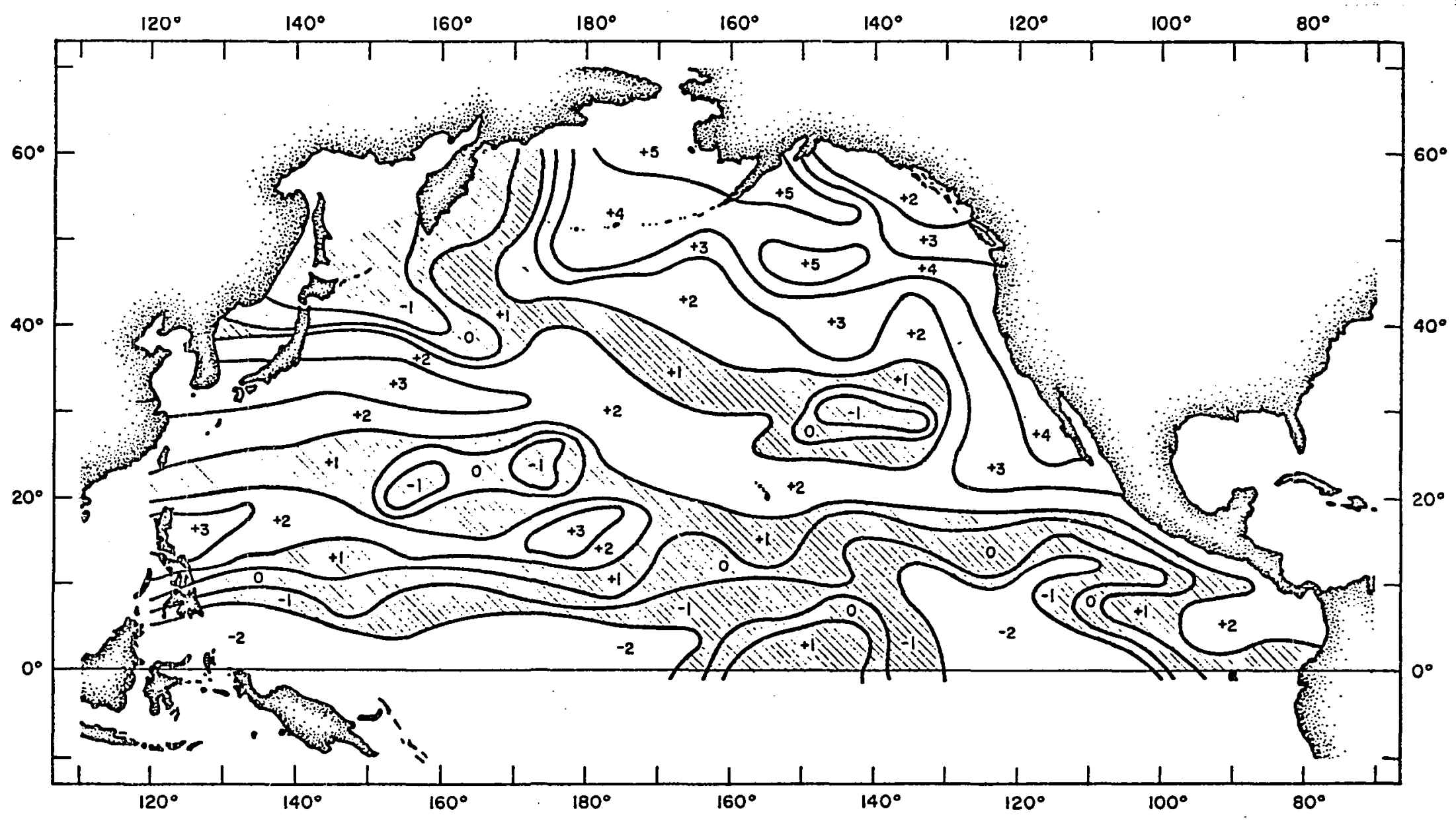

Figure 61 Phase Comparison - Month of Minimum Total Heat Storage $(0-250 \mathrm{~m})$ minus Month of Minimum Net Surface Heat Exchange

(months). Positive values show the annual minima of total heat storage lags the annual minima of the net surface heat exchange. 


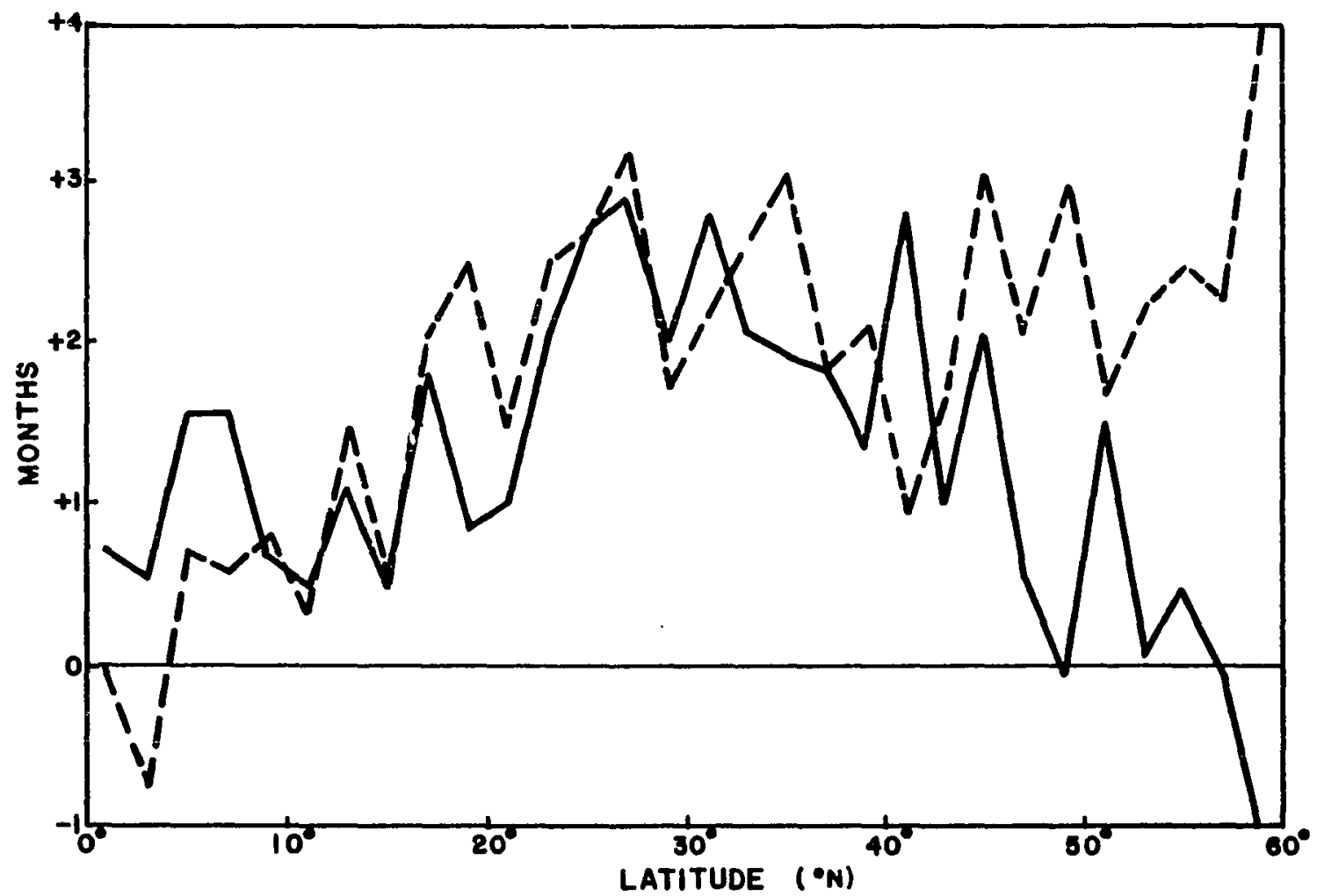

Figure 62 Algebraic Summation by $2^{\circ}$ of Latitude of the Phase Comparison between the Total Heat Storage $(0-250 \mathrm{~m})$ and Net Surface Heat Exchange (months). The phase comparison of the annual maxima (solid curve) and annual minima (dashed curve) are shown. 


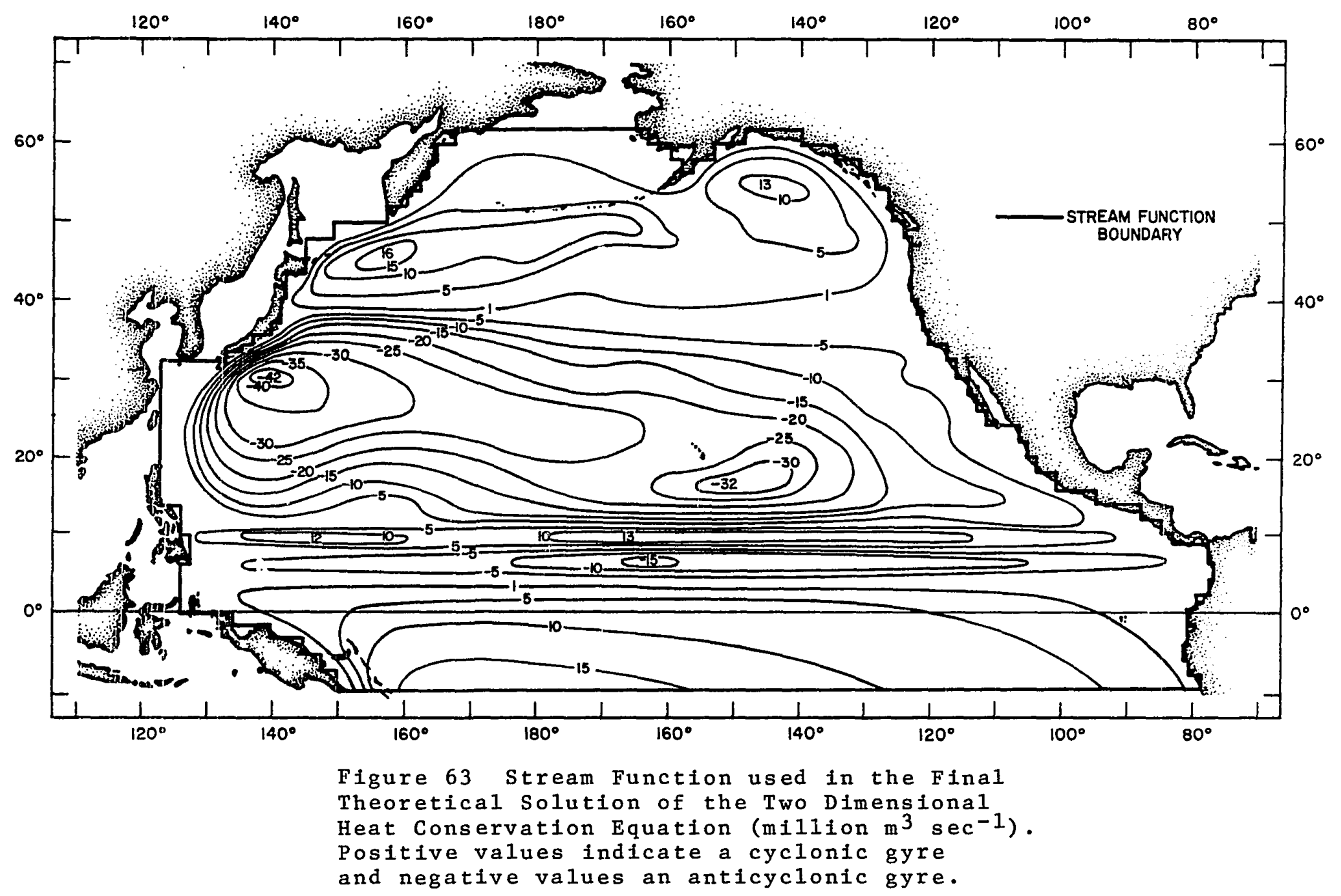



<smiles>C1CC[As]CC1</smiles> 


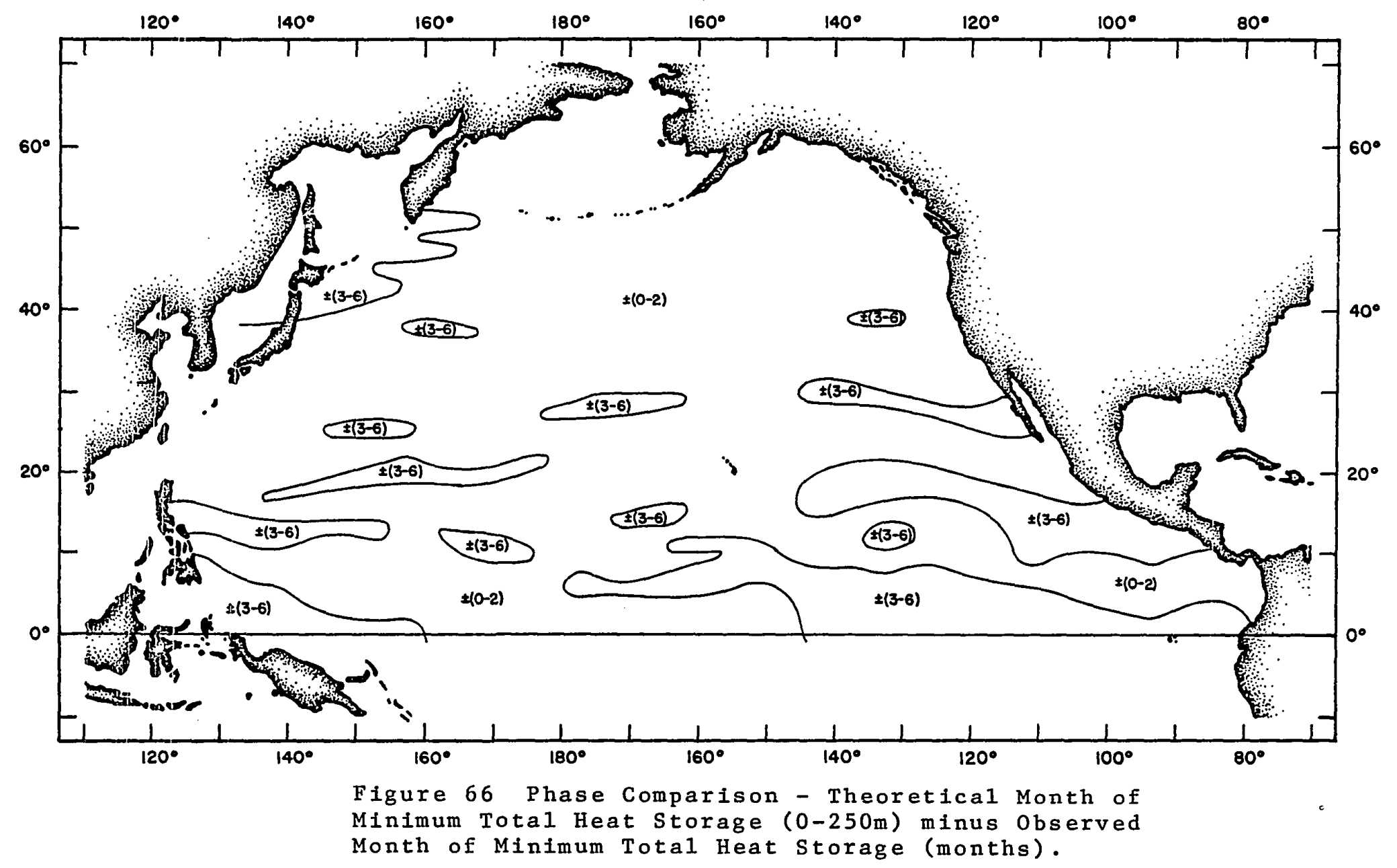




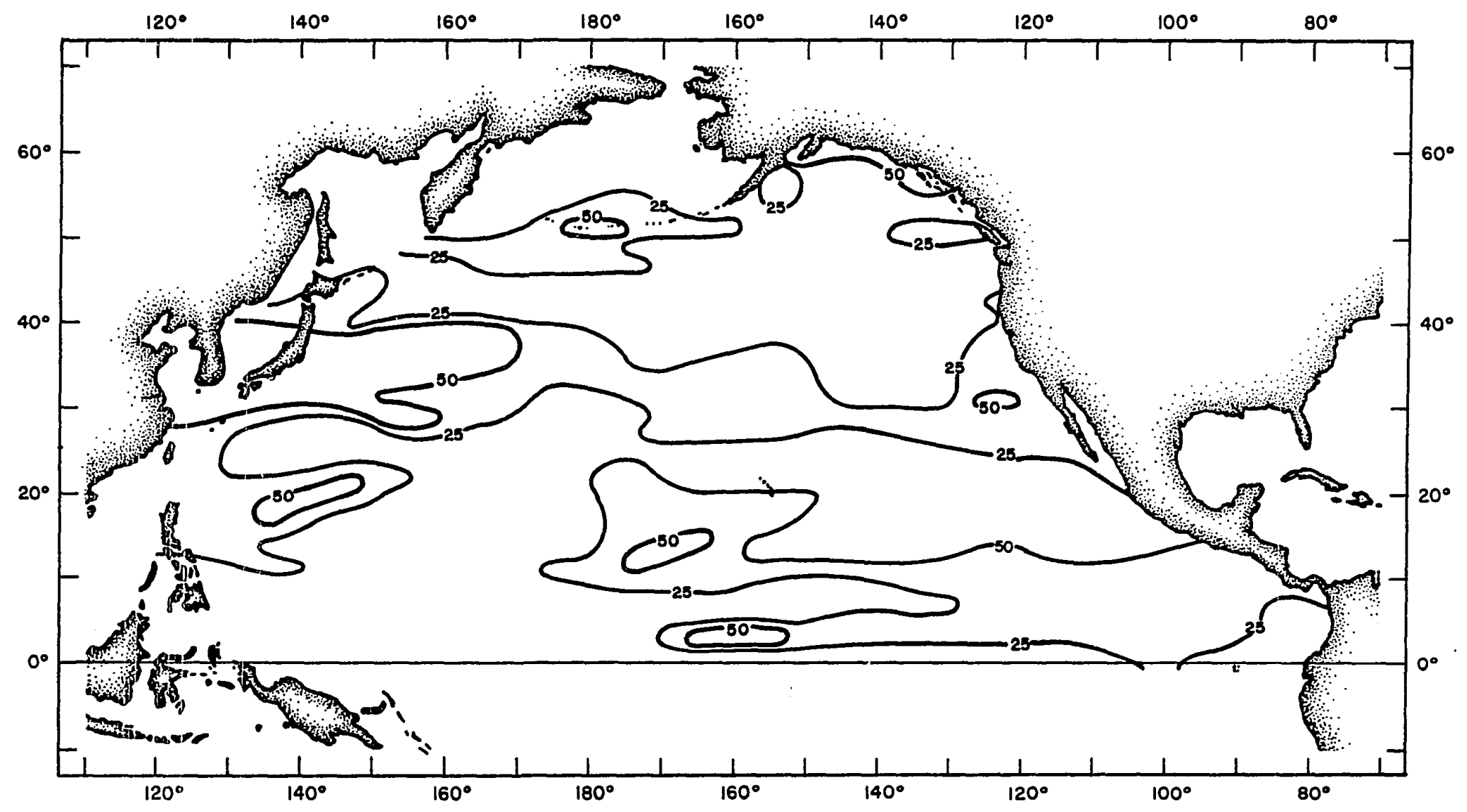

Figure 67 Theoretical Annual Amplitude of Total Heat Storage (0-250m) - Constant Mixing Coefficient (kcal $\mathrm{cm}^{-2}$ ). The mixing coefficient used in the theoretical model is constant with latitude at $5 \times 10^{6} \mathrm{~cm} 2 \mathrm{sec}^{-1}$. 


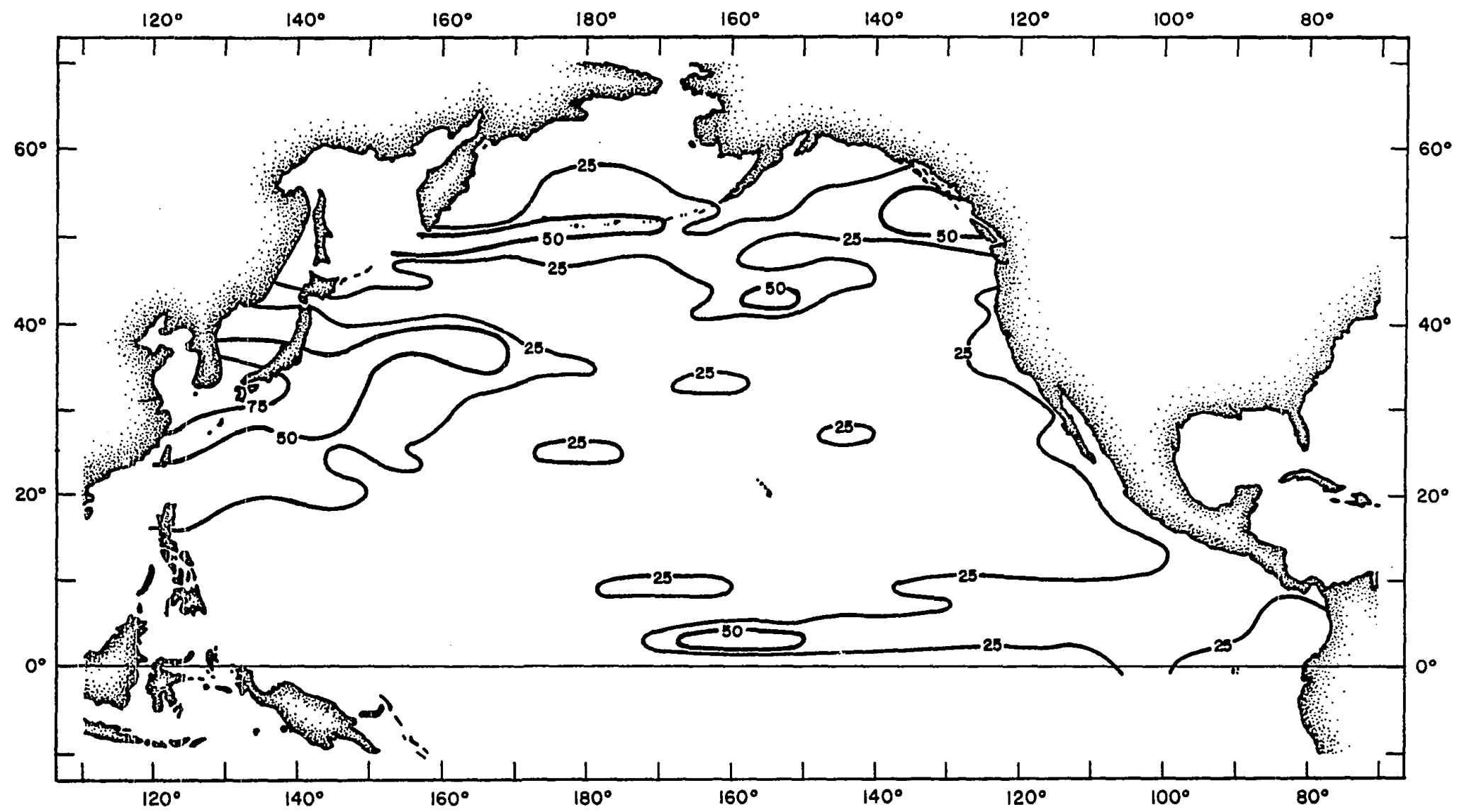

Figure 68 Theoretical Annual Amplitude of Total Heat Storage (0-250m) - Constant Mixing Coefficient (kcal $\left.\mathrm{cm}^{-2}\right)$. The mixing coefficient used in the theoretical model is constant with latitude at $5 \times 10^{6} \mathrm{~cm}^{2} \mathrm{sec}^{-1}$. No 


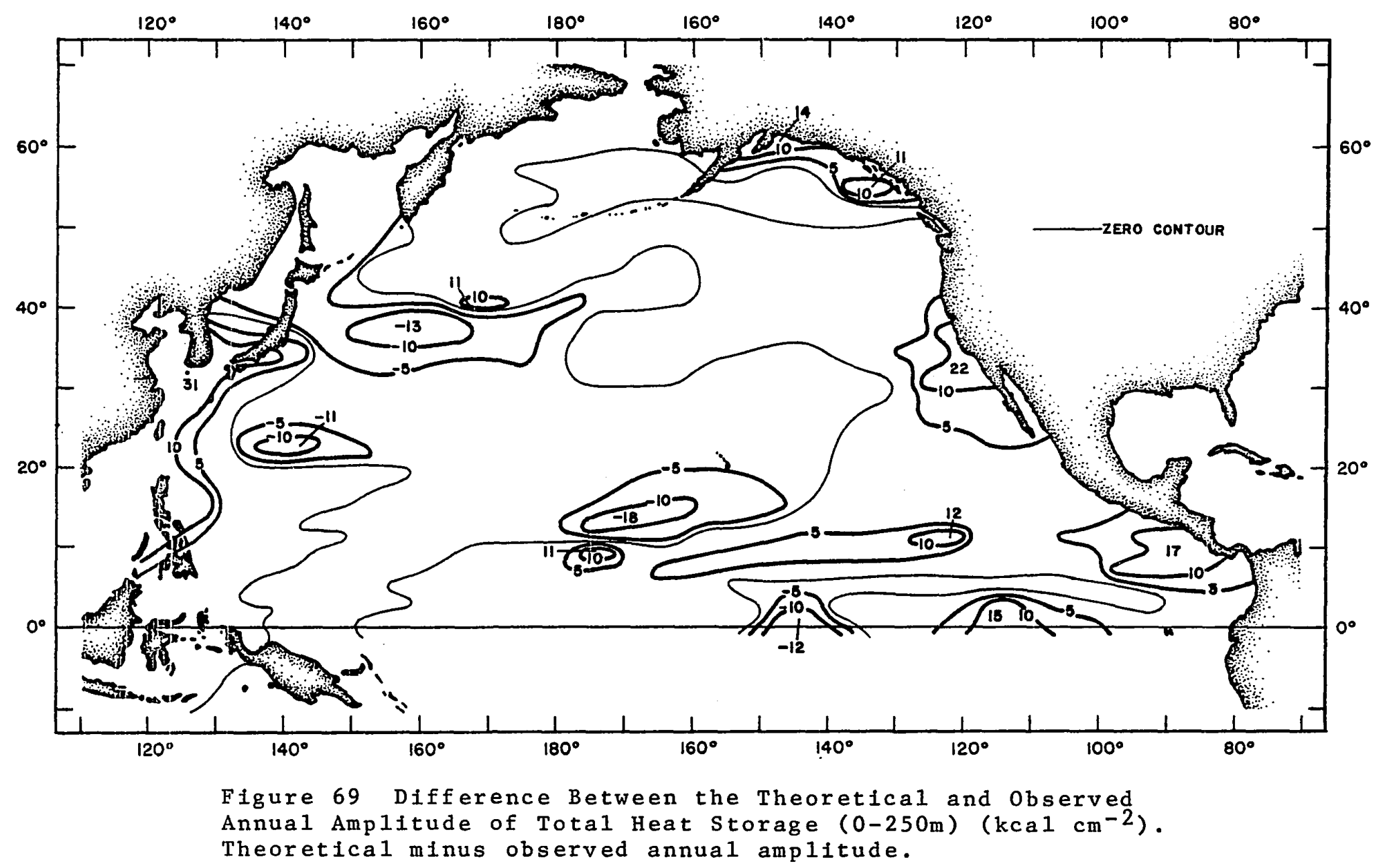



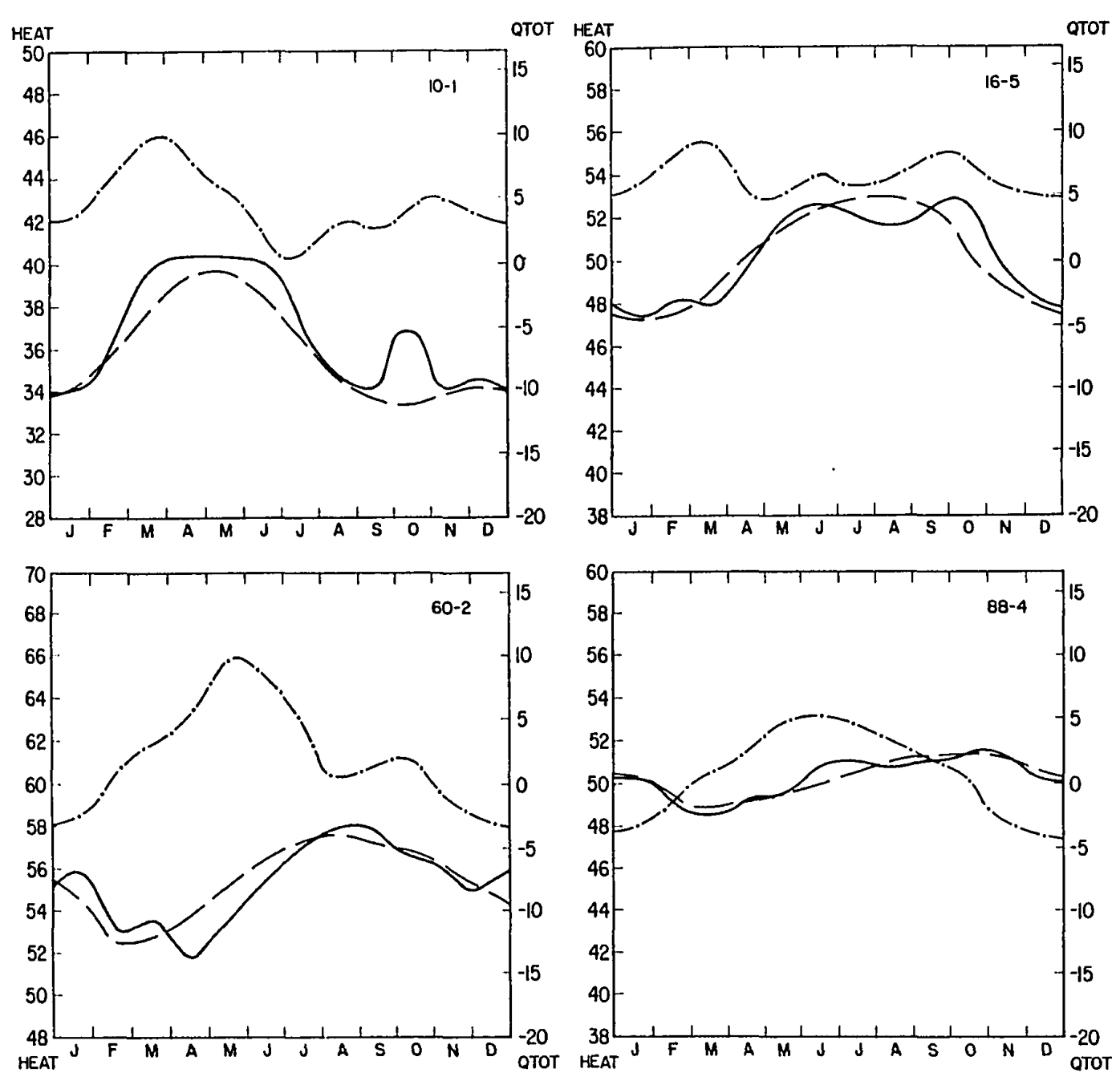

Figure 70 Seasonal Plots of the Theoretical Total Heat Storage $(0-250 \mathrm{~m})$, Observed Total Heat Storage and the Net Heating at the Surface. The solid curve is the observed total heat storage and the dotted curve is the theoretical total heat storage predicted by the horizontal heat conservation equation; both curves are in cal $\mathrm{cm}^{-2} \times 10^{4}$ (Heat axis). The dash-dot curve is the net heat exchanged at the surface each month in kcal $\mathrm{cm}^{-2}$ (QTOT axis). The location of each area is shown in Figure 1; 10-1 west of Central America, 16-5 Central Equatorial Pacific, 60-2 East of the Philippines, 88-4 North of Hawail. 

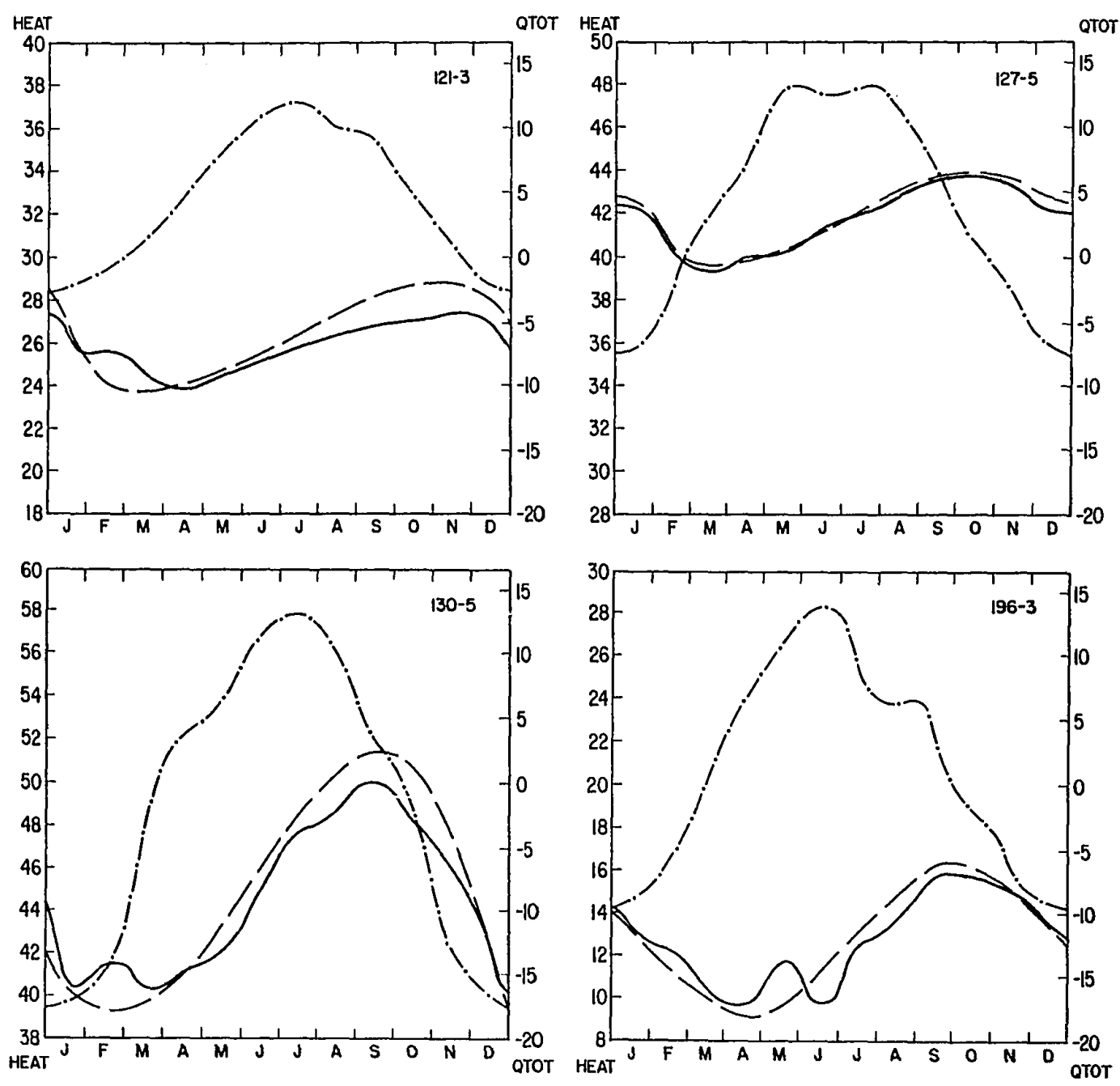

Figure 71 Seasonal Plots of the Theoretical Total Heat Storage (0-250m), Observed Total Heat Storage and the Net Heating at the Surface. The solid curve is the observed total heat storage and the dotted curve is the theoretical total heat storage predicted by the horizontal heat conservation equation; both curves are in cal $\mathrm{cm}^{-2} \times 10^{4}$ (Heat axis). The dash-dot curve is the net heat exchanged at the surface each month in kcal $\mathrm{cm}^{-2}$ (QTOT axis). The location of each area is snown in Figure 1; 121-3 west of California, 127-5 Central North Pacific, 130-5 East of Japan, 196-3 South of Alaska. 


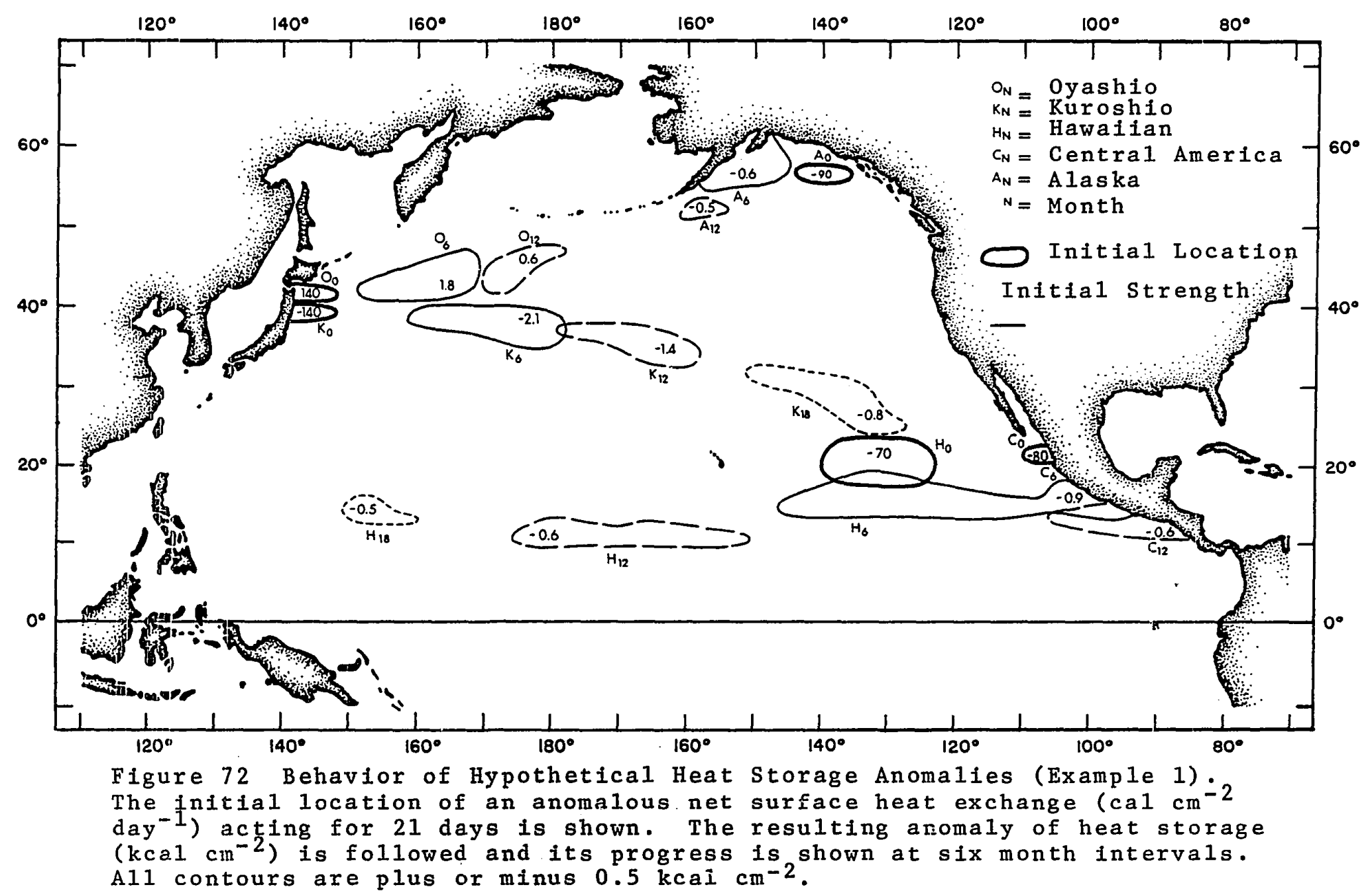




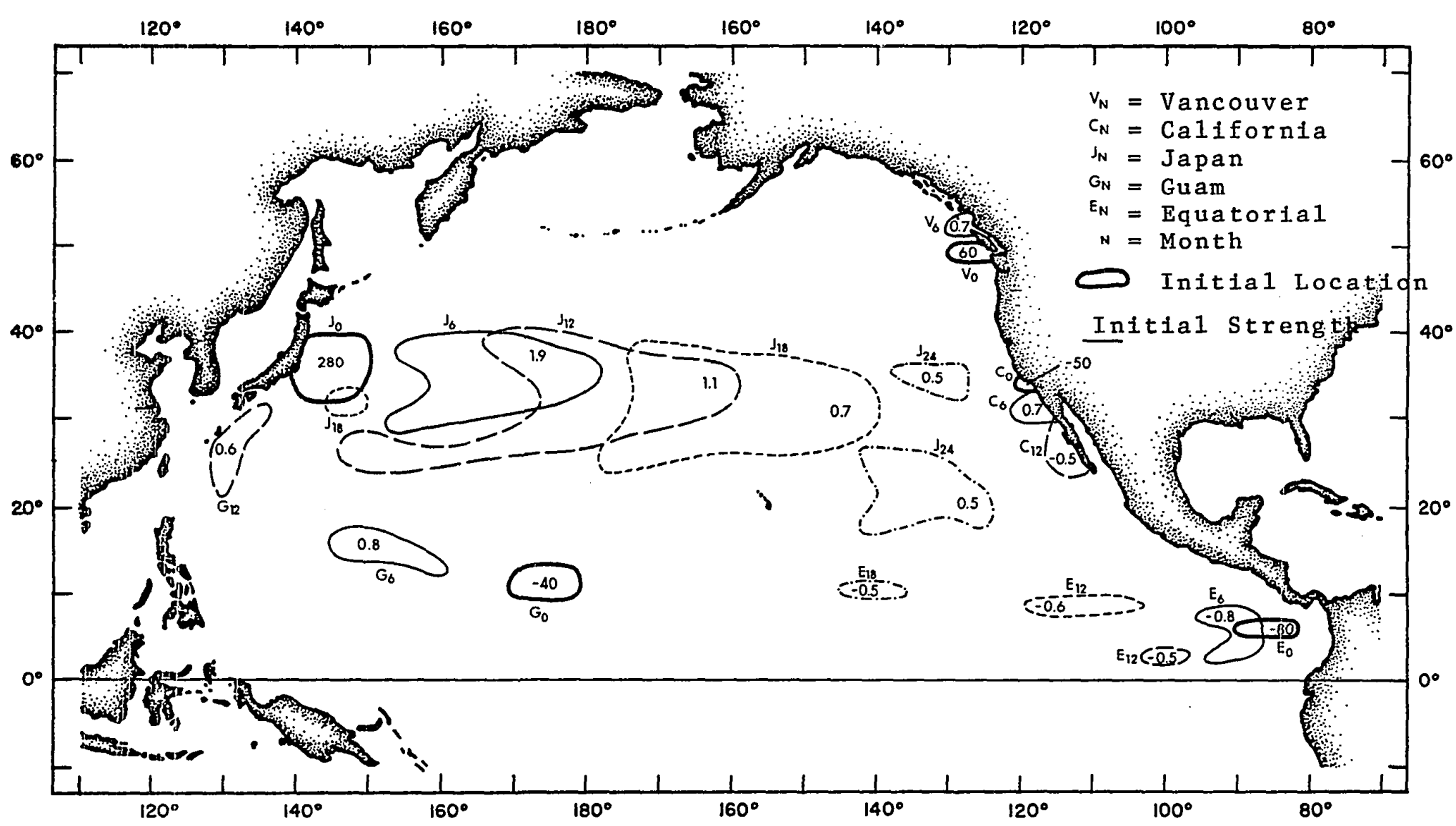
Figure 73 Behavior of Hypothetical Heat Storage Anomalies (Example 2)
The initial location of an anomalous net surface heat exchange (cal cm 2 day-1) acting for 21 days is shown. The resulting anomaly of heat storage (kcal $\mathrm{cm}^{-2}$ ) is followed and its progress is shown at six month intervals. 



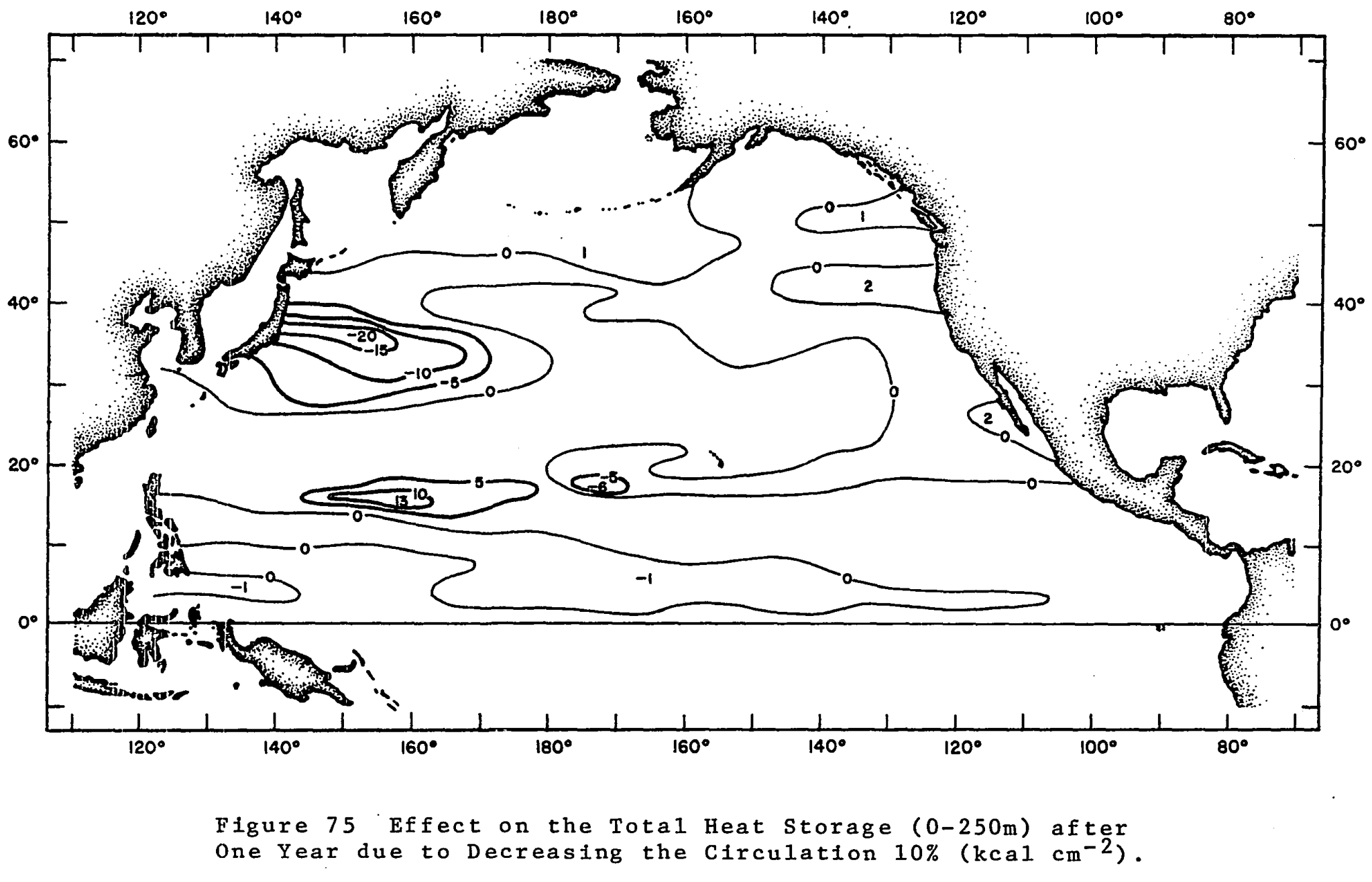

: 


\section{VI . BIBLIOGRAPHY}

Adem, J. (1969) - Numerical Prediction of Mean Monthly Ocean Temperatures; American Geophysical Union, pp. 1104-1108.

Arthur, R.S. (1966) - Estimation of mean monthly anomalies of sea-surface temperature, J.Geophys. Res., V. 71 (10), pp. 2689-2690.

Bowen, I.S. (1926) - The ratio of heat losses by conduction and by evaporation from any water surface. Phys. Rev., p. $27: 779-787$.

Bryan, K. and E. Schroeder (1960) - Seasonal Heat Storage in the North Atlantic Ocean; J. of Meteorology,

v. 17 , No. 6, pp. 670-674.

Bryan, K. (1962) - Measurements of Meridianal Heat Transport by Ocean Currents; J. Geophys. Res., V. 67(9), pp. 3403-3414.

Bureau of Commercial Fisheries (1957-1970) - California Fishery Market News Monthly Summary Department of the Interior, Bureau of Commerical Fisheries, La Jolla, California.

Clark, N.E. and H.C. Willett (1967) - Report on an investigation of large scale heat transfer processes and fluctuations of sea-surface temperatures in the North Pacific Ocean; Ph.D. Thesis, The Solar Energy Research Fund, M.I.T., Cambridge, Mass.

Fritz, S. (1958) - Seasonal heat storage in the ocean and heating of the atmosphere, Arch. Meteor. Geophys. BiokI., A, 10, pp. 291-300.

Gabites, I.F. (1950) - Seasonal variations in the atmospheric heat balance, Sc.D. Thesis, M.I.T. 1950 (unpublished).

Joseph, J. and H. Sender (1962) - on the spectrum of the mean diffusion velocities in the ocean, J. Geophys. Res., V. 67, No. 8, pp. 3201-3205.

Jung, G.H. (1955) - Heat transport in the North Atlantic Ocean. A. and M. College of Texas, Department of Oceanography, Ref. 55-34T. 41 pp. 
Knauss, J.A. (1960) - Measurements of the Cromwell Current. Deep Sea Research, Vo1. 6, No. 4, pp. 265-286.

Knauss, J.A. (1961) - The Structure of the Pacific Equatorial Countercurrent. J. Geophys. Res., Vol. 66 , No. 1 , PP. 143-155.

Knauss, J.A. (1962) - Recent Measurements of the Cromwell Current (abstract) J.Geophys.Res., Vol. 67, pp. $3571-3572$.

Koizumu, M. (1955) - Researches on variations of oceanographic conditions. Papers in Meteorology and Geophysics, $6: 185-201$.

Kraus, E.B. and J.S. Turner (1967) - One-dimensional model of the seasonal thermocline, Part II. The General Theory and its Consequents; Tellus, V. 19 (1), pp. 98-105.

McEwen, G.F. (1934) - Rate of upwelling in the region of San Diego computed from serial temperatures; Fifth Pacific Science Congress, Canada, 1933 Proceedings; V. 3, P. 1763 .

Montgomery, R.B. (1939) - Ein Versuch, Den Vertikalen und Seitlichen Austauch in der Tiefe Der Sprungschicht Im Aquaturialen Atlantischen Ozean $\mathrm{Zu}$ Bestimmen. Ann. d. Hydr. u. Marit. Meteoro1,, Vol. 67, p. 242 (BerIin).

Montgomery, R.B. (1962) - Equatorial Undercurrent observations in Review. 20th Anniv. Vol., Oceanographic Soc. Japan, pp. 487-498.

Namias, J. (1953) - Thirty-day forecasting; a review of a ten-year experiment, Meteorol. Monographs, Am. Meteorol. Soc. 2 (6), 1953 .

Namias, J. (1959) - Recent seasonal interactions between North Pacific waters and the overlying atmospheric circulations; J. Geophys. Res. 64 (6), Pp. 631-646.

Neuman, G. (1940) - Die 0zeanographischen Verhaltnisse An Der Meeresoberflache In Golfsttrumsextor Nordifch und Nordwestlich Der Azoren. Ann. d. Hydrogr. u. Mar. Meteor., Belheft Zum Juniheft, 1. Lief, 87 pp.

Norpac Atlas, The (1955) - Oceanographic Observations of the Pacific. 
Pattu110, J.G. (1956) - The Seasonal Heat Budget of the Oceans, Sc.D. Thesis, UCLA, 104 pp.

Provisional CSK Atlas for Summer 1965, March, 1967 Japanese Oceanographic Data Center, Hydrographic Division, Maritime Safety Agency, Tokyo, Japan.

Robinson, M.K. (1969) - Theoretical predictions of subtropical Countercurrent confirmed by bathythermograph (BT) data, Bul. of the Japanese Soc. of Fisheries Oc., Special Number (Prof. Uda's commemorative papers), 1969 , pp. 115-121.

Roden, G.I. (1964) - Shallow Temperature inversions in the Pacific Ocean; J. Geophys. Res., V. 69 , No. 14, pp. 2899-2916.

Salvadori, M.G. and J.L. Baron (1961) - Numerical Methods in Engineering. Prentice-Hall, Inc., pp. 302 .

Seckel, G.R. (1962) - Atlas of the Oceanographic Climate of the Hawalian Islands Region; Fishery Bulletin 193, U.S. Department of the Interior, Fish and Wildlife Service, V. 61, B.C.F.

Skogsberg, Tage (1936) - Hydrography of Monterey Bay, California. Thermal Conditions 1929-1933; Amer. Phil. Soc. Trans., N.S. V. 29, pp. 1-152.

Sverdrup, H.U. and R.H. Fleming (1941) - The waters off the Coast of Southern California, March to July, 1937; Scripps Inst. Oceanographic Bull., V. 4, No. 10, PP. 261-378.

Sverdrup, H.U., M.W. Johnson and R.H. Fleming (1946) The Oceans. New York, Prentice-Ha1l, pp. 1087 .

Tul1y, J.P. (1964) - Oceanographic Regions and Processes in the Seasonal Zone of the North Pacific Ocean. Studies in Oceanography, pp • 68-84, Tokyo.

Tsuchiya, M. (1961) - An oceanographic description of the Equatorial Current system of the Western Pacific. oceanogr. Mag., Vol. 13, No. 1, 0ct.

United States Department of the Interior, Bureau of Commercial Fisheries, California Fishery Market News Monthly Summary, Part II - Fishing Information (1947 to the present). 
United States Department of the Interior Fish and Wildife Service (1961) - Sea Surface Temperature Monthly Average and Anomaly Charts Northeastern Pacific Ocean, 1947 1958, (J. H. Johnson), Report No. 385.

United States Department of the Interior Fish and Wildife Service (1963) - Sea Surface Temperature Monthly Average and Anomaly Charts Tropical Pacific Ocean, 1947-1958, (J.A. Renner) Report No. 442.

U.S. Navy Hydrographic Office of Publications (1953) No. 569 - Atlas of Surface Currents Northwest Pacific Ocean, 12 sheets.

U.S. Navy Hydrographic Office of Publications (1953) No. 570 - Atlas of Surface Currents Northeast Pacific Ocean, 12 sheets.

Wyrtki, K. (1958) - The water exchange between the Pacific and Indian oceans in relation to upwelling processes; Proceedings of the Ninth Patific Science Congress, V. 16, pp. 61-66.

Wyrtki, K. (1961) - The Thermohaline Circulation in Relation to the General Circulation in the Oceans. Deep-Sea Res., 8 (1), 39 .

Wyrtki, K. (1964a) - The thermal structure of the Eastern Pacific Ocean; Deutsche Hydrog. Zeits., Ergan Zungsheft, pp. 1-84.

Wyrtki, K. (1964b) - Upwelling in the Costa Rica Dome; U.S. Fish and Wildife Service, Fishery Bull. 63, pp. 355-372.

Wyrtki, K. (1965a) - Surface Currents of the Eastern Equatorial Pacific Ocean; Inter. Amer. Trop. Tuna Comm. Bu11.; V. 9 (5), Pp. 270-304.

Wyrtki, K. (1965b) - The average annual heat balance of the North Pacific Ocean and its relatior to ocean circulation. J. Geophys. Res., V. 70, pp. 4547-4559.

Wyrtki, K. (1965c) - The annual and semiannual variation of sea surface temperature in the North Pacific Ocean; Limnology and oceanography, V. 10, No. 3, pp. 307-313.

Wyrtki, K. (1966) - Seasonal variation of heat exchange and surface temperature in the North Pacific; Hawai Institute of Geophysics, No. HIG-66-3, 8 pp. and 72 Figures. 
Wyrtki, K. and T. Kendall (1967) - Transports of the Pacific Equatorial Countercurrent, J. Geophys. Res.

Wyrtki, K. (1968) - Circulation and Water Masses in the Eastern Equatorial Pacific ocean, J. Oceano1. and Limnol., V. 1, No. 2, pp. 117-147.

Wyrtki, $K$. and $K$. Haberland (1968) - On the redistribution of heat in the North Pacific Ocean; Jour. of Oceano. Soc. of Japan, V. 24, No. 5, pp. 220-233. 